Portland State University

PDXScholar

8-4-1995

\title{
Treatment Approaches for Pathological Gambling: Review of Literature and Development of New Program
}

Karen Lee Hafner

Portland State University

Follow this and additional works at: https://pdxscholar.library.pdx.edu/open_access_etds

Part of the Education Commons

Let us know how access to this document benefits you.

Recommended Citation

Hafner, Karen Lee, "Treatment Approaches for Pathological Gambling: Review of Literature and Development of New Program" (1995). Dissertations and Theses. Paper 4924.

https://doi.org/10.15760/etd.6800

This Thesis is brought to you for free and open access. It has been accepted for inclusion in Dissertations and Theses by an authorized administrator of PDXScholar. Please contact us if we can make this document more accessible: pdxscholar@pdx.edu. 


\section{THESIS APPROVAL}

The abstract and thesis of Karen Lee Hafner for the Master of Science in Education: Counseling were presented on August 4, 1995, and accepted by the thesis committee and the School.

COMMITTEE APPROVALS :

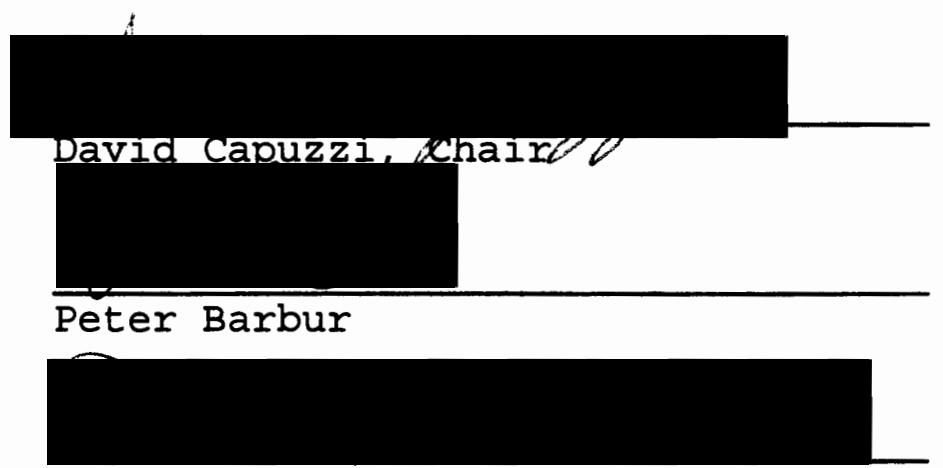

Russell D. Miars

SCHOOL APPROVAL :

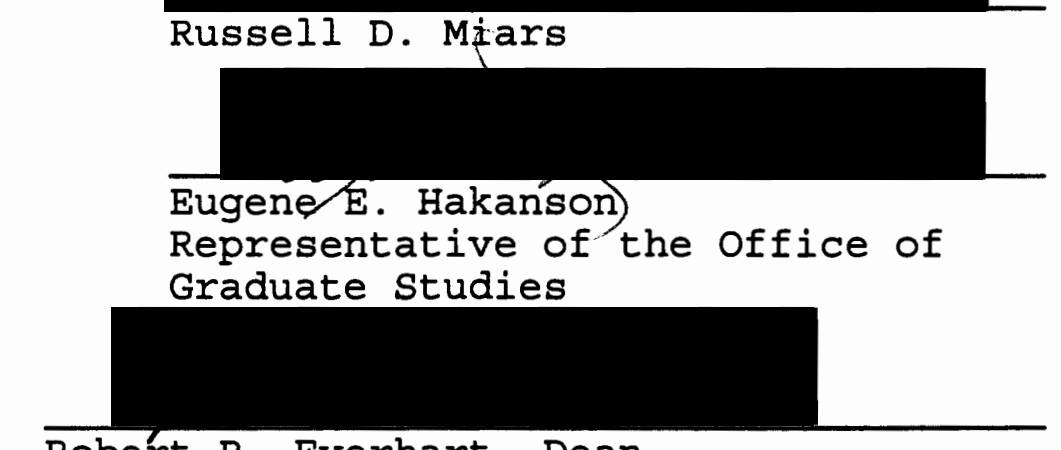

Robert B. Everhart, Dean

School of Education

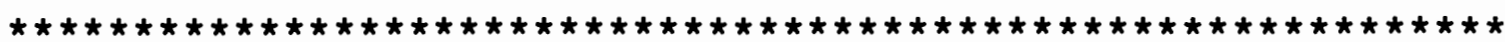

ACCEPTED FOR PORTLAND STATE UNIVERSITY BY THE LIBRARY

by on

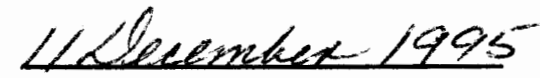




\begin{abstract}
An abstract of the thesis of Karen Lee Hafner for the Master of Science in Education: Counseling presented August 4, 1995.

Title: Treatment Approaches for Pathological Gambling: Review of Literature and Development of New Program
\end{abstract}

Pathological gambling is a treatable, but complex addiction. Defined as out of control gambling that disrupts relationships, employment and/or education. People from all social, economic and cultural groups are affected.

Pathological gambling is a problem throughout this country, and in oregon 61,000 people are estimated to have this disorder. There is a lack of information and extensive misinformation about gambling; and gambling has, historically, been considered a moral weakness. Treatment for pathological gambling is a recent development, and still is not widely available.

Pathological gambling is pervasive, poorly understood, and costly and deserves further study. Existing literature on pathological gambling, both the profile of the disorder and treatment is thoroughly reviewed. 
The portrait of the pathological gambler is contradictory. The only clear demographic trend is that the majority of pathological gamblers are men.

Psychodynamic theories explain pathological gambling through developmental and psychological determinants. Behaviorists and learning theorists delineate a series of environmental and physiological factors which combine to "teach" pathological gambling behavior. Researchers who study pathological gambling have enumerated three to four phases of progression of the disorder.

There are a variety of disorders and physical problems correlated to pathological gambling, and depression and dual addictions are clearly an issue for many.

GA has a high drop out rate and tends to work better for pathological gamblers who have few or no relapses. The intake interview should: initiate the therapeutic alliance, provide crucial data for assessment and diagnosis, and provide information about the nature and scope of the treatment. Individual therapy has a relatively long and respected history as helpful treatment for pathological gambling. Group therapy is a common and effective mode for treatment of pathological gambling. Psychodynamic treatment of is popular and effective, works at achieving abstinence, and helping the pathological gambler make deeper personality changes. Cognitive-behavioral approaches have a role in 
helping pathological gamblers change irrational beliefs surrounding gambling and themselves.

A program which uses cognitive-behavioral, behavioral and psychodynamic approaches in individual, group and family/marital counseling settings designed by author is presented and discussed. The program has four stages and includes an education component. 
TREATMENT APPROACHES FOR PATHOLOGICAL GAMBLING: REVIEW OF LITERATURE AND DEVELOPMENT OF NEW PROGRAM

by

KAREN LEE HAFNER

A thesis submitted in partial fulfillment of the requirements for the degree of

\author{
MASTER OF SCIENCE \\ in \\ EDUCATION : \\ COUNSELING
}

\author{
Portland State University \\ o1995
}


TABLE OF CONTENTS

PAGE

ACKNOWLEDGEMENTS......................... ii

CHAPTER

I INTRODUCTION....................... 1

Definition of Pathological Gambling.... 3

scope of problem................ 5

Purpose..................... 8

II PROFILE......................... 15

Characteristics.................... 15

Demographic Data................. 19

Theories of Pathological

Gambling..................... 21

Psychodynamic

Behavioral and Learning

Predisposing Factors

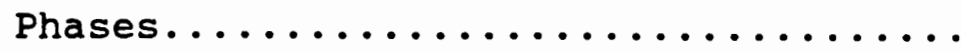

One: Winning

Two: Losing

Three: Desperation

Four: Giving Up

Co-Morbid Diagnosis................ 35

Gambling Costs.................... 37

III REVIEW OF LITERATURE ON TREATMENT.......... 41

Intake...................... 44 
Gamblers Anonymous/

12 step.................... 47

Individual Treatment.............. 53

Group Treatment................. 58

Psychodynamic Approach............. 60

Behavioral Approach.............. 74

Cognitive-Behavioral Approach........ 76

IV CONCLUSION: PROPOSED TREATMENT PROGRAM...... 80

Intake..................... 82

stage $1 \ldots \ldots \ldots \ldots \ldots \ldots \ldots \ldots \ldots \ldots$

Stage II......................... 90

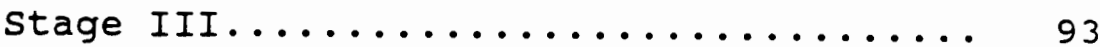

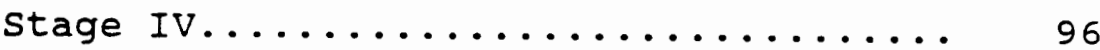

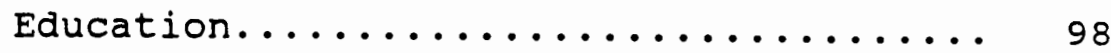

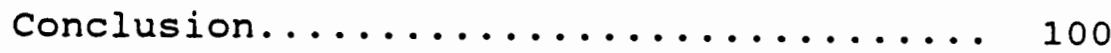

REFERENCES........................ 102

APPENDIX......................... 109 


\section{ACKNOWLEDGMENTS}

My thesis committee has been extremely helpful in fine tuning and improving this thesis. I would like to thank

David Capuzzi for his encouragement and guidance throughout the last three years. He has always inspired, and at times cajoled, me into research and writing. David's reassurance, especially during the difficult periods, gave me the confidence to complete this thesis.

Peter Barbur has helped me develop my clinical skills. He has also taken the time and effort to foster development of research and writing skills. Without Peter's confidence and prompting this thesis would still be unfinished.

Russell D. Miars has been an inspired teacher, and I greatly appreciate the time he has dedicated to helping this thesis come to fruition. Eugene Hakanson is an excellent clinician, and I feel fortunate that he was willing to read this thesis and serve on my committee.

My daughter, Ariella has been both patient and encouraging. I am thankful that she has been willing to quietly read while I worked in the computer lab when she would have preferred to be out enjoying the sunshine. I truly could not have completed this work without Ariella's cheerful cooperation and support. 
CHAPTER I

\title{
INTRODUCTION
}

\begin{abstract}
"Tomorrow, I may rise from the dead and live again! As long as I am around, I still have a chance to be a man [and gamble]!" -Fyodor Dostoevski, the Gambler
\end{abstract}

Gambling is a leisure activity that has been pursued since before recorded history. Ancient Egyptians, Chinese, Persians, Greeks, and Romans left written accounts which detailed gambling activities (Custer \& Milt, 1985; Galski, 1987). People who have problems with controlling gambling have also been around for a long time. Dostoevski (Trans., 1866/1964) wrote about, and experienced problems controlling gambling more than a century ago. In the United states currently, it is estimated that 60 percent of the adult population gambles at least once each year, and that approximately two percent cannot control gambling. Those two percent who cannot control their gambling are pathological gamblers (Commission on the Review of the National Policy Toward Gambling, 1976; Custer \& Milt, 1985). Traditionally, gambling has been considered a moral weakness. People who gambled were "condemned on social, economic and religious grounds" (Blaszczynski \& Mcconaghy, 1989, p. 44). Pathological gambling was not considered a 
mental illness until Freud started working with gamblers. He considered uncontrolled gambling a problem to be addressed through psychoanalysis. Although Freud described people with problems with gambling during the first part of this century (Blaszczynski \& Mcconaghy, 1989), pathological gambling was not considered a diagnosable psychiatric illness until 1979 in the World Health organization's International Classification of Diseases, and 1980 in the American Psychiatric Association's Diagnostic and Statistical Manual (Custer \& Milt, 1985; Galski, 1987; Lesieur \& Rosenthal, 1991).

It should be noted that some professionals who work with pathological gambling clients use the term compulsive gambling interchangeably with pathological gambling. However, according to Murray (1993), "compulsive gambler is somewhat of a misnomer because [it connotes that] such gamblers enjoy gambling rather than trying to resist the impulse" (p. 792). The term problem gambling has also been used to depict people "unable to keep their losses within manageable parameters...to control their loses...losing money to the point of serious financial and psychological difficulty" (Rosecrance, 1986, p. 1728). However, problem gambling has also been used to describe gamblers who do not meet criteria for pathological gambling (Lesieur \& Blume, 1993). Pathological gambling is recognized as an addiction to gambling (Brustuen \& Gabriel, 1991; Lesieur \& Rosenthal, 
1991; Murray, 1993). For these reasons, the author will use the term pathological gambling or gambling addiction exclusively.

\section{Definition of Pathological Gambling}

The recognized authority on psychiatric disorders is the Diagnostic and Statistical Manual of Mental Disorders, fourth edition (DSM-IV). DSM-IV classifies pathological gambling as an impulse control disorder. Similar to other addictions, people with impulse control disorders exhibit "failure to resist an impulse, drive, or temptation to perform an act that is harmful to the person or to others... increasing sense of tension or arousal before committing the act and...pleasure, gratification, or relief" (American Psychiatric Association, 1994, p. 609) during or after engaging in the behavior.

Pathological Gambling is defined by the American Psychiatric Association (1994) as "persistent and recurrent maladaptive gambling behavior...that disrupts personal, family, or vocational pursuits" (p. 615). To receive a diagnosis of pathological gambling, a person must exhibit five out of 10 symptoms. ${ }^{1}$

The close link to other addictions is clear from the fact that these 10 symptoms parallel symptoms for substance addiction (Brustuen \& Gabriel, 1991; Lesieur \& Rosenthal,

1 See appendix p. 105 for exact DSM IV criteria. 
1991; Murray, 1993). The first two symptoms parallel tolerance: preoccupation with gambling, plans to gamble, or schemes to obtain money for gambling; and a need to increase the amount of gambling and/or the amount of money which is gambled. The third symptom is a lack of control, an inability to diminish or stop gambling. The fourth symptom, withdrawal, is manifested by anxiety, restlessness or irritability when trying to stop or reduce gambling. Escape from difficult feelings or situations is the fifth symptom. The person gambles to avoid handing or experiencing problems and emotions. Symptoms seven through 10 relate to negative consequences of the gambling: lying to friends, family, and others close to the person regarding the magnitude of the gambling; committing criminal acts (regardless of being caught) to support gambling; gambling costs or damages a relationship, job, or other opportunity; a "bail out" occurs, requiring others to pay off debts incurred as a result of gambling (American Psychiatric Association, 1994).

The symptom which appears to have no direct link to substance addiction is chasing, the sixth symptom. chasing occurs when the person returns to gamble after losing in a desperate attempt to win back that money--the person cannot let go of the lost money (American Psychiatric Association, 1994; Brustuen \& Gabriel, 1991; Lesieur \& Rosenthal, 1991; Murray, 1993). 
Scope of Problem

Gambling is popular throughout the world, and in the United states it is estimated that 60 percent of the population gambles annually (Commission on the Review of the National Policy Toward Gambling, 1976; Custer \& Milt, 1985). Gambling is so widespread in this country that "more Americans went to casinos than to major league ballparks in 1993. Ninety-two million visits!" (Hirshey, 1994, p. 36). This popularity translates to $\$ 330$ billion spent on state sanctioned gambling during 1994, an estimated additional $\$ 43$ billion was spent on illegal gambling (Hirshey, 1994).

Although the gambling numbers are staggering, only a minority of the people who gamble meet the criteria for pathological gambling (Blaszczynski \& McConaghy, 1989; Custer \& Milt, 1985; Hirshey, 1994; McElroy, Hudson, Pope, Keck, Aizley, 1992; Rosecrance, 1986). Estimates vary, but studies have found that between .2 to 3.4 percent of the total population in the United States could be diagnosed with pathological gambling (Blaszczynski \& McConaghy, 1989; HcElroy, Hudson, Pope, Keck \& Aizley, 1992). The total number of people in this country with the disorder has been estimated between six and nine million, and "most likely exceeds the incidence of schizophrenia" (Harris, 1988, p. 211). 
Unfortunately the number of pathological gamblers is likely to increase rapidly, as the number of legal gambling outlets are increasing rapidly (Harris, 1988). Similar to addictions to substances--where an increase in supply leads to an increase in addiction, there appears to be a positive correlation between pathological gambling and the number of legal gambling opportunities available (Blaszczynski \& McConaghy, 1989; Lesieur \& Rosenthal, 1991; McCormick \& Taber, 1991; Rosecrance, 1986; Taber, McCormick, Russo, Adkins, \& Ramirez, 1987).

Like substance addictions, pathological gambling creates negative consequences for the gambler, friends and family, and society (Brustuen \& Gabriel, 1991; Lesieur \& Rosenthal, 1991; Murray, 1993). Pathological gamblers are much more likely to attempt suicide, 18 percent, compared to the population at large, at four percent (Lesieur \& Rosenthal, 1991).

According to Taber et al. (1987), "pathological gambling is, furthermore, a complex mental health problem often seen in conjunction with other syndromes" (p. 757). "[Pathological] gambling is associated with high rates of depression, alcoholism and other addictions, disturbed sleep and eating patterns, sexual problems, and suicidal tendencies" (England \& Gotestam, 1991, p. 113). There is also an enormous emotional cost to the family, children and spouses (McGurrin, 1992). They become victims of the up and 
down/winner or loser emotional swings of the gamblers (Custer \& Milt, 1985; Lesieur \& Rothschild, 1989).

Financially, pathological gambling is devastating to the gambler's family and society. The typical debt for men is between $\$ 53,350$ and $\$ 92,000$, for women, $\$ 14,979$ (Lesieur \& Rosenthal, 1991). Pathological gamblers do not stop once they have lost their own money. Studies show that the percentage who commit illegal acts to finance their addiction range from 50 percent (England \& Gotestam, 1991), to 65 percent (Lesieur, Blume \& Zoppa, 1986), to 93 percent (Bonneville, 1994). As a result "legal problems are a major concern for [pathological gamblers]" (Ciarrocchi \& Richardson, 1989, p. 61).

In Oregon, state-sponsored gambling brings in millions of dollars each year. Video poker appears to be causing the most problems for Oregonians, "roughly 80 percent of the gambling addicts who sign up for treatment in Multnomah County say video poker is their No. 1 problem" (Lydgate, 1995, p. 20). According to the oregon Lottery Commission, video poker brought profits of $\$ 62.1$ million in $1993, \$ 119.9$ million in 1994, and $\$ 173$ million in the first half of 1995 into the state coffers. During this same time period, people spent $\$ 347$ million, in $1993, \$ 516.1 \mathrm{million}$, in 1994 , and $\$ 615$ million during the first half of 1995 .

There are 1,509 places for oregonians to gamble at video poker. Oregonians, like their counterparts in other 
states, are getting into trouble with gambling. The oregon Department of Administrative services estimates that 61,000 oregonians are pathological gamblers. Metro Crisis reports that 1,575 people called the gambler's hotline during the first six months of 1995 .

It is clear that pathological gambling is a problem throughout this country, and is a growing problem in oregon. There is a cost to society for pathological gambling. Not only do pathological gamblers commit more crimes than the general population, and incur greater debt, similar to other addicts they lose their jobs due to their addiction (Brustuen \& Gabriel, 1991; Lesieur \& Rosenthal, 1991). The cost to the family is grave, both financially and emotionally (Custer \& Milt, 1985; Lesieur \& Rothschild, 1989). The cost in self-esteem to the gambler is also great, since our society considers gambling a moral weakness, which pathological gamblers could control if they so desired (Orford \& Mccartney, 1990).

\section{Purpose}

An addiction which is so pervasive, poorly understood, and costly deserves further study. The author will thoroughly explore existing literature on pathological gambling, both the profile of the disorder and treatment. Treatment for pathological gambling is in its infancy and few scientifically designed outcome studies have been 
developed. The majority of the literature discusses treatment strategies, rather than treatment outcomes. There are, however, areas of agreement based upon the clinical judgment of professionals who treat pathological gambling. This author will make use of consensus wherever possible and filter it through my own clinical judgment in designing a model treatment program. This model treatment program will be presented as a conclusion to the review of the literature.

There is great need for enhanced understanding of pathological gambling and its treatment. The following is a discussion of the reasons for this need. The study of all addictions is relatively new, and the study of gambling addiction has very recently begun (Lesieur \& Blume, 1991). There has only been one controlled study measuring outcomes (Mcconaghy, Blaszczynski, \& Frankova, 1991). Despite this lack of controlled studies, most treatment providers agree that "pathological gambling is an extremely treatable disorder" (Rosenthal \& Lorenz, 1992, p. 655, also Murray, 1993). That pathological gambling can be treated does not mean pathological gambling is easy to treat, nor that abstinence is easily achieved (Custer \& Milt, 1985; Galski, 1987 ; McGurrin, 1992).

When gambling is examined from a learning or behavioral perspective, it is easy to understand the reasons that abstinence from gambling is so difficult for the 
pathological gambler to achieve. Gambling creates an almost perfect intermittent and variable positive reinforcement schedule (Brown, 1987a). Regardless of the game, gamblers can never really know or control when they will win. Behaviors, such as gambling, developed through intermittent and variable reinforcers are much more difficult to extinguish than other behaviors (Ferster \& Skinner, 1957). Constructing a treatment program that actually helps pathological gamblers become and remain abstinent is difficult, as a result this author will design a program that helps gamblers develop relapse prevention skills. Although people addicted to gambling can be helped through treatment (Blackman, Simone, Thoms \& Blackman, 1989; Mccormick \& Taber, 1991), only a small percentage actually enroll in treatment (Volberg \& Steadman, 1992). Attendance by pathological gamblers in treatment is poor, and drop out rates are high (Haustein \& Schurgers, 1992). "Gamblers are known as difficult, resistive clients" (Harris, 1988, P.212). This author will develop a treatment program that encourages clients to become engaged in treatment.

Treatment for pathological gambling is a recent development, and still is not widely available (Custer \& Milt, 1985; Hudak,Jr., Varghese \& Politzer, 1989; Sharpe \& Tarrier, 1992 Volberg \& Steadman, 1992). Freud and other early psychoanalysts worked with a few clients, but the first real help for pathological gambling was modeled after 
Alcoholics Anonymous. Gamblers Anonymous (GA) started in 1957 (Blaszczynski \& McConaghy, 1989; Custer \& Milt, 1985; Volberg \& Steadman, 1992).

Actual large scale treatment for pathological gambling began much later and was based on GA. Robert Custer, M.D. began an inpatient program in a Veteran's Administration (VA) hospital addiction treatment unit in 1972 (Custer \& Milt, 1985; Harris, 1988; Taber, 1985). Since that time, most of the treatment programs available are sponsored by the VA (Custer \& Milt, 1985; Harris, 1988), and, obviously only veterans have access to these programs.

Custer and Milt (1985) were able to list all of the inpatient and the single outpatient pathological gambling treatment program in two paragraphs, five out of nine were exclusively for veterans. As recently as 1989, Hudak, Jr. et al. noted that programs were available in as few as 10 states. No doubt, the number of treatment programs has increased since then, however indisputably the shortage continues to exist (Harris, 1988, Lesieur, 1989; Volberg \& Steadman, 1992). Lesieur (1989) found "a need for basic, as well as advanced training/education" (p. 425) about pathological gambling and its treatment.

The types of treatment available are also limited and the majority of programs available are inpatient (Sharpe \& Tarrier, 1992). The reasons that the majority of programs treating pathological gambling are inpatient has not been 
discussed in the Iiterature. However, the author sees the lack of outpatient programs as indicating a need for development of such programs. Some of the advantages to outpatient treatment include: not having to quit or take leave of absence from job, learning and practicing relapse prevention behaviors in the actual settings that they will be needed, building support networks where the client actually lives, and saving the cost of overnight stays in a hospital setting.

According to Brown (1986), GA is "the only help as yet at all extensively available" (p. 130) for pathological gambling. If $G A$ is not helpful, the pathological gambler will be poorly served since most pathological gambling treatment programs are modeled on the GA twelve step program (Custer \& Milt, 1985; Rosecrance, 1986; Sharpe \& Tarrier, 1992; Volberg \& Steadman, 1992). Because there is this lack, this author will develop an approach which, while encouraging use of $G A$ as an adjunct to treatment, does not follow the 12 step approach.

There are problems with GA. Lesieur and Blume (1991) discussed the fact that "Gamblers Anonymous alone is not sufficient to produce recovery for most pathological gamblers" (p. 1018). GA has been faulted for satisfying the needs of wealthier pathological gamblers, and ignoring lower class gamblers (Volberg \& Steadman, 1992). Lesieur (1990), 
found that there was little representation of cultural and racial minorities, women and young adults.

In a series of studies of current and former $\mathrm{GA}$ members, Brown (1986) found, "GA has a considerable drop out rate" (p. 131). Brown (1987c) attributed this high drop-out rate to GA's inability to meet the needs of those pathological gamblers most severely effected by the disorder, and those most likely to relapse. That is, the people who need help the most are unlikely to be well served by GA. Because $G A$ is not effective for everyone, and there is a lack of non-GA based programs, this author will develop an approach which, while encouraging use of GA as an adjunct to treatment, does not follow the 12 step model.

Pathological gambling programs which do not rely exclusively upon a GA based format are often narrowly focused. Programs tend to be exclusively behavioral (Lesieur \& Blume, 1991; Mcconaghy et al., 1991), exclusively cognitive-behavioral (Brown, 1987a; Mccormick \& Taber, 1991; Rosecrance, 1986; Sharpe \& Tarrier, 1992; Sharpe \& Tarrier, 1993; Volberg \& Steadman, 1992), or exclusively psychodynamic (Blackman, Simone \& Thoms, 1986; Rosenthal \& Lorenz, 1992; Rosenthal \& Rugle, 1994; Rugle \& Rosenthal, 1994; Taber \& Chaplin, 1988; Taber, Russo, Adkins \& McCormick, 1986) in their approach. Additionally, programs tend to utilize either individual therapy (Taber, 1985; Miller, 1986) or group therapy (Custer \& Milt, 1985), and 
some programs focus mainly on family and couples counseling (Blackman, Simone \& Thoms, 1986).

Pathological gambling is a treatable, but complex addiction. People from all social, economic and cultural groups are effected. For these reasons, this author will design treatment that is not simple, but well-rounded. This program is a non $G A$ based program which uses cognitivebehavioral, behavioral and psychodynamic approaches in settings that include individual, group and family/marital counseling. It is theorized that a program designed using a variety of approaches will attract pathological gamblers and motivate them to remain in treatment until completion. In addition, due to the extensive misinformation which exists regarding pathological gambling (Blaszczynski \& McConaghy, 1989; Custer \& Milt, 1985; McGurrin, 1992 Orford \& Mccartney, 1990) and pathological gambler's need for help in a variety of areas an education component will be developed which would be available to gambling clients and the general public. The author will develop and present this program. 
CHAPTER II

\title{
PROFILE
}

\begin{abstract}
"'You've turned into a log of wood," he commented. 'You've not only lost contact with reality and lost all interest in world events, in your civic duties, in yourself, in your friends (and you did have friends), you've not only lost all goals in life, except for winning at roulette--you've even renounced your memories" -Fyodor Dostoevski, The Gambler
\end{abstract}

\section{Characteristics}

There is no single profile for people with pathological gambling, however there are characteristics and traits which are common to many gambling addicts. Most of the information available regarding attributes of pathological gamblers is data drawn from clinicians' experiences working with patients in treatment. Although lacking the validity of controlled research findings, this author will discuss characteristics upon which a number of different clinicians have agreed.

According to custer and Milt (1985) the typical pathological gambler "is a friendly, sociable fellow, cheerful and enthusiastic, generous and full of good will. He is clever, energetic, hardworking and he generally does successfully [sic]" (p. 61-62). Intelligence is a 
characteristic which is often associated with pathological gambling (Brustuen \& Gabriel, 1991; Custer \& Milt, 1985; Rosenthal, 1986).

Dostoevski was probably not the first to notice that pathological gamblers tend to focus on gambling to the exclusion of everyone and everything else. Recently, several sources have found pathological gamblers to be socially isolated (Blackman et al., 1989; Brustuen \& Gabriel, 1991; Galski, 1987; Miller, 1986; Steinberg, 1993; Taber \& Chaplin, 1988). Indeed, Brustuen and Gabriel (1991) state "a pathological gambler might come across as a personable, outgoing sort, but the deeper truth is that he or she is more comfortable when alone" (p. 7). According to Rosenthal, (1986) this pulling away from others is because "the greatest threat for most pathological gamblers is intimacy" (114).

Ambition and competitiveness are commonly discussed traits associated with pathological gambling (Adkins, 1988; Brustuen \& Gabriel, 1991; Custer \& Milt, 1985; Gaboury \& Ladouceur, 1989; Moravec \& Munley, 1983; Rosenthal, 1986). Adkins (1988) has found that "pathological gamblers often times are compulsive overworkers" (p.212), and custer and Milt (1985) discussed pathological gamblers' need to compete, going far beyond a mere desire to compete. In a study of inpatient pathological gambling patients at a VA hospital, Moravec and Munley (1983) examined results of a 
variety of personality tests. The pathological gamblers had elevated scores on achievement, autonomy and dominance.

Moravec and Munley (1983) also found lowered scores for pathological gamblers on endurance. This is in keeping with the general consensus in the field that pathological gamblers are impatient with long term goals, but are looking for instant success (Brustuen \& Gabriel, 1991; Custer \& Milt, 1985; Galski, 1987; McGurrin, 1992).

Power and control appear to be issues for pathological gamblers (Brustuen \& Gabriel, 1991; Galski, 1987; Miller, 1986; Rosenthal, 1986; Sharpe \& Tarrier, 1992; Steinberg, 1993). Steinberg (1993) found that pathological gamblers struggle against and fear others controlling them. Similarly, the fear of intimacy appears to be due in large part to a fear that an intimate could exert power or control over, and trap the pathological gambler (Rosenthal, 1986). While those addicted to gambling appear to dread being controlled by other people, sharpe and Tarrier (1992) noted that they "frequently believe that their problems are intractable and beyond their control" (p. 194).

Another aspect of power and control is related to the magical thinking or irrational beliefs connected with pathological gambling. Magical thinking is a primitive defense that enables a person to avoid dealing with reality, by believing in irrational, unreal thoughts even in the face of evidence to the contrary. It is a method for avoiding 
the pain of reality. There are a number of irrational beliefs common to pathological gamblers, but one of the most common is the feeling of omnipotence--they cannot lose (Brustuen \& Gabriel, 1991; Cusack, Malany \& DePry, 1993; Custer \& Milt, 1985; Galski, 1987; Rosenthal, 1986; Selzer, 1992; Sharpe \& Tarrier, 1992). According to selzer (1992), pathological gamblers "actually believe that a mysterious force is behind them, picking the right numbers or horses and causing the cards to fall the way they want them to fall" (p. 216). Regardless of how many times the pathological gambler loses such a person is still convinced that gambling equates to winning. The pathological gambler recalls the wins to bolster these irrational beliefs (Cusack, Malany \& DePry, 1993; Galski, 1987; Rosenthal, 1986; Selzer, 1992).

People with pathological gambling disorder tend to be easily bored. They quickly become restless with commonplace tasks and events. One relief from this boredom appears to be the action and excitement which gambling provides (American Psychiatric Association, 1994; Brustuen \& Gabriel, 1991; Custer \& Milt, 1985; Galski, 1987; Rosenthal, 1986; Selzer, 1992).

Finally, there is an almost universal understanding in the field that low self-esteem, and poor self image is present in pathological gambling (Brustuen \& Gabriel, 1991; Cusack, Malaney \& DePry, 1993; Custer \& Milt, 1985; Galski, 
1987 ; McGurrin, 1992; Rosenthal, 1986; Selzer, 1992; Sharpe \& Tarrier, 1992). It is not yet determined whether the low self-esteem was a precursor to or a result of the gambling. It should be apparent that the portrait of the pathological gambler is a conflicted one. The pathological gambler appears to be a walking contradiction. On the one hand, the person appears friendly and outgoing, yet, on the other hand is socially isolated. The pathological gambler is intelligent, yet tends to rely on irrational beliefs. There is an irrational belief in the pathological gambler's omnipotence existing along with a poor self image.

\section{Demographic Data}

Studies consistently find that people with pathological gambling disorder are overwhelmingly male (Custer \& Milt, 1985; England \& Gotestam, 1991). In a study of 237 pathological gambling clients in treatment, 213, or 90 percent were men (Horodecki, 1992). Ciarrochi \& Richardson, (1989) studied 186 pathological gambling inpatients and found that 92 percent were men. Volberg and steadman (1992) also found a majority of pathological gamblers to be male, although the ratio of male to female differed according to income. Men represented 86 percent of the higher income patients, but only 64 percent of the lower income patients. The Diagnostic and Statistical Manual of Mental Disorders-4th ed. (American Psychiatric Association, 1994) cites the 
lowest percentage of male pathological gamblers, indicating that one third are female, and only two third are male.

other demographic characteristics are not as clear. Murray (1993), found "nonwhite persons have higher rates of pathological gambling than white groups in some epidemiological studies and Jews are overrepresented in GA" (p. 803). However, patients in treatment appear to be mainly white (Custer \& Milt, 1985; Murray, 1993; Volberg \& Steadman, 1992).

Ciarrochi and Richardson (1989) found educated, employed, middle class pathological gambling clients. Most of the 186 pathological gambling patients had some college, and the mean level of education was 13.4 years. The mean income was $\$ 24,885$ with 76 percent of the patients employed. Average ages vary by study, although it appears that the majority of those pathological gamblers in treatment are over 30 (Ciarrochi \& Richardson, 1989; Horodecki, 1992; Volberg \& Steadman, 1992). Less than half of the pathological gambling patients in treatment are married according to Ciarrochi and Richardson (1989) and Volberg and steadman (1992). Horodecki (1992) found the opposite, 60 percent of 237 were married.

In conclusion, most of the demographic data currently available on pathological gamblers is only applicable to those in treatment. The only statement which can be made 
with any confidence is that the majority of pathological gamblers are men.

\section{Theories of Pathological Gambling}

Throughout this century, there have been efforts to explain pathological gambling. It should be noted that prior to this century, and to some extent currently, gambling is considered a moral issue, and gambling addiction is merely the result of weakness of character or moral deficiency (Blaszczynski \& McConaghy, 1989; Custer \& Milt, 1985; McGurrin, 1992; Orford \& Mccartney, 1990). Based upon the comparatively greater wealth of information available using psychodynamic theories to explain pathological gambling, psychodynamic theories appear to be favored by most clinicians in the field. However, there are also advocates of behavioral and social learning theories, and predisposing factor theories. An overview of these theories will be considered.

\section{Psychodynamic Theories}

The earliest theories were psychodynamic, and explained pathological gambling through a psychosexual orientation (Lesieur \& Rosenthal, 1991). According to Niederland (1965), Freud believed that gambling was a replacement for masturbation, and Laforgue and simmel also found gambling related to sexual arousal and satisfaction (Galski, 1987). Freud and his early colleagues believed that gambling was 
connected with the pathological gambler's relationship with parents-from whom they believed sexual identity came. While recognizing that pathological gambling was an addiction, Freud theorized that by gambling the individual played out the unresolved oedipal conflict (Galski, 1987; Lesieur \& Rosenthal, 1991; Niederland, 1965). Freud believed that winning was not what caused the pathological gambler to gamble, it was a need to be punished, or castrated by the father. The purpose of the castration is to stop being a rival for the mother's affection and obtain the father's love (Galski, 1987). As the gambler moves from winning to losing, he gains the love of his mother, then the love of his father, respectively. Freud believed that the pathological gambler had had "an extremely competitive, love-hate relationship" (Rosenthal \& Rugle, 1994, p. 22) with the father.

According to Lesieur and Rosenthal (1991), Bergler expanded upon the self-punishing, masochistic theme during the middle of this century. He believed that the pathological gambler gambles only to lose. Guilt is the motivating factor for the pathological gambler. The guilt is caused by "rebelling against the reality principal, and against those authority figures, originally the parents... imposing rules and restrictions on...pursuit of pleasure" (Galski, 1987, p. 52). The pathological gambler is not comfortable with the rebellion, and thus feels guilty. This 
guilt, then leads to an unconscious desire to punish or injure self. According to the masochism theory of Bergler, the pathological gambler learns that pain and punishment are pleasurable (Galski, 1987; Harris, 1988).

During the 1960's, it was theorized that pathological gambling was not the result of unresolved oedipal issues. Instead, pathological gambling would be the result of a failure in object relations. The pathological gambler experiences "early and severe deprivations in his affect relations with his parents" (Rabow, Comess, Conovan \& Hollos, 1984, p. 194). This would prevent the pathological gambler from developing normal boundaries and create an insatiable need for love and acceptance. This need leads the pathological gambler to look to fate for love. The outcome of gambling is based on fate, thus the individual looks to gambling to fulfill those love needs.

Rosenthal supports the theory that early deprivation and failure to fulfill developmental tasks leads to development of pathological gambling (Galski, 1987; Lesieur \& Rosenthal, 1991; Rosenthal \& Rugle, 1994). "Being dependent on others for that which should reside within himself" (Galski, 1987, p. 65) leads to a sense of being out of control. Feeling omnipotent and gambling help relieve the out of control sensation (Galski, 1987).

Rosenthal (1986) suggests that the driving force for pathological gambling is fear and avoidance of intimacy. 
When someone gets too close to the pathological gambler the gambler feels suffocated and a sense of claustrophobia. Gambling is a reaction to those fears. Pathological gambling as the result of a failure in object relations would explain this fear. The pathological gambler would have poor boundaries, and any intimacy might cause the person to feel totally lost, and suffocated.

Psychodynamic theories also have examined similarities between pathological gambling and narcissistic and borderline personality disorders. Theoretically both of these personality disorders result from poor object relations, an inability to develop healthy relations, due to problems in early relationships. From the beginning, those working with pathological gamblers have noted their sense of entitlement, grandiosity, and omnipotence (Galski, 1987; Rabow et al., 1984; Rosenthal \& Rugle, 1994). These traits are also characteristic of persons with narcissistic and borderline personality disorder.

Rosenthal (1986) continued the connection with narcissism, noting the use of primitive defenses: "splitting, primitive projection, omnipotence, idealization and devaluation, denial" (p. 119). One primitive defense which a variety of sources have noted is magical thinking. Magical thinking occurs when a person creates fantasies and irrational thoughts to explain situations, or believes that thinking something can make it happen. Feelings of 
omnipotence and grandiosity are examples of magical thinking. These irrational beliefs become real to the pathological gambler and enable the gambler to conclude that gambling will solve all problems (Custer \& Milt, 1985; Galski, 1987; Harris, 1988; Rosenthal, 1986).

similarly, it has been theorized that pathological gambling results from a lack of ego strength. Taber et al. (1986) delineated three components for ego strength which relate to coping with adversities--that is, emotional hardships and problematic events. First, people with healthy ego strength can handle adversities. Second, during adversity, people with ego strength can develop and implement coping strategies. Finally, these people understand and appreciate their capacity to deal with adversity. According to selzer (1992), poor ego development, leading to a lack of ego strength, occurs when the parent "is emotionally cold, exploitative, or unavailable, children fail to move to the next developmental stage and defend themselves from further abandonment" ( $p$. 216) trying to become what the parent wants. Haustein and Schurgers (1992) propose that pathological "gamblers yearn for a symbiotic relationship" (p. 139). This need for symbiosis can lead to magical thinking, or narcissistic grandiosity. They found that due to weak ego boundaries, the pathological gambler also feared intimate 
relationships. Thus the person is in the bind of fearing the very thing desired the most.

Rosenthal and Rugle (1994) list six reasons for gambling, stated by pathological gamblers. First, the pathological gambler needs a major success to feel good, needs to be a big winner to prove self worth. Second, the pathological gambler has rage and aggression, that is acted out through the rebellious act of gambling. Third, the pathological gambler is seeking control and freedom from dependency. Financial freedom may be confused with emotional independence. Additionally, when gambling, the pathological gambler knows what is risked--money, which provides a sense of control.

Fourth, there is a camaraderie among gamblers, the pathological gambler is looking for a social group where s/he belongs. Fifth, the pathological gambler wants to escape emotions that are too painful to manage. While gambling, the pathological gambler needn't think about, let alone experience any feelings. Finally, gambling is an opportunity to compete and show the world his/her superiority (Rosenthal \& Rugle, 1994).

Rosenthal and Rugle (1994) describe four types of pathological gamblers based upon their underlying need for gambling. The first type gambles to win. winning means success and love. This pathological gambler has internalized negative messages, and constantly sees the self 
as worthless and inadequate. For the second category of pathological gamblers losing is the focus. This gambler gambles for the thrill of risking it all and surviving. Competition drives the third variety of pathological gamblers. Battling another and winning is what counts. Finally, there is the pathological gambler who plays to feel the excitement. "strong sensations are craved, to counter feelings of emptiness or deadness" (Rosenthal \& Rugle, 1994, p. 28) .

Miller (1986) postulates that pathological gambling serves functions in four areas: "social, psychological, existential and avoidance of unpleasant affects" (p. 98). As Rosenthal and Rugle (1994) found, the pathological gambler uses gambling to replace other social activities and relationships. Often the only social image which the pathological gambler has is that of a gambler, a winner (Miller, 1986).

Psychologically, pathological gamblers use gambling to solve their dependence/independence dilemma. The pathological gambler feels above it all and independent while gambling, yet can have a close intimate relationship with gambling. Gambling also helps the pathological gambler avoid considering the lack of a sense of self. It should be noted that these "solutions" are mostly magical thinking and, not only don't solve psychological problems, gambling often adds to the problems (Miller, 1986). 
Miller (1986) has found that gambling enables the gambling addicted to avoid dealing with existential issues, such as the meaning of life, death, being alone. The sense of being part of something while gambling, allows the pathological gambler to ignore these deeper anxieties.

Finally, "sadness, guilt, shame, insecurity, helplessness, anxiety, frustration, and anger can all be absorbed or replaced by the action and fantasy world of gambling" (p. 98). Thus, for the pathological gambler, gambling becomes the perfect medication against all of the feelings that the gambler desires to avoid.

In conclusion, psychodynamic theories explain pathological gambling through developmental and psychological determinants. These theories are divergent and complex, and there is little scientific evidence which directly supports these assumptions. Finally, these theories do not adequately explain a number of facts about pathological gambling. An example is the point that as the number of gambling outlets increase the rate of pathological gamblers also increases.

\section{Behavioral and Learning Theories}

Pathological gambling from the view of behaviorists is the result of operant conditioning (England \& Gotestam, 1991). The pattern of rewards or reinforcement with gambling is ideal for learning new behaviors. According to this theory, the reinforcer is winning, which translates 
into money. Wins occur intermittently and the frequency, rate and amount won vary. This pattern of reinforcement coincides with the pattern for creating behaviors that are difficult to extinguish (England \& Gotestam, 1991; Ferster \& Skinner, 1957).

McConaghy, Blaszczynski and Frankova (1991) discuss the roll of BCMs, behavioral completion mechanisms. These mechanisms are developed when a behavior is engaged in repetitively, such as gambling by the pathological gambler. once created, BCMs act as a drive or coping mechanism when certain triggering events or emotions occur. For the pathological gambler BCMs motivate him/her to gamble whenever confronted by life events which were handled through gambling, or places where $s /$ he has gambled are encountered (McConaghy, Blaszczynski \& Frankova, 1991).

Brown (1987a) considers arousal from gambling the main conditioner or motivator for pathological gambling. Evidence to support this assumption includes the fact that pathological gamblers are aroused by gambling and describe the action and excitement which they experience when gambling. Brown (1987a) concludes that pathological gamblers become addicted "to their own arousal and its physical and psychological effects" (p. 114).

Gaboury and Ladouceur (1989) chose thirty men drawn from the population at large, with no history of pathological gambling. When these subjects gambled, most of 
the statements which they made were irrational and erroneous. It appeared that these statements and beliefs enabled the subjects to continue to gamble, fostering feelings of control. Gaboury and Ladouceur (1989) concluded that "mistaken perceptions may play an important role in the development and maintenance of gambling behaviors" ( $p .418$ ).

In conclusion, behaviorists and learning theorists delineate a series of environmental and physiological factors which combine to "teach" pathological gambling behavior. Unfortunately, these theories cannot adequately differentiate between those who experience certain environmental and physiological factors and will learn pathological gambling behaviors and those who experience the same factors and will not.

\section{Predisposing Factors}

Several researchers have found physiological factors, particularly arousal patterns, more common in pathological gamblers. Additionally, others have found psychological differences. These predisposing factors are hypothesized to be the underlying cause for pathological gambling (England \& Gotestam, 1991; Harris, 1988).

Jacobs (1988) suggests that there are two requisite predisposing factors which interact to create addiction to gambling. The first precondition is abnormal physiological arousal levels which are higher or lower than normal levels. The reduced arousal levels are usually experienced as 
boredom. The elevated arousal levels are experienced as anxiety or tension. Jacobs (1988) considers the second precedent to be "a childhood and adolescence marked by deep feelings of inadequacy, inferiority, and a pervasive sense of rejection by parents and significant others" (p. 28).

other factors which have been postulated to predispose people to pathological gambling include high sensationseeking levels (Kuley \& Jacobs, 1988), comfort with elevated risk-taking, depressed moods, perfectionism (Galski, 1987), need for instant success, and volatile mood states (McGurrin, 1992).

Predisposing factors no doubt have a role in explaining pathological gambling. However, these theories do not reveal the origin of the preconditions, nor what causes some with similar characteristics to become pathological gamblers while others do not.

Phases

Researchers who study pathological gambling have enumerated the phases of progression of the disorder. Custer and Milt (1985) listed three phases, while subsequent authors have depicted four (Rosenthal \& Lorenz, 1992). It should be noted that controlled studies have yet to be made to prove these phases exist, only anecdotal evidence from practitioners supports this supposition.

\section{One: Winning Phase}


The first phase in the course of pathological gambling is the winning phase. A person who gambles occasionally recognizes that $s /$ he is starting to win regularly. The gambler finds that people admire the winning, and enjoys the money and enhanced self-esteem (Custer \& Milt, 1985; Cusack et al., 1993; Rosenthal \& Lorenz, 1992). According to Custer and Milt (1985), "money takes on new significance...money is importance...even without friends, money can keep you from being lonely" (p. 99). Money represents power and independence. During this phase, the gambler increases the amount of time spent on gambling and honing gambling skill.

During the wining phase, the gambler usually experiences the first "big win." The pathological gambling literature is replete with descriptions of the "big win" (Custer \& Milt, 1985; Cusack et al., 1993; Galski, 1987; McGurrin, 1992 Rosenthal \& Lorenz, 1992). Defined as wining an amount of money which "is highly significant in relation to their annual salary and that seems to have been gained effortlessly and quickly" (Cusack et al., 1993, p. 173). All of this winning makes the gambler gregarious and magnanimous. The gambler begins to believe that this lifestyle will never end, and feels omnipotent that s/he cannot lose (Custer \& Milt, 1985; Cusack et al., 1993; Rosenthal \& Lorenz, 1992). 
Custer and Milt (1985) theorize that if the gambler is not rewarded by early experiences of winning the gambler will probably never progress into a pathological gambler. The self-esteem cannot handle too many loses prior to developing the omnipotent belief in winning. However, Rosenthal and Lorenz (1992), suggest that not all pathological gamblers experience a winning phase. In particular, winning phases are less common in women.

\section{Two: Losing Phase}

When the winning stops, and the losing begins, the gambler progresses to the losing phase. The gambler stops gambling "smart" during this phase. The losing is so intolerable that the gambler makes larger and riskier bets to try to recoup the losses. The chase, the pursuit of lost money, also begins during this phase. The gambler will often return to the same location to try to recapture the losses. The individual cannot accept the losses, or believe that they are happening (Custer \& Milt, 1985; Cusack et al., 1993; Rosenthal \& Lorenz, 1992).

While the winning phase is marked by gregariousness and generosity, the losing phase is defined by withdrawal from everything but gambling and urgent scrounging for money. As the situation becomes worse, lying becomes a way of life for the pathological gambler. Not only does the individual start lying about gambling and losses, but the lying usually becomes a pervasive pattern for dealing with the world 
(Custer \& Milt, 1985; Cusack et al., 1993; Rosenthal \& Lorenz, 1992).

Winning may occur during the losing phase, but the pathological gambler never actually returns to the winning phase. Instead, the pathological gambler experiences a yoyoing effect of going from the joy of winning to the sheer terror of losing. The sense of omnipotence never truly returns (Custer \& Milt, 1985).

\section{Three: Desperation Phase}

This phase usually starts with a "bail out" by close friends or family. A bail out occurs when friends or relatives provide money to enable the pathological gambler to pay off debts. In exchange, the pathological gambler usually vows to stop gambling. When the gambling doesn't stop, the desperation phase begins in earnest (custer \& Milt, 1985; Cusack et al., 1993; Rosenthal \& Lorenz, 1992). According to Custer and Milt (1985), "with the first substantial bailout, the process accelerates sharply along the downward path" (p. 112). Moral and ethical boundaries that were previously inviolate are now crossed. During this phase, pathological gambling leads to lying, cheating, stealing and criminal acts. At this point, the pathological gambler uses magical thinking and irrational thoughts to excuse immoral behavior (Custer \& Milt, 1985; Cusack et al., 1993; Rosenthal \& Lorenz, 1992). During this phase the 
pathological gambler is likely to become suicidal for the first time (Rosenthal \& Lorenz, 1992).

\section{Four: Giving Up Phase}

According to Rosenthal and Lorenz (1992), some, but not all pathological gamblers reach this phase. When the pathological gambler realizes that the lost money can never be recaptured the gambler enters the giving up phase. The purpose of gambling is no longer (if it ever has been) about winning. The purpose of gambling is to achieve the feeling that the pathological gambler can secure only when gambling. During this phase the pathological gambler is at high-risk for suicide (Rosenthal \& Lorenz, 1992).

\section{Co-morbid Diagnosis}

There are a variety of disorders and physical problems that are correlated to pathological gambling. Indeed, comorbid diagnosis are so prevalent with pathological gambling, that one study found only eight percent of the patients studied had no secondary diagnosis (Lesieur \& Rosenthal, 1991).

Pathological gambling patients often receive a comorbid diagnosis of major depressive disorder (Adkins, 1988; Bonneville, 1994; Lesieur \& Blume, 1993; Lesieur \& Rosenthal, 1991; Murray, 1993; Rugle, 1993; Taber et al., 1987). A diagnosis of depression often continues long after the patient has become stable regarding the gambling (Rugle, 
1993). Studies have found rates of depression as high as 97 percent (Murray, 1993), to 76 percent, to 72 percent (Lesieur \& Rosenthal, 1991), and a low of 52 percent (Rugle, 1993) among pathological gambling patients. Moravec and Munley (1983) found elevated scores on the depression scale on the MMPI. Pathological gambling patients also exhibit high rates of another affective disorder, cyclothymia (Adkins, 1988; Bonneville, 1994; Lesieur \& Blume, 1993; Lesieur \& Rosenthal, 1991; Rugle, 1993).

Pathological gambling patients have higher rates of dual addictions than the general population, often presenting for treatment addicted to alcohol and other drugs (Blaszczynski \& McConaghy, 1989; Lesieur \& Blume, 1993; Lesieur \& Rosenthal, 1991; Murray, 1993; Rugle, 1993). The rates of substance addictions for pathological gamblers vary by study from a high of 52 percent (Lesieur \& Rosenthal, 1991), to between 47 to 52 percent (Lesieur \& Blume, 1993), to a low of 39 percent (Lesieur \& Rosenthal, 1991).

Several studies have shown pathological gambling clients to have higher rates of adult attention deficit disorder (ADD). An essential feature of ADD is an inability to focus, which tends to be common among pathological gambling clients even when they do not meet a diagnosis of ADD (Rosenthal \& Lorenz, 1992; Sharpe \& Tarrier, 1993).

Despite pathological gamblers exhibiting similar characteristics and defenses to narcissistic and borderline 
personality disorders, there is less agreement regarding coexisting diagnoses of personality disorders. Supporting increased narcissism in pathological gamblers, Taber and Chaplin (1988) diagnosed 50 percent of the pathological gambling patients in treatment with narcissistic personality disorder. Moravec and Munley (1983) found elevated scores on the scale which measures personality disorders on the MMPI. Bonneville (1994) noted high rates of avoidant personality disorder. Cusack et al. (1993) found pathological gamblers demonstrated narcissistic and antisocial personality traits. "Some pathological gamblers represent a blend of these disorders" (Cusack et al., 1993, p. 170).

In summary, most of the information on co-morbid disorders in pathological gamblers is based upon clients in treatment. It appears, though, that depression and dual addictions are a real issue for pathological gamblers.

\section{Gambling Costs}

"The crisis that forces a pathological gambler to get help will always have a financial dimension" (Brustuen \& Gabriel, 1991, p. 9). The financial cost is just one of the costs of pathological gambling. Pathological gambling wreaks emotional havoc on the family of the pathological gambler, and is a major motivation for criminal acts (Brown, 
1987; Brustuen \& Gabriel, 1991; Custer \& Milt, 1985; Galski, 1987; Rosenthal \& Lorenz, 1992).

One of the major costs of pathological gambling is the reduction in emotional and mental health of the gambler. According to Horodecki (1992) who studied 237 pathological gamblers, these costs include "loneliness, decline of initiative, narrowing of all interest to gambling, decline in feeling of self-value, thoughts of suicide and suicide attempts" (p. 117) .

The cost to the family of pathological gambling is severe. According to Rugle and Rosenthal (1994), pathological "gamblers often come from environments (abusive, addictive, depressing, neglectful) that contribute to serious dysfunction" (p. 44). Frequently the addiction in the family of origin is gambling, thus the pathological gambler may be reaping the costs of his/her own parents gambling (Galski, 1987; Lorenz, 1989; Rugle \& Rosenthal, 1994). Some studies have found that the pathological gamblers are verbally abusive to their family (Galski, 1987). As pathological gambling progresses and the gambler's life becomes increasingly out of control, the spouse is required to handle mounting numbers of problems, especially financial. It is often the spouse who must find a method for managing the creditors (Galski, 1987; Lorenz, 1989). Perhaps it is not surprising that studies have found the spouses of pathological gamblers to be prone to both 
verbal and physical abuse of their children (Galski, 1985; Lesieur \& Rothschild, 1989).

The figures vary depending upon the study, but pathological gamblers are heavily indebted by the time they arrive for treatment. Lesieur and Rosenthal (1991) cite figures from the 1980 s wich range from $\$ 53,350$ to $\$ 92,000$. In a more recent study of Austrian pathological gamblers, 24 percent had debts exceeding $\$ 40,000$ (Horodecki, 1992). These lower figures are not explained; perhaps the difference is due to lower cost of living, or perhaps Europeans seek treatment earlier in the progression of pathological gambling than do Americans. There are no published studies which document what percentage of pathological gamblers' debts are ever paid off.

When pathological gamblers commit crimes to pay for their addiction, it costs the victim, the legal system, and the gambler. As the pathological gambler's debts increase, and credit is depleted, the gambler often turns to crime. How often? "Gambling today is at the root of at least $40 \%$ of all white collar crime" (Rosenthal \& Lorenz, 1992, p. 652). The percentages of pathological gamblers who commit crimes vary, Lesieur, Blume \& Zoppa (1986) found 65 percent of 40 inpatients had engaged in criminal activities. GA members have been studied to determine rates of illegal activities, two-thirds of all GA members have been found to have committed crimes (Brustuen \& Gabriel, 1991: Rosenthal \& 
Lorenz, 1992); similarly, 65 percent of female GA members had engaged in criminal activities (Lesieur \& Rosenthal, 1991). Bonneville (1994) noted a criminal activity rate as high as 93 percent among pathological gamblers, and Lesieur (1984) found a full 100 percent of a sample of 50 pathological gamblers had engaged in illegal acts. 
CHAPTER III

\title{
REVIEW OF LITERATURE ON TREATMENT
}

\author{
"The next best thing to gambling and \\ wining is gambling and losing." Nick \\ "the Greek" Dandolas.
}

Treatment of pathological gambling is a relatively recent phenomenon, and there is minimal research into treatment programs and their outcomes (Custer \& Milt, 1985; Hudak,Jr., Varghese, Politzer, 1989; Sharpe \& Tarrier, 1992; Volberg \& Steadman, 1992). However, most professionals in the field agree "that pathological gambling is a treatable disorder" (Mccormick \& Taber, 1991, p. 106).

Most treatments available have been modeled after treatments for alcohol and other drug addictions. (Blume, 1986; Custer \& Milt, 1985). The first help exclusively available for pathological gambling was Gamblers Anonymous (GA), which was modeled after Alcoholics Anonymous (AA) (Custer \& Milt, 1985). Pathological gambling treatment started in the substance addiction unit of a VA hospital. The treatment approach for pathological gambiing patients resembled the treatment for addictions (Custer \& Milt, 1985). Subsequent pathological gambling inpatient treatment programs also evolved out of addiction units (Blume, 1986; Custer \& Milt, 1985). 
Separate discussion of treatment for pathological gambling from drug and alcohol addictions only really started during the 1980s. Treatment of pathological gambling has gained considerably from the addictions field (Blume, 1986). In the interest of providing brief but relevant information on pathological gambling, this thesis will focus exclusively upon theories and treatment programs for pathological gamblers.

There are an assortment of types of treatment used with pathological gambling. For the purposes of this exploration, these various programs will be considered under: intake, GA, individual counseling, group counseling, psychodynamic approach, behavioral approach, and cognitivebehavioral approach.

Efficacy rates vary, not only by the treatment approach, but based upon: whether success is measured by abstinence or controlling gambling behavior; and characteristics of patients entering treatment. Different studies have found different characteristics to be decisive. According to Hudak, Jr. et al., treatment success, as measured by frequency of gambling, is also "significantly influenced by job satisfaction, and moderately influenced by marital status and family life satisfaction" (p. 201). In contrast, Mccormick and Taber (1991) found the best determinant of successful recovery to be the severity of the patient's gambling prior to treatment. The more severe the 
problem the less likely that treatment would be successful. Cognitive impairment has also been found to predict relapse (McCormick \& Taber, 1991).

The addictions field has long been conflicted by the debate on abstinence. Just as there are those who argue that controlled drinking is a viable treatment goal, some argue that controlled gambling should be considered a treatment success. The most vocal critics of using abstinence as the sole criteria for successful treatment are Blaszczynski, Mcconaghy \& Frankova (1991a, 1991b).

Blaszczynski et al. (1991b) followed 63 pathological gambling patients after brief behavioral therapy and found there were no real differences between patients who had gambled in a controlled manner and those who had achieved abstinence. These findings were based upon measures of social functioning and psychopathology ${ }^{2}$. According to Blaszczynski et al. (1991a), "pathological gamblers who report complete abstinence...do not differ on a number of psychometric and demographic parameters from those experiencing limited relapse episodes" (p. 1487).

Rosecrance (1986) goes further, believing that requiring abstinence "may be counterproductive" (p. 1735). He theorizes that pathological gamblers will be reluctant to

2 The measures used included: structured interviews, Eysenck Personality Questionaire, Xuckerman's Sensation Seeking scale, spielberger's state Trait Anxiety Inventory, and Beck Depression Inventory. 
seek treatment if required to remain abstinent. Rosecrance (1986) continues that "the efficacy of using a single limited, homogeneous goal (abstinence) for a large heterogeneous population (problem gamblers) can be seriously questioned" (p. 1735).

In contrast, most of the professionals who treat pathological gambling see one of the goals of treatment to be abstinence, and many believe that stability cannot be achieved without abstinence (Adkins, 1988; Blackman, 1989; Custer \& Milt, 1985; Galski, 1987; Lesieur, 1990; Miller, 1986; Rosenthal, \& Rugle, 1994). Although advocated by some, controlled gambling has few followers, "no supporting data and, in our opinion, without any persuasive rationale regarding the merits of such a treatment goal" (p. 139). According to Rugle (1993), abstinence for pathological gamblers "merely gives them the opportunity to begin restructuring their lives and their experience" (p. 11).

\section{Intake}

As the first contact with the pathological gambler, the intake interview is very significant. Taber (1985) outlines three major goals for this first contact. The first step is to start the therapeutic alliance. The therapist should be encouraging and mindful of the therapist's role. While being therapeutic, the therapist must also not neglect obtaining the crucial data from the client. Finally, the 
nature and scope of the treatment program must be shared with the client.

Sharpe and Tarrier (1992) advocate using Miller's motivational interviewing technique. There are four key elements. First, labeling is not necessary, the client need not identify as a pathological gambler. However, taking ownership for gambling behavior is the second requirement. The pathological gambler is encouraged in the third step to consider gambling a problem behavior that is not beyond the gambler's control. Finally, the pathological gambler becomes motivated not by confrontation by the therapist, rather by the internal inconsistencies and conflicts which are gently suggested by the therapist (Sharpe \& Tarrier, 1992 )

Cognitive and affective states should be assessed during intake according to Harris (1988). Harris (1988) delineates three goals of this assessment. First, the pathological gambler must share the personal meaning of gambling, and the gambler's motivation for gambling. Next, the therapist must evaluate magical thinking, irrational beliefs, and the extent and quality of the gambler's coping skills. Finally the therapist must "locate the client's strengths of personality that might help in learning to better adapt to life situations" (Harris, 1988, p. 221). Family issues should be discussed during the intake process (Steinberg, 1993; Taber, 1985). Steinberg (1993) 
lists five reasons for including the family in the intake process. First, it familiarizes the family with the treatment setting and encourages their involvement. The second reason is that it enables a more accurate profile of the pathological gambler by including the family's perspective. Third, the way the family interacts helps the therapist evaluate the family dynamics and the pathological gambler's interpersonal skills. Fourth, honesty is fostered when pathological gambler's realize that their family will be sharing information about the gambler. Finally, it encourages the pathological gambler's spouse to obtain needed counseling.

structured interviews may be helpful to make certain that the essential information is gathered (Lesieur \& Blume, 1991; Taber, 1985). Lesieur and Blume (1991) have used the Addiction severity Index (ASI) and state "this tool is a reliable and valid instrument that provides evaluation in seven areas of functioning" (p. 1019). These seven areas correspond to the data which Taber (1985) considers essential. The areas are: drug and alcohol history; medical conditions, past and present; employment and support, including education and training history; family and social relationships; and history of mental and emotional health. Lesieur and Blume (1991) used a modified version which includes a section on gambling history ${ }^{3}$.

3 See appendix, p. 106, for a copy of ASI. 
Psychological tests which help assess comorbid problems should also be administered at this time (Lesieur \& Blume, 1991; Taber, 1985). Many programs administer intelligence tests, a measure of gambling severity (South Oaks Gambling scale), and personality/self concept tests (Harris, 1988; Lesieur \& Blume, 1991; Taber, 1985).

Gamblers Anonymous/12 Step

Gamblers Anonymous was started in 1957, modeled after the Alcoholics Anonymous 12 step approach to addictions. one of the essential precepts of $\mathrm{GA}$ is that pathological gambling ${ }^{4}$ is a disease which can't be completely cured, although pathological gambling can go into remission--that is, recovery (Blaszczynski \& McConaghy, 1989; Gamblers Anonymous, 1988a). According to Gamblers Anonymous (1988a) "a G.A. group is the most effective instrument yet devised in bringing about a personal recovery from the problem of compulsive gambling" (p. 1).

An important aspect of $G A$ is the belief that recovering pathological gamblers can help newly recovering gamblers. This support comes not only from the meetings themselves, but from the socializing afterwards, the exchange of phone numbers, pressure relief groups, and most importantly the

4 It should be noted that $G A$ uses the term compulsive gambling almost exclusively. As discussed in Chapter I, under Definition of Pathological Gambling, compulsive gambler is somewhat of a misnomer, so pathological gambling will be used in this discussion. 
obtaining of a sponsor. A sponsor is a recovering pathological gambler with a stable period of abstinence, who the newly recovering gambler can call any time when experiencing an urge to gamble, or just needing to talk (Gamblers Anonymous, 1988a; Custer \& Milt, 1985; Rugle, 1993).

The work of $G A$ is accomplished through meetings organized by gamblers for gamblers (Custer \& Milt, 1985; Gamblers Anonymous, 1988a). The standard meeting is a structured opportunity for pathological gamblers to share their personal gambling and recovery history. This sharing of their story is called giving therapy. After introductions, the GA preamble, which describes GA and discusses its purpose, is read by a member. Next a member reads the GA 12 steps to recovery (listed below), a different member reads the GA Unity Program, and a fourth person reads the definition of gambling. At this point the chair shares his/her own therapy, and each attendee is invited to share. After the therapies, announcements and treasurer's report are made, followed by a request for financial support. The meeting usually closes with the recitation of $A A^{\prime}$ 's and GA's serenity prayer: "God grant me the serenity to accept the things I cannot change, courage to change the things I can and wisdom to know the difference" (Gamblers Anonymous, 1988a, p. 10). Following the official meeting, members are usually encouraged to 
remain for coffee and conversation (Gamblers Anonymous, 1988a).

Another important GA meeting format is the 12 step meeting. During this meeting, the essential concepts of recovery according to GA, the 12 steps, are worked on. The 12 step meeting is not as structured as general meetings. The essential feature is that one particular step is discussed during the meeting (Gamblers Anonymous, 1988b).

The 12 steps of $G A$ are as follows:

Step One [italics added]

We admitted we were powerless over gambling--that our lives had become unmanageable...

Step Two [italics added]

Came to believe that a power greater than ourselves could restore us to a normal way of thinking and living...

Step Three [italics added]

Made a decision to turn our will and our lives

over to the care of this power of our own understanding...

Step Four [italics added]

Made a searching and fearless moral and financial inventory of ourselves...

Step Five [italics added]

Admitted to ourselves and to another human being the exact nature of our wrongs...

Step Six [italics added]

Were entirely ready to have these defects of character removed...

Step Seven [italics added]

Humbly asked God (of our understanding) to remove our shortcomings...

Step Eight [italics added]

Made a list of all persons we had harmed and became willing to make amends to them all... Step Nine [italics added]

Made direct amends to such people wherever possible except when to do so would injure them or others...

Step Ten [italics added] 
Continued to take personal inventory and when we were wrong promptly admitted it...

Step Eleven [italics added]

Sought through prayer and meditation to improve our conscious contact with God as we understood Him, praying only for knowledge of His will for us and the power to carry that out...

Step Twelve [italics added]

Having made an effort to practice these principles in all our affairs, we tried to carry this message to other compulsive gamblers. (Gamblers

Anonymous, 1988b)

Pressure relief groups are a helpful option for GA members. These are small group meetings targeting a specific GA member and spouse where everyone attending will provide: assistance in creating a budget, advice on dealing with creditors--sometimes even interceding on behalf of a member, suggestions for dealing with legal difficulties, help with employment, and relief from personal pressures (Gamblers Anonymous, 1988a).

Many professionals believe that involvement of family members is crucial to success with pathological gamblers (Custer \& Milt, 1985; Galski, 1987; McGurrin, 1992; Rugle, 1993; Steinberg, 1993; Taber, 1985). Often this involvement takes the form of becoming active in Gam-Anon. "Gam-Anon is a fellowship of men and women who are husbands, wives, relatives or close friends... affected by the gambling problem...seeking a solution" (Gam-Anon, 1988, p. 2). GamAnon uses a 12 step approach similar to the GA steps. One of the major functions of Gam-Anon is to provide support for family and friends of pathological gamblers. Members are 
supported in a "tough love" strategy. This includes refusing to "bail out" the pathological gambler, making the gambler deal with finances and creditors, and possibly even leaving the gambler (Gam-Anon, 1988).

Rugle (1993) believes 12 step approaches combine a variety of treatment approaches. Twelve steps are psychodynamic in that they help with "breaking down old, faulty structures and rebuilding new ones" (Rugle, 1993, p. 13). Relationships with a sponsor, and other GA members help pathological gamblers develop new healthy defenses like trust and honesty (Rugle, 1993). GA is cognitive-behavioral because the 12 steps and therapies help pathological gamblers recognize distortions and irrational beliefs (Rugle, 1993).

$G A$ is not helpful for everyone, "GA has a considerable drop out rate" (Brown, 1986, p. 131). Brown (1986) interviewed former members of $G A$ who had dropped out, and continuers in GA. There were two main differences between the two groups. Continuers had three times higher debts and older children than drop outs. Perhaps more interesting is the similarity between those who continued and those who dropped out. Both groups were equally committed to the requirements of $G A$, both had most of the positive expectations raised during their first meetings met, heavy pressure to make GA work was placed upon both groups. 
Additionally, the majority of both groups remained abstinent or were gambling minimally (Brown, 1986).

In subsequent analysis of the study comparing $G A$ continuers with drop outs Brown (1987d) found differences and similarities. Both groups found learning from other member's mistakes most valuable; and found they could trust other GA members. The two groups diverged in numerous areas including: the dropouts were more likely to believe that GA was too harsh and unsympathetic with members who relapse; drop outs felt that they benefited from other's relapses more than continuers did; fewer dropouts felt superior to other members who relapsed; dropouts were less likely to accept complete abstinence from gambling as a goal and more likely to describe themselves as controlled gamblers; and dropouts were less likely to have connected socially with other members.

Brown (1987c) deduced two conclusions from the study of GA drop outs and continuers. GA's approach is difficult to accept, and therefore only those pathological gamblers whose gambling problems are extreme continue. Secondly, GA appears to assist members avoid relapses, but is less beneficial in working through a relapse. Therefore GA tends to work better for pathological gamblers who have few or no relapses. 
Individual Treatment

The earliest therapists treating pathological gambling used individual counseling exclusively. Freud used a psychoanalytic approach and worked with individual pathological gamblers (Galski, 1987; Rosenthal \& Rugle, 1994). Although individual therapy has been used frequently to treat pathological gambling, according to Galski (1987) there is "little in terms of either treatment technology or outcome results" (p. 139) in the pathological gambling literature.

Another early therapist who worked individually with pathological gamblers, Bergler, used a psychoanalytic approach based upon the belief that pathological gambling was based in masochism. He worked with pathological gamblers to achieve both abstinence and insight into their deeper issues. Bergler reported that he had a treatment success rate of 75 percent (Galski, 1987; Harris, 1988).

Miller (1986) advocates individual therapy with pathological gamblers centered around the grief process. Pathological gamblers have often suffered losses in the past, but more importantly are being required to forfeit their most cherished coping strategy.

According to Miller (1986), abstaining from gambling for the pathological gambler is a major psychological loss. "A recovering pathological gambler must not only struggle to 
accept the loss but all the while must resist the temptation to restore what has been lost" (Miller, 1986, p. 100).

Miller (1986) describes seven stages of grief in terms of the loss of gambling:

1. Denial: The first reaction to any loss tends to be denial. During this stage, denial takes the form of ignoring and diminishing the connection between the trouble they're in, and their out of control gambling. Indeed, pathological gamblers often can't accept that they have lost control over gambling. Pathological gamblers are not ready to accept that they must eliminate gambling from their lives. Denial is a defense against the psychic pain of the loss of gambling as a coping skill (Miller, 1986).

2. Bargaining: Much as dying patients want to make a bargain so they won't have to die, the pathological gambler wants to make a bargain so it won't really be necessary to give up gambling. They may find themselves trying to limit when they gamble, how they gamble, where they gamble-anything, just so long as they don't have to let go. When they are working on this stage, they have moved past denial and are starting to accept that their gambling must be treated (Miller, 1986).

3. Hope: When pathological gamblers start to see some of the advantages of living without gambling, then hope can begin. Hope for a better, less chaotic, anxious life provides motivation. They may feel "hey, this isn't so bad, 
stopping gambling will be easy." However, this is a brief respite in the grief process, because they will need to move on through four more stages (Miller, 1986).

4. Sadness: During this period, pathological gamblers will feel sadness and sorrow as they realize the consequences of gambling. They will be grieving the financial, social, relationship, and other losses that are results of uncontrolled gambling. They must also feel the sadness associated with the realization that the loss of gambling is permanent. Although this is a difficult time, the sorrow is a good sign, it means that they are progressing through the grief process, and commitment to abstinence will be strengthened (Miller, 1986).

5. Guilt: Feelings of guilt and shame are unavoidable during the grief process. Pathological gamblers must recognize the reality of their behaviors which resulted from addiction to gambling. They will also have to handle the loss reaction, the guilt as a result of acts which resulted in abstinence from gambling (Miller, 1986).

6. Anger: Anger is a universal reaction to loss. Pathological gamblers will feel angry as they give up/lose gambling. This anger may be misdirected at other people, things, or turned inward. Anger is an important emotion to work on during the grief process, but they will want to guard against acting-out angry feelings. The consequences of allowing the anger to overwhelm, and become physically or 
verbally destructive can send them right back to gambling (Milier, 1986).

7. Acceptance: When pathological gamblers can truly accept that they have no control over gambling, and that they cannot return to gambling as a coping strategy, they will have completed the grieving process. Although they must still work on recovery, they will have a sense of peace, and they will be able to replace gambling with other activities (Miller, 1986).

Miller (1986) has suggested four phases of individual therapy for pathological gambling. McGurrin (1992) has modified these stages, removing the grief process, to create a general psychodynamic approach. The first phase is a commitment to abstinence. The therapist can work with the pathological gambler until ready to embrace abstinence as a goal. During phase two, the pathological gambler examines the problems which have resulted from gambling. Fostering honesty within the gambler is an essential element of this stage.

The third stage forces the pathological gambler to search deep within. According to McGurrin (1993), the purpose is:

developing greater internal control over behavior and accepting greater intimacy in relationships, with more direct and expressive recognition of feelings of anger, sadness, and guilt related to gambling. (p. 52) 
The final phase focuses less on pathological gambling, and more on the psychological dynamics of the individual, while still fostering abstinence from gambling (McGurrin, 1992).

Several professionals advocate early use of individual counseling sessions with pathological gamblers followed by moving into a group therapy setting (Blackman et al., 1986; Heineman, 1989; Horodecki, 1992; Steinberg, 1993). Blackman et al. (1986), advocate using individual therapy for acclimating the pathological gambler. Priorities are established and information is gathered before transferring to group therapy.

Heineman (1989) discussed working with pathological gamblers and their parents. Both the parents and the pathological gambling clients begin treatment with separate, individual sessions. According to Heineman (1989), the parents have such anger that "they need to vent these painful emotions in a safe, supportive environment to a nonjudgmental individual who will offer understanding" ( $p$. 329). Later, both the pathological gambler and the parents participate in separate and combined group treatment. Horodecki (1992) uses initial individual consultation sessions. During this individual time, pathological gamblers become familiar with the following: handing the consequences of their gambling, relapse prevention, separating individual problems from gambling related problems, and family of origin and other background 
problems. Although pathological gamblers start treatment in individual sessions, they often begin group treatment before discontinuing individual sessions.

In conclusion, individual therapy has a relatively long and respected history as a helpful treatment for pathological gambling. However, much additional study is required to determine efficacy of such treatment.

\section{Group Counseling}

Group counseling has been used extensively in working with addictions. It is also probably the most common approach used for treating pathological gambling. Indeed, the GA format is similar to group counseling (Custer \& Milt, 1985; Galski, 1987; Haustein \& Schurgers, 1992; Murray, 1993). Taber and Chaplin (1988) strongly advocate treating pathological gambling in a group setting. Pathological gamblers "nearly all came from malparenting or nonparenting families, so they benefited enormously from exposure to a therapeutic primary family group...our group psychotherapy" (p. 184). Additionally, pathological gamblers form cohesive groups quickly which fosters self-disclosure (Murray, 1993; Taber \& Chaplin, 1988).

Lesieur and Blume (1991) have used group treatment extensively. In one study, Lesieur and Blume (1991) 
interviewed $72^{5}$ pathological gambling patients between six and 14 months after they had initially entered treatment. Apparently the group treatment was effective as 94.4 percent of the patients had an overall improvement in amount and frequency of gambling, and 63.9 percent were abstinent.

The dynamics of group therapy are especially effective in confronting denial (Galski, 1987; Taber \& Chaplin, 1988). Murray (1993) describes the sense of safety which pathological gamblers feel in a group where the other clients are also working on pathological gambling issues.

Haustein and schurgers (1992) suggest that group therapy should be focused on three areas. First, pathological gamblers should be continuously working to make it as difficult as possible for them to gamble. Second, the group should maintain focus on events and emotions prior to relapse. Finally, attention should continue to be directed to the specific feelings which the gamblers experience before, during and after gambling (Haustein and schurgers, 1992).

Both Blackman et al. (1986) and Heineman (1989) advocate moving from individual sessions to group sessions with pathological gamblers. Blackman et al. (1986) use the group setting to "enhance interpersonal and communication skills" (p. 404). This approach appears highly successful,

5 It should be noted that there were originally 119 patients, but 39.5 percent could not be interviewed for the study. 
since abstinence was reported by 72 percent of the clients at termination.

Heineman (1989) has used a group approach for both pathological gamblers and their parents. Both the parents and the clients found the group to be a safe and supportive environment for working on pathological gambling issues.

In conclusion, group therapy appears to be a common and effective mode for treatment of pathological gambling. It should be noted that most of the therapists using group therapy have also used individual sessions with pathological gamblers. It is unclear whether group therapy alone would be equally effective.

\section{Psychodynamic Approach}

As discussed previously, the earliest approaches to treatment of pathological gambling were psychodynamic in orientation (Custer \& Milt, 1985; Hudak,Jr. et al., 1989; Sharpe \& Tarrier, 1992; Volberg \& Steadman, 1992). Although psychodynamic approaches vary, "treatment is geared to uncover the underlying dynamics that precipitate disorders of impulse control and contribute to the chaotic life-style of the gambler" (Blackman et al., 1989, p. 30).

Uncovering underlying problems is a common theme for psychodynamic therapy for pathological gambling. Rugle (1993) advocates helping clients uncover and examine their defenses, and understand how they have been using childhood 
defenses as adults. Focusing on developmental deficits the pathological gambler rebuilds structures and defenses. Rugle (1993) stresses the need for support from outside sources and the therapist during the period of rebuilding. Rosenthal and Rugle (1994) suggest that while using a psychodynamic approach is important to successful treatment of pathological gamblers, it could--and often should--be supplemented by other treatment approaches. In particular, they recommend cognitive-behavioral therapy, GA, and medication as needed.

Using a psychodynamic based strategy, Rosenthal and Rugle (1994) discuss three important issues during early treatment of pathological gambling: omnipotent defenses, chasing behavior and denial. First, omnipotence is "an illusion (some would say delusion) of power and control which defends against helplessness and other intolerable feelings" (Rosenthal \& Rugle, 1994, p. 31). Omnipotence is a universal defense among pathological gamblers and must be gently confronted.

Rosenthal and Rugle (1994) delineate three kinds of omnipotence: of thought, of action and of provocation. Omnipotence of thought is the belief of the pathological gambler that personal thoughts are all-powerful, thinking something makes it happen. Omnipotent action is the belief that any action, even self-destructive action is better than 
inaction. Omnipotent provocation is the belief that the pathological gambler can take great risks and survive.

Chasing, a desperate attempt to recoup losses, is often an early motive for relapse. The therapist must help the pathological gambler recognize and relinquish the sense of entitlement implied by the belief that the client has a right to recapture the lost money. The pathological gambler needs to honestly share the extent of losses. Sharing with friends and family may eliminate the need to chase, since it may be related to the client's fear of exposure as a "loser." The pathological gambler must also become aware of the shame related to out of control gambling. The gambler must be supported to examine and deal with the emotional consequences (Rosenthal \& Rugle, 1994).

Finally, the pathological gambler will have to face the gambling problem and the resulting losses. This denial must be confronted to help the pathological gambler achieve abstinence. According to Rosenthal and Rugle (1994), it is not easy to convince the pathological gambler that gambling is a coping strategy no longer available. Coping with such a major loss necessitates obtaining something new. Rosenthal and Rugle (1994) suggest "the experience of being understood, the possibility of forgiveness, and hope derived from the therapist's belief that pathological gambling is a treatable disorder" (p. 36) may fulfill this requirement. 
McGurrin (1992) describes 10 guidelines for therapists using psychodynamic therapy with pathological gamblers:

1. Therapists should be directive and assertive with pathological gambling clients while maintaining empathy.

2. Therapists should strive for a balance between expectations for client improvement and remembering that progress will not always be forward.

3. Therapists should not encourage "war stories." Discussion of the act of gambling and gambling practices may be counter productive.

4. Therapists should expect missed and cancelled appointments and develop clear consequences.

5. Therapists should require payment, at least in part, for each session.

6. Therapists should be vigilant in watching for the possibility of clients replacing addiction to gambling with another addiction.

7. Therapists should expect anxiety, depression and devaluation of therapy when gambling is triggered by significant events.

8. Therapists should stay focused and keep the early sessions, up to the fifth, very structured.

9. Therapists should not work to convince clients that they can never beat the odds gambling. Pathological gamblers really already know this. 
10. Therapists should promote continuing involvement in therapy of family members of the client (McGurrin, 1992).

Taber and Chaplin (1988) discuss a number of common problems which are encountered in psychodynamic treatment of pathological gamblers. The first problem is lack of motivation to work in treatment. Very few pathological gamblers enter treatment because they are truly tired of gambling, and ready to stop. More clients are motivated to enter treatment by family pressures, financial crisis, or desire for help with legal difficulties. Most of these pathological gamblers without "pure" motives can work in treatment, it just takes longer.

Narcissism is another common problem working with pathological gamblers. A person with narcissistic traits or personality disorder is easily injured, so confrontation should be used very carefully until a therapeutic alliance is achieved. With the narcissistic pathological gambler one of the most important tasks is moving him/her beyond a sense of entitlement. Narcissistic pathological gamblers are prone to leave treatment early. They do "not expect to be made uncomfortable in therapy and getting in touch with feelings" (Taber \& Chaplin, 1988, p. 188) makes them feel manipulated.

The third common difficulty is with the client who wants to be the co-therapist. This may mean that the pathological gambler is avoiding working on personal issues. 
This may also be the result of transference issues, and the client may be modelling the behavior of an admired therapist. It is important that the client not become "stuck" in this mode. The pathological gambler will have to examine his/her own issues to progress (Taber \& Chaplin, 1988).

Fourth, pathological gambling clients can become so absorbed in a need to find the definitive answer for the reason they gamble, that they lose sight of treatment. According to Taber and Chaplin (1988) "the search for insight is really a desperate effort to feel good about oneself and to see oneself in a positive light as a victim rather than as a culprit" (p. 187). The therapist's task is to help the client learn to love the self and separate who s/he is from behavior.

Challenging the belief that gambling is enjoyable for the pathological gambler is the fifth common problem. Taber and Chaplin (1988) have found "that the urge to gamble is stronger at times than the desire for food, sex, or social esteem" (p. 188). The therapist must help the pathological gambler see how sordid and desperate gambling actually is. The loss of gambling should not be minimized, and the client should be encouraged to mourn the loss (Taber \& Chaplin, $1988)$.

Magical thinking is a common problem for pathological gamblers. Part of this irrational belief system is 
evidenced in their chasing behavior. They must learn to accept that they are not "owed" for their past losses. All of the pathological gambler's irrational beliefs must be explored and challenged in therapy (Taber \& Chaplin, 1988).

The seventh common problem is manipulative behavior. The pathological gambler will not stop manipulative behavior merely due to entering treatment. Taber and Chaplin (1988) suggest that pathological gamblers must be trained in behaviors which are assertive rather than manipulative. "They are encouraged to report their feelings about an issue, to state very simply what they need or want from the other person, and finally to mention the realistic consequences" (Taber \& Chaplin, 1988. p. 189). Pathological gambling clients need to learn that they are not required to be manipulative to have their needs meet, rather they can be straightforward and honest and still achieve those goals (Taber \& Chaplin, 1988).

The eighth common problem is angry rebelition. Pathological gamblers must become aware of their anger, and examine the sources of it during therapy. They must learn to take responsibility for their anger and its consequences. Finally, after learning to understand the anger, the pathological gambler must learn to let go of the anger (Taber \& Chaplin, 1988).

Cross addictions are another serious problem when working with pathological gamblers. It may seem 
overwhelming to the client to stop all addictive behavior, but it is important to help the pathological gambler focus on the long-term consequences of these addictions. Taber and Chaplin (1988) suggest that clients be empowered to work on these issues over time.

Rejection of GA is the tenth common problem. Although the pathological gambler may report a dislike or inability to identify with $G A$, the gambler should be urged to attend. The therapist should listen to the complaints, but be firm in requiring GA attendance. The pathological gambler need not totally embrace GA, merely attending is sufficient (Taber \& Chaplin, 1988).

Dwelling on guilt can be a problem in treating pathological gambling. Although guilt can motivate clients to positive changes, it is important that the pathological gambler not dwell on guilt to the exclusion of other issues and emotions. "It may be easier for them to concentrate on the negative aspects of the illness rather than plan a program of personal growth" (Taber \& Chaplin, 1988. p. 191). According to Taber and Chaplin (1988) low ego strength is the twelfth common problem. The pathological gambler often has no sense of self as a unique individual, which indicates a deficiency in ego strength. Inner moral structure and confidence may be totally lacking. One method of helping clients cope with these lacks is to encourage them to develop strong social structures. External sources, 
such as community groups, $G A$, and interpersonal relationships can be very helpful.

Although this is an extensive list of common treatment problems, Taber and Chaplin (1988) indicate that all of them can be addressed in therapy. Indeed, these problems provide opportunities for the pathological gambler to progress and change.

Rugle and Rosenthal (1994) warn about a number of common transference and countertransference issues when treating pathological gambling. Transferences are behaviors that the client uses to act out problems in therapy. These issues have underlying roots in the client's psyche. The following transference issues should be anticipated and addressed in treatment:

1. Seeking attention and therapist's approval: This transference is really the pathological gambler's need to maintain control and a sense of omnipotence. These narcissistic demands and needs must be gently addressed and countered by the therapist. The pathological gambler needs to learn that approval is not necessary nor important to treatment (Rugle \& Rosenthal, 1994).

2. Protecting the therapist: This transference is probably due to the pathological gambler's grandiose sense that $s /$ he is responsible for everything negative which occurs. The client has probably decided that $s /$ he is beyond redemption and is truly evil. It is important to help the 
pathological gambler understand that emotions can be expressed and that the therapist and others will survive (Rugle \& Rosenthal, 1994).

3. Idealizing the therapist: This transference may also have grandiose underpinnings. In being grandiose, the pathological gambler can only be treated by the perfect therapist. This also fosters the gambler's need to be cared for, and protected. The all or nothing thinking must be discussed with the client, and replaced with realistic expectations (Rugle \& Rosenthal, 1994).

4. Idealization, devaluation and ambivalence: The result of idealizing the therapist as all-knowing and allpowerful may well be a need for the pathological gambler to devalue or become ambivalent about therapy. This is still the grandiose all or nothing thinking at work. Often the client moves from idealization to devaluation to ambivalence and back again rapidly. The movement to devaluation often comes when therapy is becoming the most helpful, this leads to anxiety within the pathological due to fear that the therapist is getting too close. The client cannot handle being challenged or confronted, so must devalue the therapist who is now all bad. It is important to discuss the client's feelings which lead to both idealization and devaluation (Rugle \& Rosenthal, 1994).

5. Competition as negative transference: The pathological gambler may see all aspects of life as 
requiring a power struggle, including a need to feel superior to retain a fragile sense of self-esteem. This transference may take the form of resistance, the client may relapse, or leave treatment. The therapist should share with the client from the beginning that the pathological gambler can outsmart or defeat the therapist. The therapist should urge the client to follow the more difficult path of learning how to accept the therapist's help (Rugle \& Rosenthal, 1994).

6. Pseudo-independence as negative transference: Pathological gamblers may present for treatment as aloof and not needing help. The client probably has learned early that others cannot be trusted and this bravado is merely a facade. The pathological gambler may need to maintain this facade or lose all sense of self esteem. When injured, the client may withdraw from participating in treatment. often, pointing out the withdrawal may be an effective method for reengaging the client in treatment (Rugle \& Rosenthal, $1994)$.

7. Abstinence: The pathological gambler may resist abstinence, feeling that gambling is an action that $s /$ he chooses to do. Often the client feels that $s /$ he is in treatment for everyone else. This inaccuracy must be pointed out and the pathological gambler must be encouraged to commit to treatment for the client's own sake(Rugle \& Rosenthal, 1994). 
Rugle and Rosenthal (1994) also discuss countertransference issues. Countertransferences are the therapist's behaviors toward the client which are caused by the therapist's own emotions. Pathological gambling clients often notice and confront the therapist about countertransference issues before the therapist has fully recognized them. In these situations, the therapist should be straightforward about the feelings and behavior without dwelling on his/her own issues. The therapist should vigilantly examine his/her behaviors and feelings for the following countertransferences:

1. Hypomania: It is possible for the therapist to become too enamored of the pathological gambler's grandiose and energetic demeanor. The therapist must look beyond this facade in treatment (Rugle \& Rosenthal, 1994).

2. Codependency: When the therapist finds him/herself altering the therapeutic contract and bending the rules there is probably countertransference. The danger here is that the therapist will "rescue" the pathological gambler from experiencing the consequences of his/her behavior, robbing the client of an important learning opportunity. There is also the potential for the client to feel trapped and suffocated by this lack of boundaries and leave treatment in crisis (Rugle \& Rosenthal, 1994).

3. Competitiveness: It is easy for the therapist to become enmeshed in a power struggle with the pathological 
gambling client. The therapist should maintain firm and consistent boundaries and be aware of own feelings of inadequacy (Rugle \& Rosenthal, 1994).

4. Fear of being "conned": No one enjoys being lied to, but the therapist must not allow the ability to recognize a lie to be a measure of effectiveness of therapy. The therapist should share with the pathological gambler that the client may be able to successfully lie to the therapist, but it will not further treatment goals. Rugle and Rosenthal (1994) note that often the pathological gambler does not tell the therapist about gambling, etc. because the therapist never asks. The therapist should always ask directly about the client's actions (Rugle \& Rosenthal, 1994).

5. Reactions to superior and aggressive positions: Pathological gamblers frequently are condescending to therapists. Therapists should not take such behavior personally and guard against resentment and anger (Rugle \& Rosenthal, 1994).

6. Need for recognition: The pathological gambler may appear independent and aloof. The therapist must remember that the purpose of treatment is not to meet the therapist's needs. When the therapist reacts by becoming detached from the therapy, there is probably countertransference at work (Rugle \& Rosenthal, 1994). 
7. Reactions to entitlement and dependency: The pathological gambler may demand a great deal of time and attention. When the therapist responds with anger, annoyance or boredom, the therapist's fears and other emotions are at play. Clear rules and boundaries are necessary when dealing with entitlement and dependency. The therapist can also use this countertransference therapeutically by exploring whether others experience the same reactions to the pathological gambler (Rugle \& Rosenthal, 1994).

8. Abstinence: If the therapist is looking to the pathological gambler to remain abstinent to foster the therapist's feeling of worth, it is countertransference (Rugle \& Rosenthal, 1994).

9. Countertransference and GA: The pathological gambler's all or nothing thinking may lead to devaluation of therapy and praise of GA. The therapist must consistently encourage the client to see GA and therapy as working together for the client's benefit (Rugle \& Rosenthal, 1994).

In conclusion, psychodynamic treatment of pathological gambling is a popular approach. This approach works not only at achieving abstinence, but helping the pathological gambler make deeper personality changes. There are two studies comparing pathological gamblers before psychodynamic therapy and after. Blackman et al. (1989) found that the 88 percent clients' self reported rating of severity of 
gambling was significantly improved after therapy. similarly, Taber et al. (1987) interviewed 57 patients after leaving treatment and found 56 percent had remained abstinent.

\section{Behavioral Approach}

The use of behavioral approaches to treatment are supported by the theory that pathological gambling is the result of operant conditioning (England \& Gotestam, 1991; Harris, 1988). A variety of behavioral techniques have been used for treatment of pathological gambling. These treatments include aversion therapy, imaginal desensitization therapy, desensitization therapy, positive reinforcement of gambling abstinence, and outside controls for behavior (Brown, 1987a; Harris, 1988; McConaghy et al., 1991).

Aversion therapy has used mild electric shocks when the pathological gambler played a slot machine, read about gambling, or watched slides of gambling. According to Galski (1987), aversion therapy has been unsuccessful at helping pathological gamblers remain abstinent.

Desensitization therapy has used a heart rate recorder to register arousal levels. The pathological gambler works to extinguish gambling cues by monitoring arousal (Brown, 1987a). McConaghy et al. (1991) report successful treatment of pathological gambling using imaginal desensitization 
therapy. The pathological gambling client recalled and shared four scenes from past gambling experiences. The therapist guides the client through a visualization of each scene, but instead of gambling, the therapist guides the client through visualizing losing interest and leaving without gambling. Mcconaghy et al. (1991) interviewed 33 clients after completing and leaving treatment. Seventynine percent had stopped gambling or reported controlled gambling.

England and Gotestam (1991) outlined a treatment program which places behavioral constraints upon pathological gamblers. First, the client is removed from gambling situations and other stimuli which are reminders of gambling. Second, the pathological gambler obtains alternate financial control, plans for repaying debts and is prohibited from gambling to obtain money. Third, the therapist works with the pathological gambler to develop more realistic financial goals.

Fourth, the client learns new activities to replace gambling which will be rewarding and fulfilling. Fifth, England and Gotestam (1991) treat anxiety, depression and collateral problems. Sixth, the pathological gambler is allowed to return to low level gambling. Finally, clients are urged to make use of outside legal, financial, and other sources, including GA. 
In conclusion, the use of behavioral techniques has some support in the treatment of pathological gambling. However, few professionals advocate the use of behavioral therapies exclusively. According to Galski (1987), various behavior therapy methods are "valuable additions to treatment programs for compulsive gamblers, but... when applied alone these specific methods neglect major areas of needed personality and lifestyle change" (p. 140).

\section{Cognitive-Behavioral Approach}

Cognitive-behavioral strategies are often advocated in the literature, either alone or in conjunction with psychodynamic or behavioral therapies (Lesieur \& Rosenthal, 1991; Rosenthal \& Rugle, 1994). However discussion of specific strategies and outcomes for cognitive-behavioral therapy are minimal.

Most cognitive-behavioral approaches work on changing the client's irrational thoughts and beliefs as a method for changing their emotions and behaviors. Pathological gamblers tend to hold irrational beliefs surrounding gambling and other behaviors. Helping the gambler change these beliefs or cognitions is the purpose of cognitivebehavioral treatment of pathological gambling (Sharpe \& Tarrier, 1992). Sharpe and Tarrier (1992) have clients share their distorted thoughts which lead them to gamble. The clients then develop accurate statements to counter the 
distortions, and place the accurate statements on cards and review the cards when they want to gamble.

Brown (1987a) suggests changing irrational beliefs by forcing the pathological gambler to face reality. First the pathological gambler lists all debts and establishes a repayment plan. This helps the client face the reality and prevents pressure from debt to act as a trigger ${ }^{6}$ for gambling. Second, the potential trigger of money is removed by having someone other than the pathological gambler handle money

McCormick (1994) has worked with pathological gamblers to enhance coping skills. Pathological gamblers learn to examine decisions, in particular, decisions made at the point where they must choose a mal-adaptive or adaptive" (McCormick, 1994, p. 79) response.

McCormick (1994) emphasizes pathological gamblers' need for improved coping skills in problem solving and seeking emotional support. Learning problem solving skills is an important part of treatment. The client "is taught to break the presenting problem into its parts, to brainstorm possible solutions, to choose what seems to be the best solution and then to try it" (McCormick, 1994, p. 81). After choosing the solution, the pathological gambler

\footnotetext{
6 Triggers, as used here, are urges or compulsions to gamble.
} 
considers the results, and whether another solution would prove more beneficial.

Mccormick (1994) teaches the pathological gambler methods for seeking emotional support. The client is first taught basic social skills. Practice assignments for these skills are used. Pathological gamblers are then directed to use these new skills at GA meetings.

Harris (1988) works on relapse prevention. First, treatment focuses on motivating the client to change. There is no requirement for complete abstinence at this stage, to foster therapeutic alliance and reduce the client's feeling threatened. The second step is to help the pathological gambler obtain stability. "The gambler's impulsivity, lack of future planning, and magical thinking" (Harris, 1988, p. 222 ) are explored and improved coping strategies are learned and practiced.

During the final stage, Harris (1988) works on abstinence. Triggers and high risk relapse situations are examined and addressed. Alternative behaviors and new coping strategies are developed for each step in the decision making process.

In conclusion, cognitive-behavioral approaches appear to have a place in the treatment of pathological gambling. It seems clear that pathological gamblers need to change their irrational beliefs surrounding gambling and 
themselves. However, outcome studies and discussion of specific treatment approaches are needed. 
CHAPTER IV

\title{
CONCLUSION: PROPOSED TREATMENT PROGRAM
}

\begin{abstract}
"There is little mystery about why gamblers gamble. They love it. They love it more than spouse, child, mother or material gain. If we could teach them to hate gambling the problem would be solved." Julian I. Taber
\end{abstract}

In conclusion to this research into pathological gambling and treatment, this author has developed an entire treatment program for use with pathological gamblers. The literature on treatment for pathological gambling is in its infancy, discusses treatment strategies, rather than treatment outcomes, and few scientifically designed outcome studies have been developed. However, as indicated in the review of the literature, there are some areas of agreement based upon the clinical judgment of professionals who treat pathological gambling. This author has made use of consensus wherever possible, and borrowed parts from other pathological gambling treatment programs. These elements were then refined through my own clinical judgment to design an inclusive outpatient treatment program. This program is fully described, and support or rationale in the literature for program elements is indicated.

This is a four stage approach, using both individual and group therapy. Both group (Blackman et al., 1986; 
Haustein and Schurgers, 1992; Heineman, 1989; Murray, 1993; Taber \& Chaplin, 1988) and individual therapy (Galski, 1987; Harris, 1988; Horodecki, 1992; Miller, 1986; steinberg, 1993) have been advocated in the literature and found to generate successful treatment outcomes. Each client would be scheduled for group therapy for one and one half hour each week. These groups are grouped by gender, and cognitive functioning. At least one individual therapy session, lasting one hour should be scheduled each week. In addition, sessions with family members and close friends are scheduled on an as-needed basis.

This program is intended to be implemented using psychodynamic, behavioral and cognitive behavioral strategies. Psychodynamic approaches have been found effective by Blackman et al. (1989), and Taber et al. (1987); behavioral approaches determined effective by Mcconaghy et al. (1991), and use of cognitive-behavioral techniques supported by Brown (1987a), Harris (1988), McCormick (1994), Sharpe and Tarrier (1992).

Treatment progresses through four stages. Although there are four, similar to McGurrin's (1993) suggested approach, these stages vary. stability and commitment to abstinence exemplify the first stage. The second stage includes assessing and rebuilding social structure, selfesteem building, grief work, and commitment to treatment. Examining past behavior and its consequences, self- 
awareness, and rebuilding are the essentials of stage three. During the final stage, new awareness, new behaviors, and completion of grief process occurs. This progress from stability to work on deeper issues has been suggested by England and Gotestam (1991), and McGurrin (1992).

Where the author believes a specific strategy should be employed it will be discussed. Generally, this treatment program is designed to rely heavily upon cognitivebehavioral approaches during the first two stages, utilizing psychodynamic approaches during the latter stages. Using cognitive-behavioral approaches early to help stabilize gambling is discussed in the literature (Brown, 1987a; Harris, 1988; McCormick, 1994; Sharpe \& Tarrier, 1992); as is using psychodynamic approaches to work on deeper, underlying dynamics of the client (Blackman et al., 1989; Rugle, 1993; Rugle \& Rosenthal, 1994; Taber \& Chaplin, $1988)$.

Both an intake and an education component have been developed for this treatment program. The author has developed and borrowed work sheets/handouts for all elements of this program. Most of these handouts have been included in the Appendix, and will be noted by footnotes.

Intake

Pathological gambling clients generally present for treatment in crisis (Brustuen \& Gabriel, 1991; Taber \& 
Chaplin, 1988). The major purpose of this initial contact is to help the client become more stable. As a result, the intake is designed for flexibility to help the client become comfortable and reduce anxiety. This comfort and encouragement helps start the therapeutic alliance, which Taber (1985) considers the first requirement for the intake. Developing a therapeutic alliance early encourages clients to become engaged in treatment.

An outline of the treatment program, treatment plan, and discussion of the nature of therapy, the third requirement according to Taber (1985), are provided. outside resources are also supplied and include a list of AA meetings in the general area, a list of GA meetings in the area, the number for consumer credit (an agency which helps with financial planning and debt reduction), the number for career counseling through the local community college, and low cost legal resources.

This flexible intake approach is actually fostered by using a structured interview. The structured interview has been used with pathological gamblers and is recommended by practitioners (Lesieur \& Blume, 1991; Taber, 1985). This structure enables the interviewer to stop the intake process, and restart the process as needed, and still obtain the essential data needed (second requirement of intake, Taber, 1986). This author has chosen the gambling modified 
Addiction severity Index ${ }^{7}$. The modified ASI is advocated by Lesieur and Blume (1991); and covers eight areas essential, according to Taber (1985), to accurate assessment. The eight areas are: drug and alcohol history; gambling history; medical conditions, past and present; employment and support, including education and training history ${ }^{8}$; family and social relationships (an important aspect of assessment according to steinberg (1993); and history of mental and emotional health.

The gambling section assesses current and past participation for money in the following gambling activities: card games, horse or dog races, sporting events, dice games, casino, lottery or numbers, bingo, speculating on stocks or commodities, slot or mechanical card machines, video poker, video keno, and games of skill. At the end of each of the sections, both a subjective severity rating (by the client) and an objective severity rating are obtained.

Part of the structured interview, but separate from the ASI, is the intake addendum ${ }^{9}$. The interviewer asks 10

\footnotetext{
7 See appendix, p. 106, for complete ASI.

8 Assessment in this area will be helpful to signal when a client should be referred for career counseling services more extensive then those provided through the Education series. Hudak, Jr., et al. (1989) has found that job satisfaction is positively correlated with treatment success.
} 124.

9 The intake addendum is included in the appendix, $p$. 
questions based upon the DSM-IV criteria for pathological gambling. Specific questions on affective disorders (see Harris, 1988), psychosis, anxiety disorders, obsessivecompulsive disorders, eating disorders, post-traumatic stress disorder, $A D D$, and somatoform disorder are also administered. Finally, the client is administered the Folstein Mini Mental Status Examination, to assess general cognitive functioning, a potential factor in predicting relapse (McCormick \& Taber, 1991).

Appropriate testing which does not overwhelm the pathological gambling client is essential (Lesieur \& Blume, 1991). Before meeting with the client at the initial intake, a Beck Depression Inventory ${ }^{10}$ is administered. The Beck asks questions about 21 symptoms of depression and is an effective diagnostic tool for determining symptoms of depressive affective disorder, a common co-morbid diagnosis among pathological gamblers (Adkins, 1988; Bonneville, 1994; Lesieur \& Blume, 1993; Lesieur \& Rosenthal, 1991; Murray, 1993; Rugle, 1993; Taber et al., 1987).

The South Oaks Gambling Scale ${ }^{11}$ has been used in research to determine severity of gambling addiction (Lesieur \& Rosenthal, 1991), and is part of the intake. The SOGS asks questions about feelings and behaviors related to gambling. There is a possible high score of 22 , and any

10 See appendix, p. 128, for copy.

11 See appendix, p. 139, for copy of the sogs. 
score of three or higher is suggestive of problems with gambling. Assessment of severity may be helpful, as it has been found that the more severe the gambling problem the less likely that treatment will be successful (Mccormick \& Taber, 1991).

The assessment of attention deficit disorder (ADD) is part of the intake process, as it has been found frequently with pathological gambling (Rosenthal \& Lorenz, 1992; Sharpe \& Tarrier, 1993). The wender Utah Rating scale (WURS) is a self report measuring childhood $A_{D D}^{12}$. There are 25 items which are rated from zero to four, four representing strong agreement. Scores of 36 and higher indicate a likelihood of childhood ADD. Those clients with elevated scores will be referred for further assessment for adult $A D D$, and will be provided with medication for this disorder as needed. (Rosenthal and Rugle (1994) advocate treating co-morbid disorders whenever possible.)

During intake the Tennessee Self-Concept Scale is also administered. It is important to assess self-esteem, as an important treatment issue, since low self-esteem, and poor self image is present in most pathological gambling clients (Brustuen \& Gabriel, 1991; Cusack et al., 1993; Custer \& Milt, 1985; Galski, 1987; McGurrin, 1992; Rosentha1, 1986; Selzer, 1992; Sharpe \& Tarrier, 1992). This test can be self-administered by the client in approximately 20 minutes 
and measures self concept. The TSCS asks the client to rate $\mathrm{him} /$ herself on 100 self-descriptive statements. The TSCS has been well-researched and provides self concept scores in the following areas: identity, self-satisfaction, behavior and actions, physical body/health/appearance/ability/ sexuality, moral-ethical self, personal worth and adequacy, family self, and social interaction. The TSCS also provides empirical data comparing the client to specific populations with various psychiatric diagnoses. The scales relate to: defensiveness, general maladjustment, psychosis, personality disorder, neurosis, and personality integration (Roid \& Fitts, 1991).

Finally, a quick measure of the client's intellect, the Shipley-Hartford is administered. This is supported by the correlation between relapse and lowered cognitive functioning (McCormick \& Taber, 1991). Assessment will help the therapist make extra efforts with relapse prevention work. This timed test takes 20 minutes and provides a score on verbal and problem solving capabilities.

The intake is conducted in one hour sessions, and may take several sessions to complete. However, after the initial meeting, the client is assigned to a gambling treatment group. Starting group therapy with other pathological gamblers will help relieve the client's sense of isolation and hopelessness (Sharpe \& Tarrier, 1992). 
During intake, clients are assessed for dual addictions, which are common amongst pathological gamblers (Blaszczynski \& McConaghy, 1989; Lesieur \& Blume, 1993; Lesieur \& Rosenthal, 1991; Murray, 1993; Rugle, 1993). If there are multiple addictions, the client is asked to work on all of the addictions together. The need for sobriety to do the work of treatment is stressed at this point. Antabuse is used when appropriate.

clients should be referred to a staff psychiatrist when there are potential additional psychological disorders (Lesieur \& Blume, 1991; Rosenthal \& Rugle, 1994). Medication, when indicated, will be an adjunct to treatment. In addition, the impact of co-morbid disorders can be monitored and worked on during treatment.

\section{Stage I}

The purpose of stage one $e^{13}$ is to help the pathological gambler achieve stability, as recommended by Harris (1988). Completion of this stage occurs when the client has met two criteria: gambling and/or substance abuse has stabilized, and the client has become committed to treatment.

The client is provided tools for working on stabilizing gambling and substance use. During this period, the client is asked to commit to working toward abstinence. Abstinence

13 A copy of the treatment plan based upon the four stages is provided in the appendix, p. 139. 
is not a requirement, rather it is a goal to be achieved. Using abstinence as a goal, not a requirement. incorporates Rosecrance's, (1986) suggestion that requiring abstinence might prevent gamblers from seeking treatment; while incorporating the recommendation of the majority of authorities (Adkins, 1988; Blackman, 1989; Custer \& Milt, 1985; Galski, 1987; Lesieur, 1990; Miller, 1986; Rosenthal, \& Rugle, 1994) that stability cannot be achieved without abstinence.

The client must also develop outside financial control, this is advocated by Brown (1987a); England and Gotestam (1991); Haustein and Schurgers (1992). Achieving financial control is difficult, the therapist must help the client develop a plan. Financial control options include: having spouse, family member, or trusted friend handle the client's money; direct deposit of salary and other payments; destruction of credit cards and ATM cards; change from checking account to savings account without checks or ATM card; dual signature requirement on checking account.

The client is provided with information for recognizing and managing urges and triggers for gambling and drugs and alcohol ${ }^{14}$. The client is directed to make a daily gambling and substance trigger journal, suggested by Harris (1988), Sharpe and Tarrier (1992). The client is taught what

14 Trigger information handout is included in appendix, p. 139-146. 
cognitive distortions and irrational beliefs are (see $^{15}$ Harris, 1988; Taber \& Chaplin, 1988). During this stage, the client is helped to examine cognitive distortions associated with gambling, substance abuse, and self-concept. Working with clients to alter cognitive distortions and irrational beliefs is advocated by Harris, (1988); McGurrin (1992); Rosenthal and Rugle (1994); Rugle (1993); Sharpe and Tarrier (1992); Taber and Chaplin (1988).

The second requirement, to participate in treatment, can be assessed through the client's behaviors. Obviously, attendance is an important aspect. The client is also expected to study and complete the handouts. These homework assignments are to be shared both in group and individual sessions. Although the homework tends to be cognitivebehavioral, dealing with resistance to completion of these assignments is a therapeutic issue, possibly indicating a form of transference, and should be handled using a psychodynamic approach (see Rosenthal \& Rugle, 1994). The client should be encouraged to participate in discussions and connect with other group members.

\section{stage II}

The client is working on five criteria during this stage: gambling abstinence, social structure, self-esteem

15 Handouts on cognitive distortions are included in the appendix, p. $147-152$. 
building, mourning losses, and commitment to treatment. To further the first treatment criterion, gambling abstinence, the client is directed to develop a plan for relapse prevention ${ }^{16}$. Relapse prevention is recommended by Harris (1988), Haustein and Schurgers (1992), Horodecki (1992), Rosenthal and Rugle (1994). The client has completed this requirement when abstinent from gambling for 45 days.

During this stage, social supports play a critical role in recovery. The following authors advocate helping client develop and improve social supports: England and Gotestam (1991), Harris (1988), McCormick (1994), McGurrin (1992), Rugle and Rosenthal (1994) and Taber and Chaplin (1988). The client is advised to assess existing social network and supports, and alter existing supports, or create new social supports to provide an environment favorable to maintaining abstinence from drugs, alcohol and gambling ${ }^{17}$ clients should be encouraged to make use of $G A$ as a source for a ready-made social network (Custer \& Milt, 1985; Taber \& Chaplin, 1988).

The client is urged to involve family in treatment at this point, as suggested by McGurrin (1992); Rosenthal and Rugle (1994); and steinberg (1993). Family and friends of the pathological gambler are also encouraged to attend the

16 The outline for the relapse prevention plan is included in the appendix, p. 153-163.

17 Handouts on social network assessment are in appendix, p. 164-175. 
education workshops. An important requirement is for the client to examine relationships with friends and relatives and learn to ask them to be supportive of abstinence ${ }^{18}$ (see Heineman, 1989; Horodecki, 1992).

Pathological gamblers often have lowered self-esteem and self image (Brustuen \& Gabriel, 1991; Cusack et al., 1993; Custer \& Milt, 1985; Galski, 1987; McGurrin, 1992; Rosenthal, 1986; Selzer, 1992; Sharpe \& Tarrier, 1992). During this stage, clients work at improving self-esteem. This cognitive-behavioral approach requires the client to complete assignments in the following area: evaluate positive personal characteristics, make a list of positive and negative attributes, examine cognitive distortions about self and develop appropriate counter thoughts, start acknowledging and congratulating self for changes and successes $^{19}$.

Loss is an aspect of recovery which should be addressed according to Miller (1986); Rosenthal and Rugle (1994); and Taber and Chaplin (1988). The client is encouraged to accept the loss of gambling, and start the grieving process $^{20}$. The client is also expected to start evaluating

18 Handouts on problems with friends and family are included in appendix, p. 176. p. 180 .

19 Handout on positive actions is included in appendix,

20 Handout on mourning the loss of gambling is included in appendix, p. 183 . 
the losses resulting from gambling, as recommended by Horodecki (1992), Miller (1986), Rosenthal and Rugle (1994), Taber and Chaplin (1988).

commitment to treatment is measured by the client's active participation in group and individual treatment. Participation is measured in part by: providing constructive feedback to other group members, continuing to work on treatment issues between treatment sessions, and completing and sharing homework assignments.

\section{Stage III}

Stage three requires the client to look forward and backward. This work is accomplished in the following six areas: gambling abstinence, social structure, consequences of addictions, self-awareness, relationships, and leadership and commitment to treatment. Work on abstinence from gambling and substances continues, but is not the major focus unless relapse occurs. The client should continue to practice his/her plan for relapse prevention (Harris, 1988; Haustein \& Schurgers, 1992; Horodecki, 1992; Rosenthal \& Rugle, 1994). The client has completed this criterion after achieving abstinence from gambling for 90 days.

Changing social networks and supports is not a simple task and should continue throughout the remainder of treatment. During the third stage, the client continues assessing and changing social networks, as suggested by 
England and Gotestam (1991), Harris (1988), McCormick (1994), McGurrin (1992), Rugle and Rosenthal (1994) and Taber and Chaplin (1988). Friends and family should be an integral part of recovery during this time, and the client needs to continue working with them to support abstinence. The gambler needs to examine how addictive behavior and its consequences have effected family, friends and social supports, as suggested by Horodecki (1992), McCormick (1994), Miller (1986), Rosenthal and Rugle (1994), Taber and Chaplin (1988).

The grieving process continues during this time. The client must examine the effects and consequences of addiction, and mourn the losses without being selfcondemning. This will help the client continue needed selfesteem work (Brustuen \& Gabriel, 1991; Cusack et al., 1993; Custer \& Milt, 1985; Galski, 1987; MCGurrin, 1992; Rosenthal, 1986; Selzer, 1992; Sharpe \& Tarrier, 1992) and needed grief work (Miller, 1986; Rosenthal \& Rugle, 1994; Taber \& Chaplin, 1988). The client will be directed to 1 ist the people whom s/he has hurt and start making amends ${ }^{21}$. During this time, the client should develop a plan for restitution as advised by Miller (1986) and McGurrin (1992). The therapist should use a psychodynamic approach to help the client develop self-awareness as suggested by Rugle

21 Handouts for listing people hurt by addiction are included in appendix, p. 185 . 
and Rosenthal (1994) and Taber and Chaplin (1988).

Irrational beliefs and cognitive distortions should be pointed out in treatment and as homework. clients should continue acknowledging and congratulating themselves for changes and successes (Sharpe \& Tarrier, 1992).

Because many clients will have used their addictions to avoid dealing with emotions, they will need to work on becoming aware of their emotions ${ }^{22}$, as advocated in the literature (Haustein \& Schurgers, 1992; McCormick, 1994 ; McGurrin, 1992; Miller, 1986). The client must be guided to explore dishonesty and inaccuracies in thoughts and actions; then make and implement a plan to address them as recommended by Mccormick (1994), McGurrin (1992), Rosenthal and Rugle (1994), Steinberg (1993). Decisions which lead to problems and gambling behavior are explored (Mccormick, 1994)..$^{23}$ The client must be helped to understand how irrational thoughts and dishonesty fit into the larger context of life and personality (Harris, 1988; McGurrin, 1992 ; Rosenthal \& Rugle, 1994; Rugle, 1993; Sharpe \& Tarrier, 1992); Taber \& Chaplin, 1988).

During this period, the client may begin to develop new relationships. The literature supports encouragement of this process (McGurrin, 1992; Taber \& Chaplin, 1988). Part p. 187 .

22 Handout on emotions journal is included in appendix,

23 Seemingly Irrelevant Decisions handout is on p. 158 in the appendix. 
of the encouragement includes helping the client examine past addictive behavior and assess how that behavior influenced, shaped and effected relationships. Once the client has examined these behaviors, the client can learn to anticipate behaviors harmful to relationships prior to engaging in them, and replace them with effective behaviors and coping strategies as advocated by Harris (1988), Mccormick (1994), Rosenthal and Rugle (1994).

The pathological gambler has been in treatment for considerable time at this point. To help enhance selfesteem and take ownership for recovery, the client should be encouraged to take a leadership role in group sessions by initiating and actively participating. The client should be sharing successes and difficulties with the group. The work on changing past ineffective behaviors should be shared. New behaviors should be used in group, and integrated into the client's daily life. Homework should continue.

\section{Stage IV}

This treatment program may last one year or longer, as a result, disengaging from treatment may be difficult. The final stage is intended to help the client prepare for leaving treatment while continuing growth. Abstinence from gambling continues to be an important aspect, and continuing relapse prevention work is essential (Harris, 1988; Haustein 
\& Schurgers, 1992; Horodecki, 1992; Rosenthal \& Rugle, 1994 ).

New relationships and support are especially important as the client prepares to leave the other group members and the therapist (McGurrin, 1992; Taber \& Chaplin, 1988). clients should be encouraged to practice effective new behaviors and coping skills which foster healthy relationships, as suggested by Harris (1988), McCormick (1994), Rosenthal and Rugle (1994). Their social network and relationships should be fine-tuned to support abstinence (England \& Gotestam, 1991; Harris, 1988; McCormick, 1994 ; McGurrin, 1992; Rugle \& Rosenthal, 1994; Taber \& Chaplin, 1988).

The pathological gambler will be affected by consequences of addiction for a long time. The client should be helped to continue the grief process, mourning losses without self-condemnation (Miller, 1986; Rosenthal \& Rugle, 1994; Taber \& Chaplin, 1988). The client should make an effort to complete making amends to the people whom $s /$ he has injured, and start following the restitution plan (Taber \& Chaplin, 1988).

The client should be able to recognize and address cognitive distortions (Harris, 1988; McGurrin, 1992; Rosenthal \& Rugle, 1994; Rugle, 1993; Sharpe \& Tarrier, 1992; Taber \& Chaplin, 1988). Taking credit for accomplishments should become comfortable during this stage. 
The client will need to maintain awareness of emotions, irrational thoughts and dishonesty, and continue using effective coping skills (Harris, 1988; McCormick, 1994; Rosenthal \& Rugle, 1994). The client should exhibit insight, reflection, and mature self expression. Being able to leave treatment in a mature manner is an important aspect of this stage (McCormick, 1994). The client should be guided to examine emotions and distortions surrounding completion of treatment, and anticipate and plan for managing the losses (Miller, 1986).

Finally, the client must develop and practice a discharge plan, based upon earlier relapse prevention work. This plan will be shared with the group ${ }^{24}$.

\section{Education}

The education component is a series of 12 workshops designed to familiarize pathological gamblers, friends, family and the public about pathological gambling treatment issues. Many of these workshops will include hands on activities and will last one hour. The 12 work shops will be rotated, and clients and others can attend them in any order. The subjects are as follows:

1. What is Pathological Gambling? Pathological gambling will be defined. Theories of pathological gambling

24 Handout for making discharge plan is included in appendix, p. 195 . 
will be briefly discussed. The course of the disease will also be presented.

2. What is Group Therapy? Group therapy will be defined. The purposes and benefits will be discussed. Guidelines for group participation will be shared ${ }^{25}$.

3. How Do I Plan for Relapse? Relapse prevention will be discussed. Coping strategies will be practiced, and relapse prevention plans will be made ${ }^{26}$.

4. What is Substance Abuse? Diagnostic criteria for substance abuse and dependence is described. The course and theories of causes of addiction are briefly discussed.

5. What is GA? A GA member discusses GA, including the 12 steps. Gam-Anon is also discussed.

6. What is $A A$ ? An $A A$ member describes $A A$, including the 12 steps. Al-Anon is discussed.

7. How Do I Deal With the Loss? The grief process is discussed. Discussion of the effects of "losing" an addiction is presented.

8. How do I Find a Job/New Career? Job search skills are discussed. A brief career interest inventory is administered.

9. How Do I Make a Budget? Budgeting strategies and debt relief are discussed.

25 Handout on guidelines is included in appendix, $p$. 198.

26 Handouts on relapse prevention are included in appendix, p. 152-162. 
10. What Are My Legal Options? An attorney discusses legal issues that often result from gambling. Options are shared.

11. What Is Depression? Depression and other common Axis I disorders are discussed.

12. How Do I support Abstinence? Ways to develop social networks that support abstinence are shared. Ways to Educate friends of substance abusers are discussed.

\section{Conclusion}

This pathological gambling program has been designed to make use of the most recent literature on treating gambling. It is true that the literature on treatment for pathological gambling is very new; examines treatment strategies, rather than treatment outcomes; and few scientifically designed outcome studies have been developed. However, there are some areas of agreement based upon the clinical judgment of professionals who treat pathological gambling, and this author designed a treatment program which makes use of consensus wherever possible, then filters these elements through my own clinical judgment to design a total outpatient treatment program. The therapist can follow this program design from the first contact through completion of therapy.

If this program is implemented as designed, it will be a blend of psychodynamic, cognitive-behavioral, and 
behavioral approaches. The competent therapist will need to be prepared to use a mixture of these three approaches to effectively treat pathological gambling.

The program is designed to allow the therapist and client to assess the pathological gambler's progress throughout treatment. Together, they can tailor the amount and method of therapy to suit the client's needs. As a result, pathological gamblers in this program will work on individual, family and social-interaction issues.

Further study in the area of treatment for pathological gambling is needed. It is the author's intention to implement this newly designed program to evaluate the efficacy of such a multi-dimensional approach. 


\section{REFERENCES}

Adkins, B. J. (1988). Discharge planning with pathological gamblers: An ongoing process. Journal of Gambling Behavior, $4(3), 208-218$.

American Psychiatric Association. (1994). Diagnostic and statistical manual of mental disorders (4th ed.). Washington, D.C.: Author.

Blackman, S., Simone, R. V., \& Thoms, D. R. (1986). Treatment of gamblers. Hospital and Community Psychiatry, 37(4), 404 .

Blackman, S., Simone, R. V., Thoms, D. R., \& Blackman, S. (1989). The gamblers treatment clinic of St. Vincent's North Richmond community mental health center: Characteristics of the clients and outcome of treatment. The International Journal of the Addictions, 24(1), 29-37.

Blaszczynski, A. P., \& McConaghy, N. (1989). The medical model of pathological gambling: Current shortcomings. Journal of Gambling Behavior, $\underline{5}(1), 42-52$.

Blaszczynski, A., McConaghy, N., \& Frankova, A. (1991a) . A comparison of relapsed and non-relapsed abstinent pathological gamblers following behavioral treatment. British Journal of Addictions, 86, 1485-1489.

Blaszczynski, A., Mcconaghy, N., \& Frankova, A. (1991b). Control versus abstinence in the treatment of pathological gambling: A two to nine year follow-up. British Journal of Addictions, 86, 299-306.

Blume, S. B. (1986). Treatment for the addictions: Alcoholism, drug dependence and compulsive gambling in a psychiatric setting. Journal of Substance Abuse Treatment, $3,131-133$.

Bonneville, G. (1994, Fall). Not so lucky. University of Minnesota: Health Sciences, Fall 1994, 17-21.

Brown, R. I. F. (1986). Dropouts and continuers in Gamblers Anonymous: Life-context and other factors. Journal of Gambling Behavior, 2 (2), 130-140. 
Brown, R. I. F. (1987a). Classical and operant paradigms in the management of gambling addictions. Behavioral Psychotherapy, 15, 111-122.

Brown, R. I. F. (1987b). Dropouts and continuers in Gamblers Anonymous: Part 2. Analysis of free-style accounts of experiences with GA. Journal of Gambling Behavior, $3(1), 68-79$.

Brown, R. I. F. (1987c). Dropouts and continuers in Gamblers Anonymous: Part 4. Evaluation and summary. Journal of Gambling Behavior, 3 (3), 202-210.

Brown, R. I. F. (1987d). Dropouts and continuers in Gamblers Anonymous: Part 3. Some possible specific reasons for dropout. Journal of Gambling Behavior, 3 (3), 202-210.

Brown, R. I. F. (1987e). Pathological gambling and associated patterns of crime: Comparisons with alcohol and other drug addictions. Journal of Gambling Behavior, $3(2), 98-114$.

Brustuen, S., \& Gabriel, G. (1991). Pathological gambling \& chemical dependency: Similarities and unique characteristics. Minnesota: Project Turnaround/Vanguard.

Ciarrocchi, J., \& Richardson, R. (1989). Profile of compulsive gamblers in treatment: Update and comparisons. Journal of Gambling Behavior, $\underline{5}(1), 53-$ 65.

Commission on the Review of the National Policy Toward Gambling. (1976). Gambling in America. Washington, DC: U.S. Government Printing office.

Cusack, J. R., Malaney, K. R., \& DePry, D. L. (1993). Insights about pathological gamblers: 'Chasing losses' in spite of the consequences. Postgraduate Medicine, 93(5), 169-179.

Custer, R., \& Milt, H. (1985). When luck runs out. New York: Facts on File Publication.

Dostoevski, F. (1964). The qambler (A. R. MacAndrew, Trans.). New York: W. W. Norton Company. (Original work published 1866)

England, L., \& Gotestam, S. (1991). The nature and treatment of excessive gambling. Acta Psychiatrica Scandinavica, 84(2), 113-120. 
Ferster, C. B., \& Skinner, B. F. (1957). Schedules of reinforcement. New York: Prentice-Hall.

Gaboury, A., \& Ladouceur, R. (1989) . Erroneous perceptions and gambling. Journal of Social Behavior and

Personality, $4(4), 411-420$.

Galski, T. (Ed.). (1987). The handbook of pathological gambling. Springfield, IL: Charles C. Thomas.

Gam-Anon. (1988). Gam-Anon family groups: The Gam-Anon way of life. Whitestone, NY: Gam-Anon International Service office.

Gamblers Anonymous. (1988a). Gamblers Anonymous group handbook. Los Angeles: Gamblers Anonymous International Service office.

Gamblers Anonymous. (1988b) . The Gamblers Anonymous step meeting handbook. Los Angeles: Gamblers Anonymous International Service office.

Harris, J. L. (1988). A Model for treating compulsive gamblers through cognitive-behavioral approaches. The Psychotherapy Patient, $4,211-226$.

Haustein, J., \& Schurgers, G. (1992). Therapy with male pathological gamblers: Between self help group and group therapy--report of a developmental process. Journal of Gambling studies, $8(2), 131-142$.

Heineman, M. (1989). Parents of male compulsive gamblers: Clinical issues/treatment approaches. Journal of Gambling Behavior, $\underline{5}(4), 321-333$.

Hirshey, G. (1994, July 17). Gambling nation. The New York Times Magazine, pp. 34-44.

Horodecki, I. (1992). The treatment model of the Guidance Center for gamblers and their relatives in

Vienna/Austria. Journal of Gambling Studies, $8(2)$, 115-129.

Hudak, C. J.,Jr., Varghese, R., \& Politzer, R. M. (1989). Family, marital, and occupational satisfaction for recovering pathological gamblers. Journal of Gambling Behavior, $4(3), 201-210$.

Jacobs, D. F. (1988). Evidence for a common dissociativelike reaction among addicts. Journal of Gambling Behavior, $\underline{4}(1), 27-37$. 
Kuley, N. B., \& Jacobs, D. J. (1988). The relationship between dissociative-like experiences and sensation seeking among social and problem gamblers. Journal of Gambling Behavior, 4 (3), 197-207.

Lesieur, H. R. (1984). The Chase: Career of the compulsive gambler. Cambridge: Schenkman Books.

Lesieur, H. R. (1989). Experience of employee assistance programs with pathological gamblers. Journal of Drug Issues, 19, 425-436.

Lesieur, H. R. (1990). Working with and understanding Gambler's Anonymous. In T. J. Powell (Ed.), Working with self-help (pp. 237-253). Homewood, IL: Dorsey.

Lesieur, H. R., \& Blume, S. B. (1991). Evaluation of patients treated for pathological gambling in a combined alcohol, substance abuse and pathological gambling treatment unit using the Addiction severity Index. British Journal of Addiction, 86, 1017-1028.

Lesieur, H. R., \& Blume, S. B. (1993). Pathological gambling, eating disorders, and the psychoactive substance use disorders. Journal of Addictive Diseased, 12(3), 89-102.

Lesieur, H. R., Blume, S. B., \& Zoppa, R. M. (1986). Alcoholism, drug abuse, and gambling. Alcoholism: Clinical and Experimental Research, 10(1), 33-38.

Lesieur, H. R. , \& Rosenthal, R. J. (1991). Pathological Gambling: A review of the literature (prepared for the American Psychiatric Association Task Force on DSM-IV Committee on disorders of impulse control not elsewhere classified). Journal of Gambling Studies, 7(1), 5-39.

Lesieur, H. R. \& Rothschild, J. (1989) . Children of gamblers anonymous members. Journal of Gambling Behavior, $\underline{5}(4), 269-281$.

Lydgate, C. (1995, May 23). State run gambling: Hi, I'm Jim, and I'm a compulsive gambler. Willamette Week, pp. 19-28.

McConaghy, N., Blaszczynski, A., \& Frankova, A. (1991). Comparison of imaginal desensitization with other behavioral treatments of pathological gambling: A twoto nine-year follow-up. British Journal of Psychiatry, 159, 390-393. 
Mccormick, R. A. (1991). The importance of coping skill enhancement in the treatment of the pathological gambler. Journal of Gambling studies, 10(1), 7787.

McCormick, R. A., \& Taber, J. I. (1991). Follow-up of male pathological gamblers after treatment: The relationship of intellectual variables to relapse. Journal of Gambling studies, I(2), 99-108.

McElroy, S. I., Hudson, J. I., Pope, H. G., Jr., Keck, P. E. , Aizley, H. G. (1992). American Journal of Psychiatry, $149(3), 318-327$.

McGurrin, M. C. (1992). Pathological gambling: Conceptual, diagnostic, and treatment issues. Sarasota, FL: Professional Resource Press.

Miller, W. (1986). Individual outpatient treatment of pathological gambling. Journal of Gambling Studies, $\underline{2}(2), 95-107$.

Moravec, J. D., \& Munley, P. H. (1983). Psychological test findings on pathological gamblers in treatment. The International Journal of the addictions, 18(7), 10031009 .

Murray, J. B. (1993). Review of research on pathological gambling. Psychological Reports, 72, 791-810.

Niederland, W. G. (1965). A contribution to the psychology of gambling. Psychoanalytic Forum, 2, 175-185.

Orford, J., \& McCartney, J. (1990). Is excessive gambling seen as a form of dependence? Evidence from the community and the clinic. Journal of Gambling studies, $\underline{6}(2), 139-152$.

Rabow, J., Comess, L., Conovan, N., \& Hollos, C. (1984). Compulsive gambling: Psychoanalytic and sociological perspectives. Israel Journal of Psychiatry and Related Sciences, 21(3), 189-207.

Roid, G. H., \& Fitts, W. H. (1991). Tennessee Self-Concept Scale (TSCS): Revised manual. Los Angeles: Western Psychological Services.

Rosecrance, J. (1986). "The next best thing": A study of problem gambling. The International Journal of the Addictions, 20, 1727-1739. 
Rosenthal, R. J. (1986). The pathological gambler's system for self-deception. Journal of Gambling Behavior, $\underline{2}(2), 108-120$.

Rosenthal, R. J. \& \& Lorenz, V. C. (1992). The pathological gambler as criminal offender: Comments on evaluation and treatment. Clinical Forensic Psychiatry, 15, 647660 .

Rosenthal, R. J., \& Rugle, L. J. (1994) . A psychodynamic approach to the treatment of pathological gambling: Part I. Achieving abstinence. Journal of Gambling Studies, 10(1), 21-42.

Rugle, L. J. (1993). Initial thoughts on viewing pathological gambling from a physiological and intrapsychic structural perspective. Journal of Gambling studies, $\underline{9}(1), 3-16$.

Rugle, L. J. \& Rosenthal, R. J. (1994). Transference and countertransference reactions in the psychotherapy of pathological gamblers. Journal of Gambling studies, $10(1), 43-65$.

Selzer, J. (1992). Borderline omnipotence in pathological gambling. Archives of Psychiatric Nursing, 6 (4), 215218 .

Sharpe, L., \& Tarrier, N. (1992). A cognitive-behavioral approach for problem gambling. Journal of Cognitive Psychotherapy: An International Quarterly, 6(3), 193203.

Sharpe, L., \& Tarrier, N. (1993). Towards a cognitivebehavioral theory of problem gambling. British Journal of Psychiatry, 162, 407-412.

Steinberg, M. A. (1993). Couples treatment issues for recovering male compulsive gamblers and their partners. Journal of Gambling studies, $9(2), 153-167$.

Taber, J. I. (1985). Pathological gambling: The initial screening interview. Journal of Gambling Behavior, $1(1), 23-34$.

Taber, J. I., \& Chaplin, M. P. (1988) . Group psychotherapy with pathological gamblers. Journal of Gambling Behavior, $4(3), 183-196$. 
Taber, J. I., McCormick, R. A., Russo, A. M., Adkins, B. J., \& Ramirez, L. F. (1987). Follow-up of pathological gamblers after treatment. American Journal of Psychiatry, 144(6), 757-761.

Taber, J. I., Russo, A. M., Adkins B. J., \& McCormick, R. A. (1986). Ego Strength and achievement motivation in pathological gamblers. Journal of Gambling Behavior, $\underline{2}(2), 69-80$.

Volberg, R. A., \& Steadman, H. J. (1992). Accurately depicting pathological gamblers: Policy and treatment implications. Journal of Gambling Studies, 8 (4), 401412 . 
APPENDIX 


\section{Diagnostic criteria for 312.31 Pathological Gambling}

A. Persistent and recurrent maladaptive gambling behavior as indicated by five (or more) of the following:

(1) is preoccupied with gambling (e.g., preoccupied with reliving past gambling experiences, handicapping or planning the next venture, or thinking of ways to get money with which to gamble)

(2) needs to gamble with increasing amounts of money in order to achieve the desired excitement

(3) has repeated unsuccessful efforts to control, cut back, or stop gambling

(4) is restless or irritable when attempting to cut down or stop gambling

(5) gambles as a way of escaping from problems or of relieving a dysphoric mood (e.g., feelings of helplessness, guilt, anxiety, depression)

(6) after losing money gambling, often retums another day to get even ("chasing" one's losses)

(7) lies to family members, therapist, or others to conceal the extent of involvement with gambling

(8) has committed illegal acts such as forgery, fraud, thef, or embezzlement to finance gambling

(9) has jeopardized or lost a significant relationship, job, or educational or career opportunity because of gambling

(10) relies on others to provide money to relieve a desperate financial situation caused by gambling

B. The gambling behavior is not better accounted for by a Manic Episode. 
ADOICTION SEVERITH INOEX $(11 / 21 / 94)$

Name

Date

Therapist

Gender Male Female

GENERAL INFORUATION

1. How long at current address?

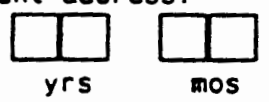

2. Is this residence owned by you or your fawily?

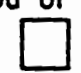

$$
0 \text { - No } 1 \text { - Yes }
$$

3. Date of birth

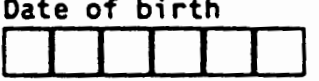

4. Race

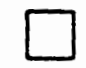

1 - White

2 - Black

3 - Nat. Am.

4. Alaskan

5 - Asian/Pacific Islander

5. Religious preference

6 - His-Mex

7 - Mis-PR

8- His-Cuban

9 - Other His

1 - Protestant

2 - Catholic

3 - Jewish

$$
\begin{aligned}
& 4 \text { - Islamic } \\
& 5 \text { - Other } \\
& 6 \text { - None }
\end{aligned}
$$

6. Have you been in a controlled environment in the last 30 days?

1 - No

2 - Jail

3 - Alcohol or Drug Treatment

4 - Medical Treatment

5 - Psychiatric Treatment

6 - Other

7. How many days?

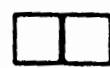

TEST RESULTS

8. Folstein

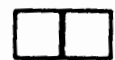

9. Beck

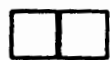

9. Shipley

10

co
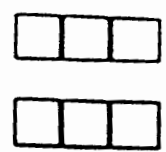

10. WURS

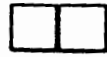

11. SOGS

12. TSCS

A - Self Criticism

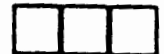

B - Total Positive

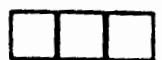

C - Identity

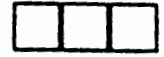

D - Self-Satisfaction

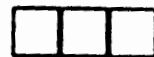

E - Behavior

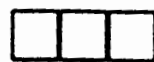

F - Physical Self

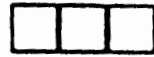

G - Moral-Ethical Self

H - Personal Self

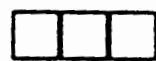

I. Family Self

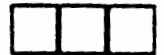

J - Social Self

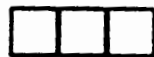

K - Defensive Positive

L - General Maladjust.

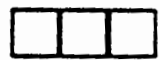

M- Psychosis

N - Personality Dis.

o- Neurosis

P - Personality Integ.
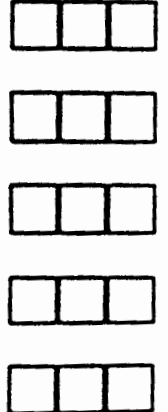
SEVERTTY PROFIIE

\begin{tabular}{|l|l|l|l|l|l|l|l|l|}
\hline 9 & & & & & & & & \\
\hline 8 & & & & & & & & \\
\hline 7 & & & & & & & & \\
\hline 5 & & & & & & & & \\
\hline 4 & & & & & & & & \\
\hline 3 & & & & & & & & \\
\hline 2 & & & & & & & & \\
\hline 1 & & & & & & & & \\
\hline 0 & & & & & & & & \\
\hline & IIC & DRUG & GAMB & MED & FAM & EMPL & LEGAL & PSYCH \\
\hline
\end{tabular}

PLACE AN "X" IN THE APPROPRIATE BOX

Name

Date of intake

Date of staffing.

Diagnosis: Axis I

Axis II

Axis III 
Name

1 - oral

- non iv injection

2. nesal

IV injection

ALCOHOL/DRUG HISTORY

CODE H

$\begin{array}{llll}\begin{array}{l}\text { Past } 30 \\ \text { days }\end{array} & \begin{array}{l}\text { Lifetime Use } \\ \text { yrs }\end{array} & \text { Route Amount } & \begin{array}{c}\text { Date last } \\ \text { use }\end{array}\end{array}$

01 * Alcohol

(any use at all)
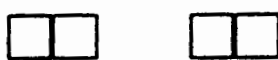

$\square$

$02 *$ Alcohol
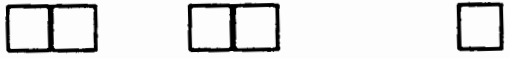

(intoxication)

$03 *$ Heroin
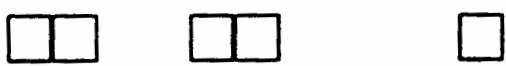

04 * Methadone
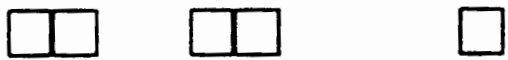

05 * Other Opiates
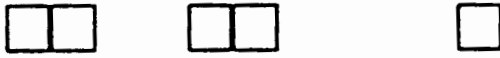

Analgesics
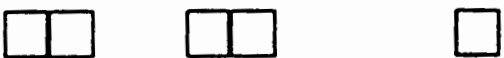

06 * Barbiturates
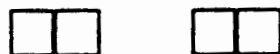

07 * Other Sed/Hypnotics Tranquilizers

$08 *$ Cocaine
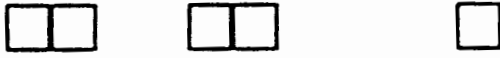

09 * Amphetamine
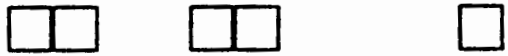

10 * Cannabis
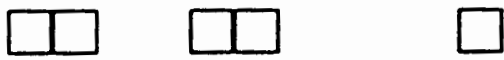

11 * Hallucinogens
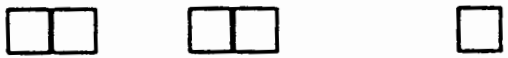

12. * Inhalants
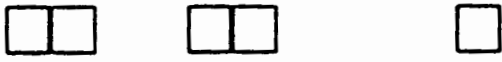

13. * More than one substance
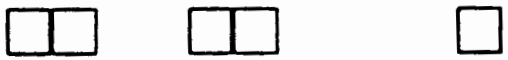
per day inclu. alcohol 
Name

ORUG/ALCOHOL CON't

14. Which substance is the major problea? (USe OO-No problem; otherwise 14-dual or 15-polydrug)

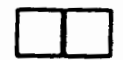

15. How long was your last period of voluntary abstinence from this major substance? (00-Never abstinent)

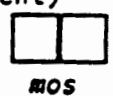

16. How many months ago did this abstinence end? (00-Still abstinent)

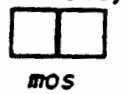

17. How many times have you:

had alcohol OTs

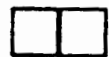

overdosed on drugs

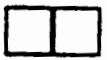

18. * How any tices in your life have you been treated for:

alcohol abuse

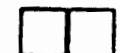

drug abuse

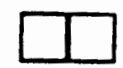

19. How many of these were detox only?

$$
\begin{aligned}
& \text { alcohol } \\
& \text { drug }
\end{aligned}
$$
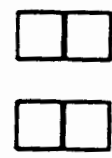

20. * How auch would you say that you spent during the past 30 stays on:

$$
\text { alcohol }
$$

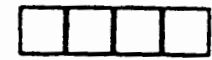

drugs
21. How many days have you been treated in an outpatient setting for alcohol or drugs in the past 30 days?

(Include AA, NA)

22. * How any days in the past 30 have you experienced:

$$
\begin{aligned}
& \text { alcohol problems } \\
& \text { drug problems }
\end{aligned}
$$
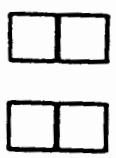

FOR QUESTIONS $23 \& 24$ USE THE PATIENT RATING SCALE $(0-4)$

23. How troubled or bothered have you been in the past 30 days by:

$$
\begin{aligned}
& \text { alcohol problems } \\
& \text { drug problems }
\end{aligned}
$$

24. How important to you now is treatment for your:

$$
\begin{aligned}
& \text { alcohol problems } \\
& \text { drug problems }
\end{aligned}
$$

\section{INTERVIEWER SEVERITY RATING $(0-9)$}

25. * How would you rate the patient's need for treatment for:

$$
\begin{aligned}
& \text { alcohol abuse } \\
& \text { drug abuse }
\end{aligned}
$$

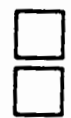

\section{CONFIDENCE RATINGS}

Is the above information significantly distorted by:

\section{Misrepresentation \\ 0 - No 1 - Yes}

27. Inability to understand 
Name

GAMBLING

Code

Past 30

Days

1 Card Games

2 Horses, Dogs

3 Sporting Events

4 Dice Games

5 Casino

6 Lottery, Numbers

7 Bingo

8 Stocks, Commoditles

9 Sjot/Poker Machines (Mechanical)

10 Video Poker

11 Video Keno

12 Games of skill (bow), pool, golf, etc)

13 Gampling more than could afford
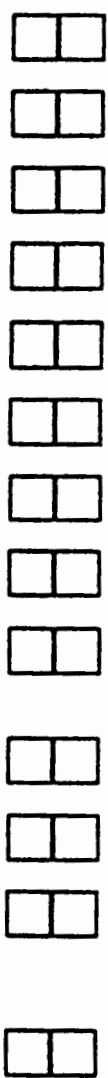

Lifet ime

play
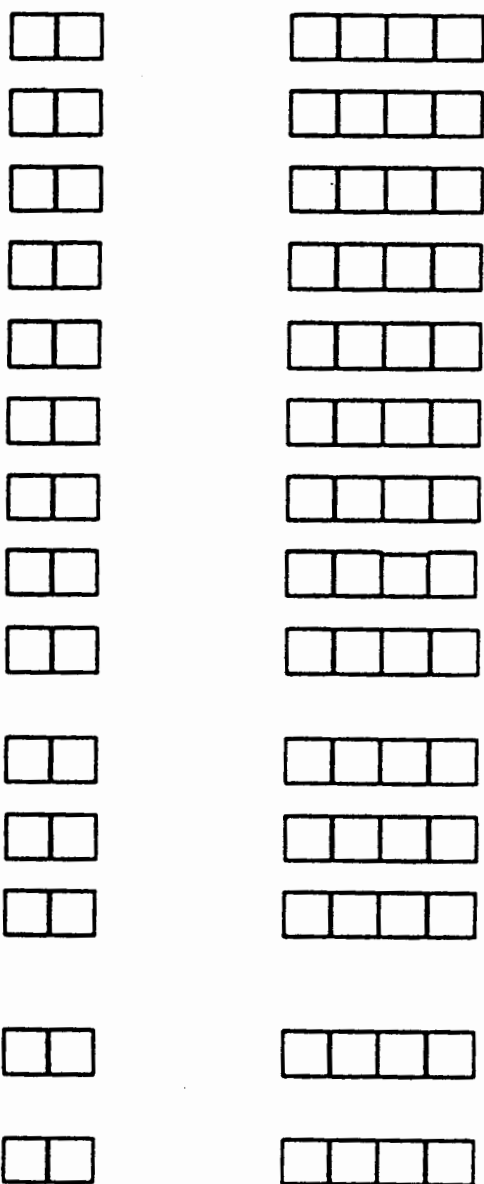

Comments 14 Gambling/substance 
Name

GAMBLING con't

14. * Wich type of gabling is the major problem? (00 - no problem)

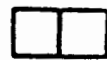

15. * How long was your last period of voluntary abstinence frou gambling? (Months)

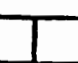

16. How any months ago did abstinence from gambling end? (00-

Still abstinent)

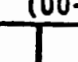

17. How any tiaes in your life have you been treated for gambling?

18. * How much would you say you spend per week on gambling?

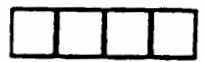

19. How many days in the last 30 have you been treated in an outpatient setting for gabling problems? (Include GA)

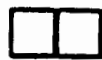

20. How many days in the past 30 have you experienced garbling problens?

21. During how wany wonths in the last 12 months have you been bothered by gaming probleas?
FOR QUESTIONS $21 \& 22$ USE THE PATIENT RATING SCALE $(0-4)$

22. How troubled or bothered have you been in the past 30 days by:

$$
\text { gambling problems }
$$

23. How important to you now is treatment for your:

$$
\text { gambling problems }
$$

IKTERVIEWER SEVERITY RATING (0-9)

24. How would you rate the patient's need for treatment for:

$$
\text { gambling probleas }
$$

\section{COMFIDENCE RATINGS}

is the above information significantly distorted by:

25. Misrepresentation

O-No 1 - Yes

26. Inability to understand

o - No 1 - Yes

convents 
Name

\section{FAKILY HISTORY}

Have any of your relatives had what you would call a significant drinking, orug use, psychiatric or gambling problem that did or should have led to treatwent?

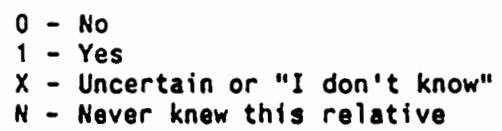

Code most problematic relative in cases of multiple members per category.

Alcohol Drugs Psychiatric Gambling

Mother's Side
Grandmother
Grandfather
Mother
Gather's Side
Grandmother
Gunt
Uncle




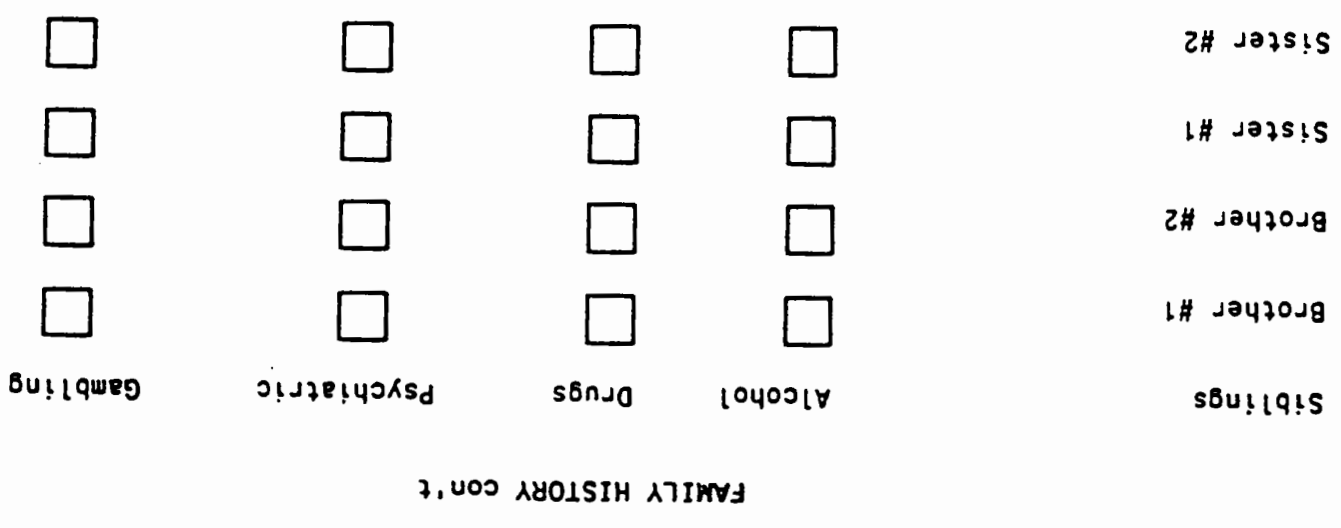

OUPN 
Name

MEOICAL

1. How many times in your life have you been hospitalized for medical problems? (Include OTs and ODs, exciude detox)

2. How long ago was your last hospitalization for a physical

problea?

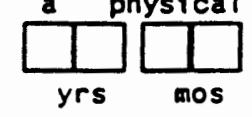

3. Do you have any chronic medical problems that continue to interfere with your life?

O - No 1 - Yes

4.* Are you taking any prescribed medication on a regular basis for a physical problem?

0 - No 1 - Yes

5.* Are you now or in the past have you received care for an infectious disease like hepatitis $A$ or $B$, tuberculosis (TB), sexually transwitted diseases (include HIV). strep or strep infections?

0 - No 1 - Yes

6. Do you receive a pension for a physical disability? (Exclude

psychiatric disability)

0 - No 1 - Yes

Specify

7. How many days have you experienced aedical problems in the

last 30 ?

FOR QUESTIONS $7 \& 8$ USE PATIENT RATING SCALE $(0-4)$

8. How troubled or bothered have you been these medical problems in the

last 30 days?
9. How important to you now is treatment for these medical problems?

\section{INTERVIEWER SEVERITY RATING (0-9)}

10. How would you rate the patient's

need for medical treatment?

CONFIDENCE RATINGS

Is the information significantly distorted by:

11. Misrepresentation

0 - No 1 - Yes

12. Inability to understand

0 - No 1 - Yes

COANENTS 
Name

\section{FAMILY/SOCIAL RELATIONSHIPS}

\section{1.* Marital status}

1. $\quad$ Married
2. Remarried
3. Widowed

4. Separated

5. Divorced

2. How long have you been in this marital status? (If never married subtract current age from 18)

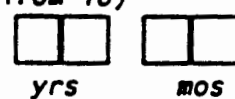

3. * Are you satisfied with this situation?

0 - No 1 - Indifferent 2 - Yes

4. * Usual living arrangements (past 3 years)

1 - With sexual partner and children

2 - With sexual partner alone

3 - With children alone

4 - With parents

5 - With family

6 - Kith friends

7 - Alone

8 - Controlled environment

9 - No stable arrangenents

5. How long have you lived in these arrangewents? (If with parents or

family since, 18)

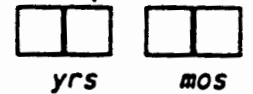

6. Are you satisfied with these

living arrangements?

0 - No 1 - Indifferent 2 - Yes

Do you live with anyone who:

0 - No 1 - Yes

6A. Has a current alcohol problea

6B. Use non-prescribed drugs
7. With whow do you spend most of your free time?

1- Family 2 - Friends 3 - Alone

8. Are you satisfied spending your

free time this way?

0 - No 1 - Indifferent 2 - Yes

9. How wany close friends do you have?

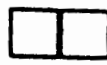

9A-18: Place 0 in relative category where the answer is clearly no for all relatives in the category; 1 where the answer is clearly yes for any relatives in the category; $\bar{x}$ where the answer is uncertain or I don't know; $N$ where there never was a relative from that catecory

9A. Would you say that you had a close, long lasting, personal relationship with any of the following people in your life:

Mother

Father

Brothers/Sisters

Sexual Partner/Spouse

Children

Friends

Have you had significant periods in

which you have experienced serious problems with: 0 - No 1 - Yes past so in your

10. * Mother

days life

11.* Father

12.* Brothers/Sisters spouse

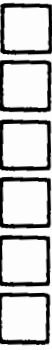<smiles>C1CCC1</smiles><smiles>C1CCC1</smiles>

\section{3.* Sexual partner/}


Name

FAMILY/SOCIAL RELATIONSHIPS cont'

21. Social problems

0 - No 1 - Yes

How important to you now is treatment or counseling for these:

Past 30 life

$$
\text { 14.* Children }
$$

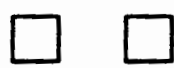

22. Family problems?

23. Social problems

15.* Other significant

$$
\text { family. }
$$

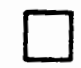

16. * Close friends

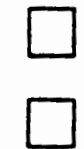

17.* Neighbors

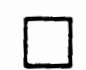

18. Co-workers

Did any of these people $(10-18)$ abuse you: 0 - No 1 - Yes

18A. Emotionally

(make you feel bad

through harsh words)

188. Physically

(cause you physica? hara)

18C. Sexually

(force sexual advances

or sexual acts)

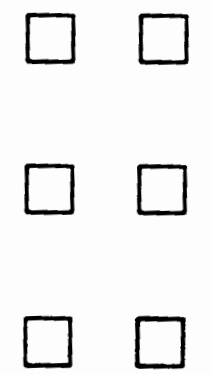

19. How many days in the past 30 have you had serious conflicts:

A. with your family

6. with other people (excluding family)

FOR QUESTIONS 20-23 USE PATIENT RATING SCALE $(0-4)$

How troubled or bothered have you been in the past 30 days by:

20. Familv oroblems?
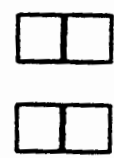
Name

EMPLONENT/SUPPORT

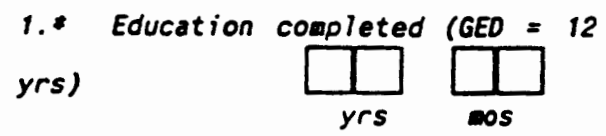

2. * Training or technical education completed

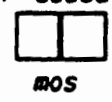

3. Do you have a profession, trade or skill? 0 - No, - Yes

Specify

4.* Do you have a valid driver's license?

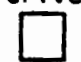

0 - No 1 - Yes

5. Do you have an autombile available for your use? (Answer No if

no valid driver's license)

0 - No 1 - Yes

6. How long was your longest

full time job?

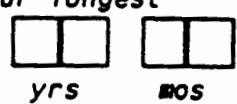

7.* Usual or last occupation

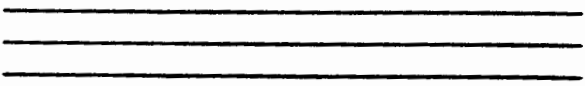

6. Does someone contribute to your support in any way?

0 - No 1 - Yes

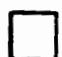

9.* If 48 was yes, does this constitute the ajority of your support? 0 - No 1 - Yes

10. Usual employment pattern in the last 3 years

1. Full time ( $40 \mathrm{hrs} / \mathrm{wk})$

2. Part time (reg. hrs)

3. Part time (irreg. hrs)

4. Student

5. Service

6. Retired/oisabled

7. Unemployed

8. In controlled environment

11. How many days were you paid for

working in the past 30 ? (Inlcude

"under the table" work)

How much woney did you recieve frow the following sources in the past 30 days?

12. Employment

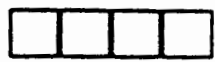

13.* Unemployment

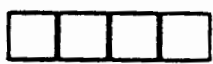

14. * Public Assistance

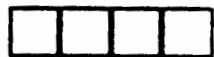

15.* Pension or Social Security Benefits

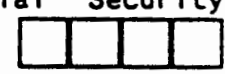

16. Mate, family or friends (Money for personal expenses)

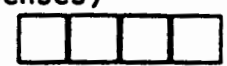

17.* Illegal

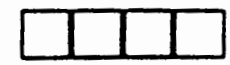

18. *ambling

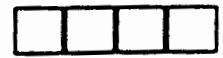


Name

EMPLOMENT/SUPPORT cOn't

Comments

18. * How many people depend on you for the majority of their food, shelter, etc?

19.* How any days have you experienced employment problens in the past 30 days?

FOR QUESTIONS $20 \& 21$ USE THE PATIENT RATING SCALE $(0-4)$

20.* How troubled or bothered have you been by these employment problems in the past 30 days?

21. How important to you now is
counseling for these employeent
problems?

INTERVIEWER SEVERITY RATING $(0-9)$

22. How would you rate the patient's need for employment counseling?

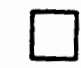

CONFIOENCE RATINGS

Is the above inforation

significantly distorted by:

23. Misrepresentation

- No 1 - Yes

24. Inability to understand

0 - No 1 - Yes 
Name

LEGAL STATUS

1. Was this admission prompted or suggested by the criminal justice systen (judge, probation/parole officer, etc.)

0 - No 1 - Yes

2. Are you on probation or parole?

0 - No 1 - Yes

How many times in your life have you been arrested and charged with the following criminal offenses:

03 * Shoplift/Vandalism

04* Parole/Prob. Viol

05* Drug charges

06 * Forg/Fraud/Embezz

$07 *$ Weapons Offense

$08 *$ Burg. , Lar., B\&E

$09 *$ Robbery

10* Assault

$11 *$ Arson

12* Rape/Sex Offenses

13* Howicide, Mansl.

14* Prostitution

15* Contempt of Court

16* Gambling Offenses

$17 *$ Other
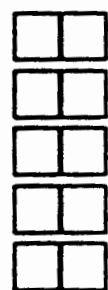

18. How many of these

resulted in convictions
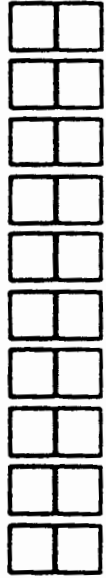

charges

How many times in your life have you been charged with the following:

19. Disorderly conduct, vagrancy, public intoxication
20. DUII/DWI

21. * Major driving violations (reckless driving speeding, no license, etc)

22. How many months have you been incarcerated in your life?

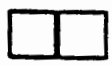

23. How long was your last incarceration? (months)

24. What was it for? (Use codes 3 -

17, 19-21 If multiple codes use the most severel

25. * Are you presently awaiting charges, trial or sentencing?

0 - No 1 - Yes

26. What for? (If multiple, use most severe)

27. How many days within the past 30 were you detained or incarcerated?

28. * How many days in the past 30 have you engaged in illegal activities for profit?

FOR QUESTIONS 29 \& 30 USE THE PATIENT'S RATING SCALE $(0-4)$

29. How serious do you think that your present legal problems are? (Exclude civil problems)

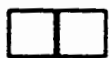

30. How important to you now is counseling or referral for these legal problems?

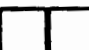


Name

LEGAL cont'

INTERVIEWER SEVERITY RATING (0-9)

31. How would you rate the patient's need for legal services or counseling

CONFIDENCE RATINGS

Is the above information significantly distorted by:

32. Misrepresentation

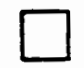

0 - No 1 - Yes

33. Inability to understand

0 - No 1 - Yes

COMANTS 
Name

PSYCHIATRIC STATUS

1. How many times have you been treated for any psychological or emotional problems?
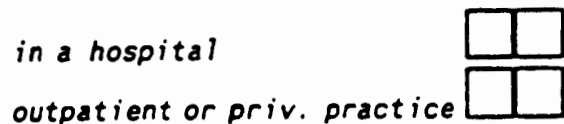

2. Do you receive a pension for a psychiatric disability?

0 - No 1 - Yes

Have you had a significant period, (that was not a direct result of alcohol/drug use or gambling), in which you have:

$$
\begin{aligned}
& 0 \text { - No } 1 \text { - Yes Past } 30 \quad \begin{array}{c}
\text { In your } \\
\text { life } \\
\text { days }
\end{array} \\
& \begin{array}{l}
\text { depressions } \\
\text { depression }
\end{array}
\end{aligned}
$$

4. * serious anx. or tension

5. hallucinations

6.* trouble understand, concen, remember

7.* trouble controlling violent behavior

8. : serious thoughts of sui.

9. attempted sui.

10. *taken prescr. oed for psychol/ emotional problems

11. How many days in the past 30 have you had psychiatric or emotional problems?

FOR QUESTIONS 12 \& 13 USE THE PATIENT
12. * How troubled have you been in the past 30 days by psychological or emotional problems?

13.* How important to you now is treatment for these psychological problems?

The following items are to be completed by the interviewer

At the time of the interview is patient:

0 - No 1 - Yes

14. Obviously depressed/ withdrawn

15. Obviously hostile

16. Obviously anxious/ nervous

17. Having trouble with with reality testing, thought disorder, paranoid thinking

18. Having trouble comprehending, concentrating, recembering

19. Having suicidal thoughts

INTERVIEWER SEVERITY RATING $(0-9)$

20. How would you rate the patient's need for psychiatric/psychological

treatment?

CONFIDENCE RATINGS

Is the above information significantly distorted by:

\section{Misrepresentation \\ O - No 1 - Yes}

22. Inability to understand 
Name

PATIENT'S RATING SCALE

0 - Not at all

1 - Slightly

2 - Moderately

3 - Considerably

4 - Extremely
INTERVIEWERS RATING SCALE

0 - 1 No real problem; tx not indicated

2 - 3 slight problem; tx probably not indicated

4 - 5 Moderate problem; some tx indicated

6 - 7 Considerable problem; tx necessary

8 - 9 Extreme problem; tx absolutely necessary

\section{SEVERITY PROFILE}


Commonly used substances

Alcohol: beer, wine, liquor, grain

Methadone: LAAM, dolophine

Other opiates: Pain killersmorphine, diaudid, demerol, percocet, percodan, dia-quel, darvon, darvocet, talwin, codeine (tylenol 2, 3, 4), syrups (robitussin, actifed-C). fentanyl

Barbiturates: nembutal, seconal, tuinol, amytal, pentobarbital. secobarbital, phenobarbital, fiorinol, doridan, placidyl

\section{Sed/Hyp/Tranq:}

benzodiazepines: valium, librium, ativan, serax, tranxexe, dalmane, halcyon, xanax

antipsychotics: thorazine, mellaril, stelazine, haldol, navane, serentil, compazine

Cocaine: crack, rock, free base, crystal

Amphetamines: monster, crank, benzedrine (bennies), dexedrine, ritalin, preludin, methamphetamine (meth), speed, ice (crystal)

Cannabis: marijuana, hashish, mary jane, weed, dope

Hallucinogens: LSO (acid), mescaline, mushrooms (psilocybin), peyote (buttons), green, PCP (phencyclidine), angel dust

Inhalants: nitrous oxide, amyl nitrate (whippets, poppers), glue, solvents, gasoline
Hollingshead Categories (Employment)

1 - higher executives, major professionals, owners of large businesses

2 - business managers (med. size businesses), professionals (nurses, opticians, pharmacists, social workers, teachers)

3 - administrative personnel, managers, owners/proprietors of smali businesses, actor, reporter, travel agent

4 - clerical and sales, technictan, bank teller, bookkeeper, clerk, secretary, drafter

5 - skilled manual labor (usually requiring training)- baker, barber, electrician, firefighter, machinist, mechanic, tailor, welder, police, plumber

6 - semiskilled- hospital aid, painter, bartender, bus driver, cook, guard, machine operator, grocery checker

7 - unskilled- attendant, janitor, construction helper, laborer. unemployed 


\section{Intake Addendum}

\section{Depression}

Have there been times in your life that you have felt sad.

How long did this last?
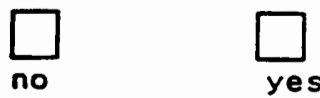

$$
\text { low, or hopeless? }
$$
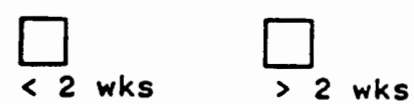

Did you have problems getting to sleep, staying asleep, or getting up too early?
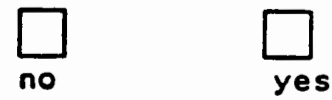

How was your appetite at that time?
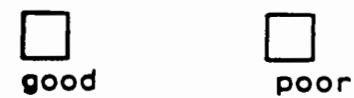

Did you gain or lose any weight at that time?<smiles>C1CCC1</smiles><smiles>CC1CCC1</smiles>

Did you feel tearful?<smiles>C1CCC1</smiles>

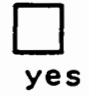

Did you have feeling of guilt, worthlessness, or hopelessness?
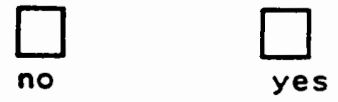

Have you ever felt so bad that you wanted to hurt yourself or end your life?
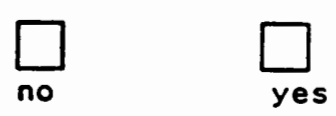

How would you have taken, or how would you take your life if you were thinking about it?

Do you have these feelings now?
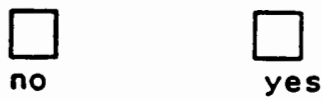

Have you ever wanted to hurt or kill someone else?<smiles>C1CC2CCC12</smiles><smiles>[AsH2]C1CCC1</smiles>

Do you have these feelings now<smiles>C1CCC1</smiles>

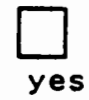


Mania

Have there been times in your iffe that you have felt unusualiy high or charged up?
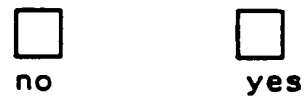

Did this increase in energy last more than one week? If no then go to next section.

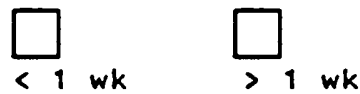

Did your sleep patterns changed because of this energy?

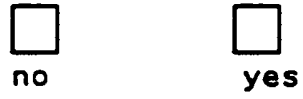

Did your family or friends tell you that you were too excited, revved up, or talkative?

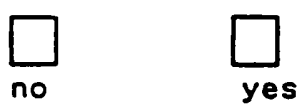

Did you feel euphoric, irritable, or anxious at that time?

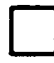

no

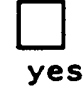

Did you do anything unusual or impulsive at that time?
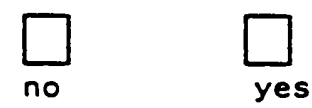

If so, how long did this period last

\section{Psychosis}

Have you ever felt that others
wanted to hurt you or get you
for some reason? (Do not include when intoxicated)<smiles>C1CCC1</smiles>

no

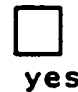

Have you seen things or heard things that others have not seen or heard?
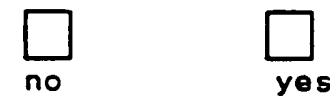

Has the television or the radio ever sent you personal or private messages?
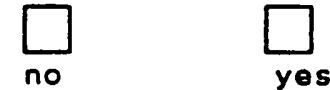

Do you feel that other people can insert, withdrawal, or control your thoughts? 
Anxiety

Do you feel that you are a nervous person?

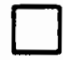

no

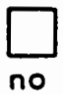

If you are, does this nervousness keep you from going out of the house? (shopping, eating out, public events)

Do you have any strong fears or phobias?

Are there times in which you
become fearful or anxious without apparent reasons?

If yes, what is the frequency and duration of these episodes?

Have you ever felt that the world around you or you yourself were unreal?

Obsessive-Compulsive Disorder

Have you ever felt that you had to do things repeatedly though you had just done them? (locking doors, counting objects, checking appliances)

Have you ever had thoughts stick in your head; even ones that make no sense?

Post-Traumatic Stress Disorder

Have you ever had flashbacks or nightmares in which you relive some upsetting event that happened to you in the past?
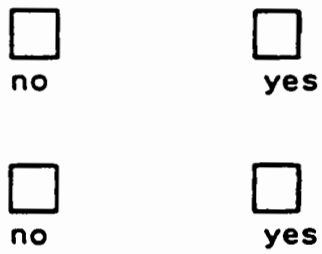

yes
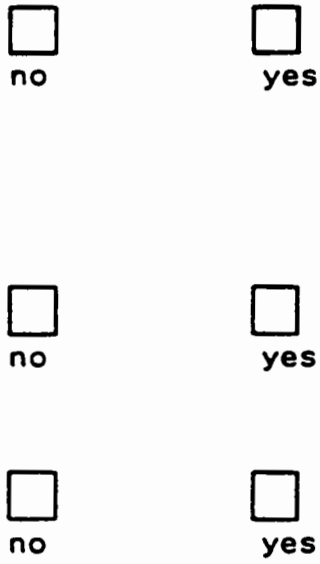
Eating Disorders

Have you ever used laxatives or diuretics to control your weight?

$\square_{\text {no }} \square_{\text {yes }}$

Have you ever made yourself throw up or starved yourself because you thought you were to fat?

Have you ever lost so much weight that others were worried about you?

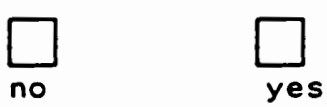

Have you ever felt fat when other told you that you were thin?

Attention-Deficit Hyperactivity Disorder

As a child were you more active or restless that the other children?
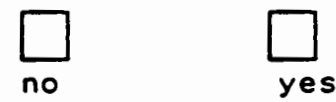

Did you have problems sitting still or paying attention?

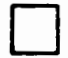

no

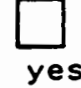

Were you told that you daydreamed a lot?

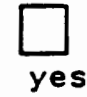

Were you the class clown?

Were you called hyperactive by friend or family?
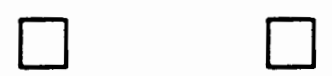

Have you ever been medicated for hyperactivity?

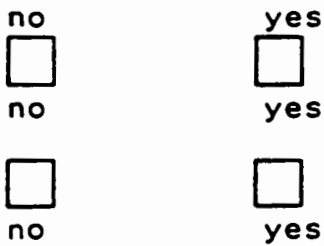

\section{Somatoform Disorder}

Have you had a lot of medical problems in which a doctor has not been able to tell you what is wrong?

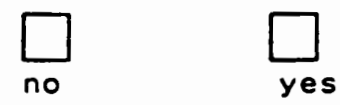




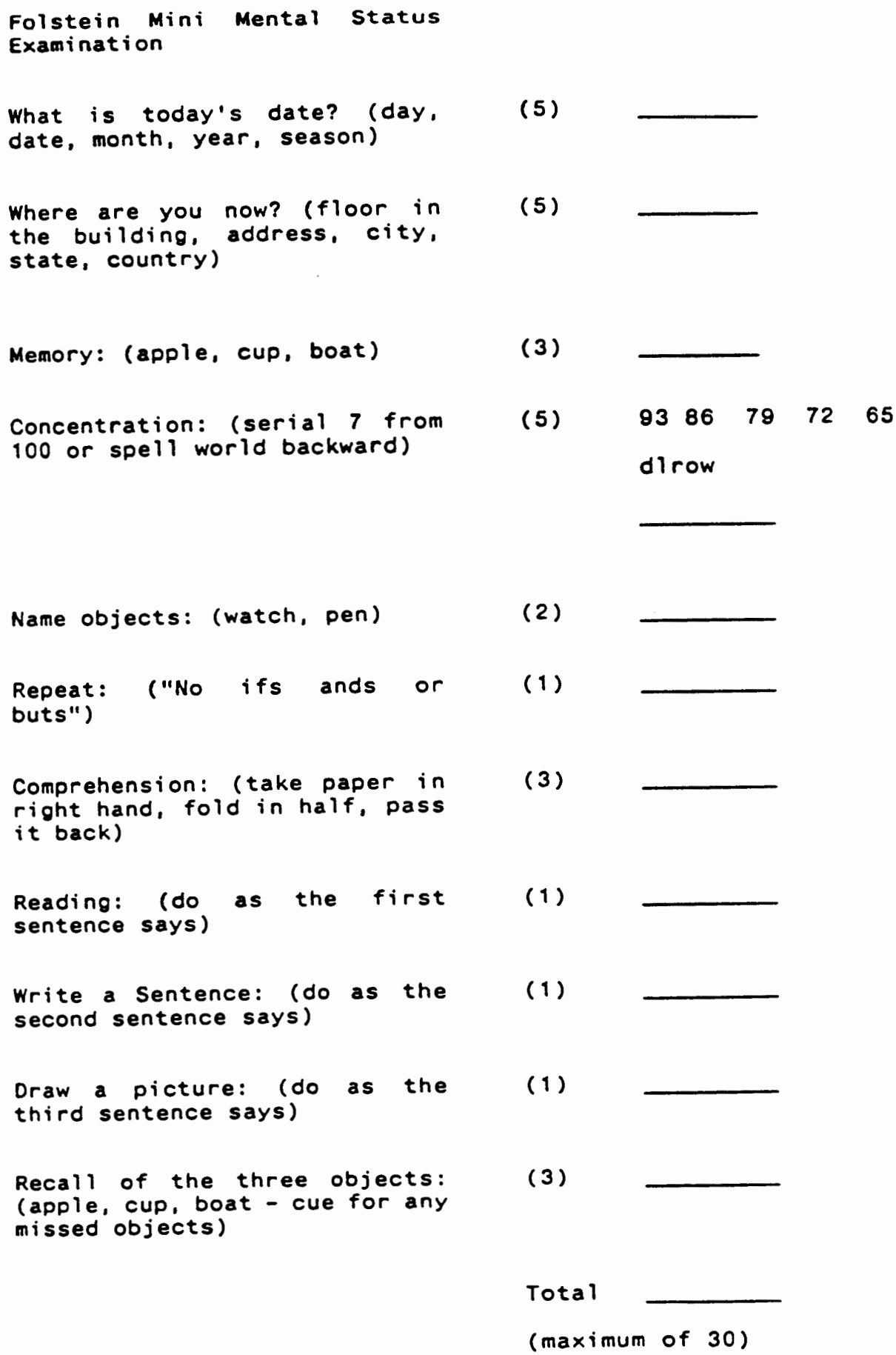

Total

(maximum of 30 ) 


\section{Please close your eyes}

Please write a sentence.

Please copy the picture shown below.

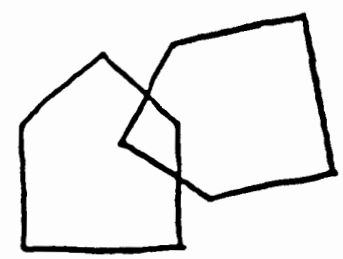

Proverbs

Don't cry over spilt milk

Don't count your chickens before they hatch 
Mental Status Ecamination:

Appearance :

Neat

Unusual Features:

Grooning/Hygiene:

Good

Attitude:

Friendly

Rapid

Normal
Casual

Fair

Cooperative

Motor Activity: Agitated

slow

Pressured

Notmal
Disheveled

Poor

Hostile

Restless

Notmal

Soft

Loudness:

Loud

Speech Rate:

Rapid

slow

Quantity:

Eluency:

How does the client describe thein now

Labile

Affect:

Wide

Blunted

Flat

Inappropriate

Restricted Depressed

Rate and Flow of Ideas: Circumstantial

Thought Process:

coal-di rected slow/Retarded

Blocking

Quality of Associations: Cohesive

Tangential

FOI

Evasive

Loose

Hallucinations

Ibought content:

Paranoia

Delusions

Reality Testing:

Intact

Deficient

Strengths:

Weaknesses: 


\section{BBCK INVBNTORY}

This is a questionnaire that will help us to help you with some of the feelings that come up in treatment. In each group of statements, pick out the statement that best describes how you feel today (right now). Circle the number by the statement you have chosen. If several statements seem to
apply equally well, circle each one.

Be sure to read all the statements in each group before you make your choicel

\section{DEPRESSION INVENTORY}

A. (SADNBSS)

0 I do aot foel sad

1 I feel blue or sad

22. I 200 blue or sad all the time and I cra't sasp out of it

2b I sm $c 0$ sad or unhappy that it is quite pelnful

3 I 200 so sad or unheppy that I can't stend it

B. (PBSSDASM)

- I an not particularly pessimistic or discouraged about the future

12 I foel discouraged about the future

22 I feel I have nothiag to look forward to

$2 b$ I feel that I woa't erer get ores my troubles

3 I feel that the future is bopeless and that things canoot improve

c. (SBNSB OF RAIIURB)

- I do aot feel like a feillure

1 I foel I have fallod mose then the average pecson

$2 \mathrm{~b}$ As I look back on my life all I can see is 2 lot of falle or that meros anything

3 I feel I back oa my life all I cin see is a lot of fallures

3 I feel I ach a complete failure as a person (purent, husband, wife)

D. (DISSATISRACTION)

- I em not perticulacly dissatisfied

I2 I feel bored most of the time

Ib I doa't cajoy things the way I used to

2 I doa't get satisf action out of anything any more

3 I 200 dissztisfied with everything

B. (GUIIT)

0 I don't feel particulasly guilty

I I feel bad or unworthy a good part of the time

22. I feel quite guilty

2b I feel bad or unworthy prectically all the thine now

3 I feel as though I 200 very bad or worthless 
N. (BODY IMAGE CHANGE)

- I don't feel I look any worse than I used to

I I sm worried that I am looking old or unattractive

2 I feel that there are permanent changes in my appearance and they make me look unattractive

3 I feel that I am ugly or repulsive looking

O. (WORK RBTARDATION)

o I can work about as well as before

1s It takes extra effort to get started at doing something

ib I don't work as well as I used to

2 I beve to push engself very hard to do angthing

3 I cen't do say work at all

P. (INSOMONIA)

- I cen sleep es well es usuel

1 I wake up more tired in the moming then I used to

2 I wake up 1-2 bours eartier then usual end fiod it herd to get back to sleep

3 I wake up early eresy day and can't get mose than $s$ hours sleep

Q. (FATIGABIITY)

- I doa't get say mose tired then usuel

1 I get tired more easily then I used to

2 I get tired from doing enything

3 I get too tired to do saything

R. (ANOREXIA)

0 My eppetite is no worse then usual

1 My eppetite is not es good as it used to be

2 MY appetite is much wosse a0w

3 I bave do appetite at all eng more

S. (WEIGHT LOSS)

o I berea't lost much weight, if eny, Lately

1 I bave lost more then 5 pounds

2 I have lost more then 10 pounds

3 I heve lost more then 15 poinds

T. (SOMATIC PRBOCCUPATION)

o I 20 no more coaceraed about wy bealth than usual

I I im concerned about aches and pains or upset stomech or constipation

2 I sm so concerned with bow I feel or what I feel that it's bard to think of much else

3 I 20 completely absorbed in whet I feel

U. (LOSS OF LIBDO)

0 . I bave not ootiond any recent change in my interest in sex

1 I son less interested in sex then I used to be

2 I son much less interested in ser now

3. I bave lost interest in sex completely 


\section{F. (EXPECTATION OF PUNISHMENT)}

O I don't feel I am being punished

1 I have 2 feeling that something bad may happen to me

2 I feel I am being punished or will be punished

32 I feel I deserve to be punished

$3 b$ I want to be punished

G. (SELP-DISLIKE)

- I don't feel diszppointed in myself

12 I am disappointed in myself

ib I doa't like myself

2 I am disgusted with myself

3 I hate myself

H. (SELP-ACCUSATIONS)

- I don't feel I am any worse than anybody else

2 I am critical of myself for my weaknesses or mistakes

2 I blame myself for my faults

3 I blame myself for everything bad that happeas

I. (SUICIDAI DDEAS)

- I dog't have ang thoughts of harming myself

1 I. have thoughts of harming myself but I would not carry them out

22. I feel I would be better off dead

$2 b$ I feel my family would be better off if I'were dead

32. I have definite plens about committing suicide

3b I would kill myself if I could

J. (CRYNNG)

o I doa't ory any more then usual

1 I cry more now then I used to

2 I or all the time now. I can't stop it

3 I used to be able to cy but now I can't cry at all even though I want to

K. (RRRTTABIITTY)

- I am no more irritated now than I ever am

1 I get anooyed or irritated more easily than I used to

2 I feel irritated all the time

3 I don't get irritated at all at the things that used to irritate me

L. (SOCIAI WITHDRAWAI)

- I have not lost interest in other people

I I am less interested in other people now than I used to be

2 I have lost most of my interest in other people and have little feeling for them

3 I have lost all my interest in other people and don't care about them at all

M. (INDECISIVBNESS)

- I make decisions about as well as ever

1 I try to put of making decisions

2 I have great difficulty in making decisions

2 I ren't mete anv derieinoe et 11 one mon.e 
Name

Date

1. Please indicate whicti of the following types of gambiling you have dow in your ilfetime. For each type, mark one answer: "not at all," "less than once a week," or "once a week or more."

$\begin{array}{lcc} & \text { less } & \text { once } \\ \text { than } & \text { a } \\ \text { not } & \text { once } & \text { week } \\ \text { at } & \text { a } & \text { or } \\ \text { all } & \text { week } & \text { more }\end{array}$

a. - - - -

play cards for money

bet on horses, oggs or other andmals (at 018, the track or vitth abisolie)

c. - - -

bet on sports (parlay; cirds, whth bookle, or at Jal Alas)

d. "Played dloe?garies "(Including cicips, over and under or other atce. games) for mosey

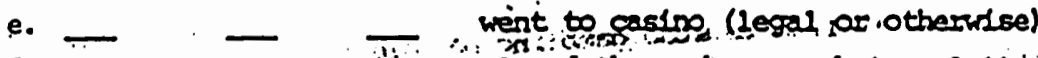

f. - - T - it played tho mubers or bet on lotterles

g. — - Tlayed binge.

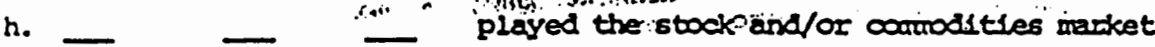

1. _- _ - played slot michines, poker machines or other gambling mactiries

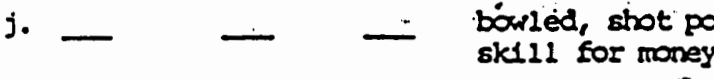

2. What is the largest amount of inoniey you have ever gambled w1th on any one day? never have gambled

il or less

more than $\$ 1$ up to $\$ 10$

more tivin $\$ 10$ up to $\$ 100 \cdots$

ri: than $\$ 100$ up to $\$ 1000$

more than $\$ 1000$ up to $\$ 10,000$

moge than $\$ 10,000$

3. Do (did) ت̈our parents have a groblung peoblent? both in father and rother gamble (d) too mich

ing father gambles (or gambled to much

Iny mother gambles (or gambled) 00 meh

nelther one gambles too much

4. When you gamble, how often a you go back another däy to whl back money you lost?

never

sane of the time (less than half the time I lose)

most of the time I lose

every time I lose

CONIINUE QUESTIONRAIRE ON OTHER SIDE. THANK YOU.

1986 south aaks Foundation 
5. Have you ever clasmed to be whining money gambling but weren't really?

In fact, you lost?

never (or never gamble)

yes, less than half the time I lost

yes, most of the time

6. Do you feel you have ever had a problem wa th gambling?

no

yes, in the past but not now

yes

7. DId you ever gamble more than you fntended tor.......................

8. Have people crlticlzed your gamblingz .

9. Have you ever felt gullty about the way you : gamble or what happens wher you gamblez ..................

10. Have you ever felt Like you would -2ske to stop gambiling but didn't

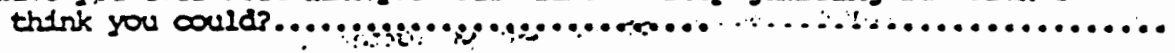

11. Have you ever hidden betting slips, lotbery ticièts; gaimbling money, yes $\overline{n o}$ yes $\bar{n}$ or other signs of ganbling fran jour spouse; chlidien or other important people in your llfer.................................

12. Have you ever argued with people you live with over bow you handle maney?

13. (If you answered yes to question 12): Have money arguments ever centered on your gambling?

14. Have you ever borrowed from sotrieme and not pald then back as a result of your ganbling?.

15. Have you ever lost the fran work for sctiool due to gamblings..........

16. If you borrowed money to ganble or to pay:gabling-debts, who or where did you borrow from? (check "yes" or "no" for eactil.

a. Erom bousebold money....................................... n

b. Exan your spouse.

c. fran other relatives or in-laws.

d. from banks, losn companles or credit unsons............................. ( )

e. from credut cards.......................................... ,

f. from loan sharks ("Shylocks") ................................... )

g. you cashed in stocks, bonds or other securlties..................... ,

h. you sold personal or fanlly property............................. .

1. you borrowed on your checking acoount (passed bad checks) ............... ( )

j. you have (had) a credit line with a bookle.........................

r. you have (had) a credut ine with a casino. 


\section{PATHOLOGICAL GAMBLING DIAGNOSTIC CRITERIA: DSM IV}

(five or more)

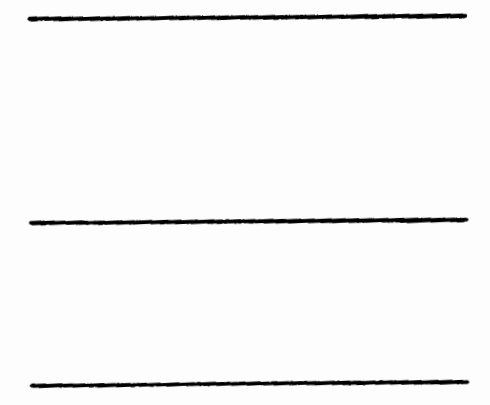

Do you spend lots of time remembering past gambling experiences, handicapping, or planning ways to gamble/get money to gamble?

Do you need to gamble with increasingly larger amounts of money to get the same effect?

Have you tried unsuccessfully to control, cut back, or stop gambling?

Do you feel restless or irritable when you attempt to reduce, or stop gambling?

Do you gamble (in part) to escape from problems or down moods?

Have you ever returned to gamble, after losing, in order to win back the money you lost?

Have you lied to hide the amount of your gambling from others?

Have you committed illegal acts to finance gambling?

Have you lost a job, relationship, or education or career opportunity as a result of gambling?

Have you relied on others to bail you out of financial difficulty resulting from gambling? 
WENDER UTAH RATING SCALE (WURS)

Name

Date

Iisted below are items concerning your behavior. Read each item carefully and decide how much you think you were bothered by these behaviors in childhood. Use the following scale to mark your response.

Not at all Mildy Moderately quite a bit Very much 0 1 2 3 4

As a child I was (or had): Circle your response

1. Concentration problems, easily distracted

$\begin{array}{lllll}0 & 1 & 2 & 3 & 4\end{array}$

2. Anxious, worrying $\begin{array}{lllll}0 & 1 & 2 & 3 & 4\end{array}$

3. Nervous, fidgety $\begin{array}{lllll}0 & 1 & 2 & 3 & 4\end{array}$

4. Inattentive, daydreaming $\begin{array}{lllll}0 & 1 & 2 & 3 & 4\end{array}$

5. Hot- or short-tempered, low boiling point

$\begin{array}{lllll}0 & 1 & 2 & 3 & 4\end{array}$

6. Temper outbursts, tantrums $\begin{array}{lllll}0 & 1 & 2 & 3 & 4\end{array}$

7. Trouble with stick-to-it-tiveness, not following through, failing to finish things started

8. Stubborn strong willed $\begin{array}{lllll}0 & 1 & 2 & 3 & 4\end{array}$

9. Sad or blue, depressed, unhappy $0 \quad 1 \quad 2 \quad 2 \quad 3 \quad 4$

10. Disobedient with parents, rebellious, sassy 
Not at all Mildly Moderately quite a bit very much

0

1

As a child I was or (had):

11. Low opinion of myself

12. Irritable

13. Moody, ups and downs

14. Angry

15. Trouble seeing things from some one else's point of view

16. Acting without thinking, impulsive

17. Tendency to be immature

18. Guilty feelings, regretful

19. Losing control of myself

20. Tendency to be or act irrational

21. Unpopular with other children

22. Trouble with authorities, trouble in school, visits to the principal's office

23. Overall a poor student, slow learner

24. Trouble with mathematics or numbers $0 \quad 1 \quad 2 \quad 3 \quad 4$

25. Not achieving up to potential
3

4

Circle your response $\begin{array}{lllll}0 & 1 & 2 & 3 & 4\end{array}$

$\begin{array}{lllll}0 & 1 & 2 & 3 & 4 \\ 0 & 1 & 2 & 3 & 4 \\ 0 & 1 & 2 & 3 & 4 \\ 0 & 1 & 2 & 3 & 4\end{array}$

$\begin{array}{lllll}0 & 1 & 2 & 3 & 4\end{array}$

$\begin{array}{lllll}0 & 1 & 2 & 3 & 4\end{array}$

$\begin{array}{lllll}0 & 1 & 2 & 3 & 4\end{array}$

$\begin{array}{lllll}0 & 1 & 2 & 3 & 4\end{array}$

$\begin{array}{lllll}0 & 1 & 2 & 3 & 4\end{array}$

$\begin{array}{lllll}0 & 1 & 2 & 3 & 4\end{array}$

$\begin{array}{lllll}0 & 1 & 2 & 3 & 4\end{array}$

$\begin{array}{lllll}0 & 1 & 2 & 3 & 4\end{array}$

$\begin{array}{lllll}0 & 1 & 2 & 3 & 4\end{array}$

$>/ 36$

$=$

6

Subtotal page 1

Total

Subtotal page 2

Total
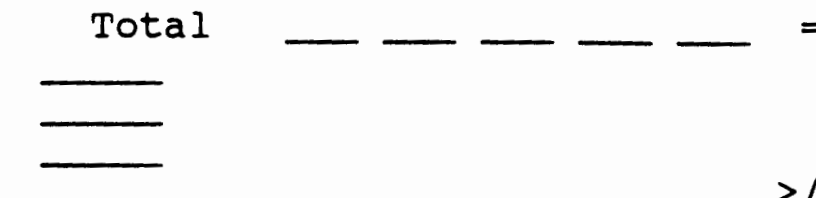


\section{GAMBLING TREATMENT PLAN}

CLIENT:

DATE :

CLIENT:

THERAPIST:

DRUG AND ALCOHOL ABU8E

Abstinence from all drugs including

alcohol is a part of the gambling

treatment program. As part of the

program, you will learn skills to help

you achieve abstinence. Working on the

skills occurs during stages I and II.

Mastery occurs during stages III and IV.

ALCOHOL :

DRUG 1:

DRUG 2:

Criteria:

1) Acknowledge adverse consequences:

2) Acknowledge loss of control:

3) Coping with craving/urges:

4) Drink/drug refusal skilis:

5) Healthy social networking:

6) Relapse prevention:

\section{STAGE I}

CRITERIA :

1) 8TABIIIZE GAKBIING: Commit to working toward abstinence. Develop financial control. Start recognizing gambling urges and triggers. Make a daily gambling journal. Examine cognitive distortions associated with gambling.

2) PARTICIPATE IN TREATMENT: Complete homework assignments and bring to treatment. Discuss gambling urges and triggers. Participate in discussions with other group members. 


\section{STAGE II}

CRITERIA :

1) GAMBLING AB8TINENCE: Abstinence from gambling for 45 days. Develop plan for relapse prevention.

2) SOCIAL 8TRUCTURE: Assess your existing social network and supports. Alter existing supports, or create new social supports to provide an environment favorable to maintaining abstinence from drugs, alcohol and gambling. Examine relationships with friends and relatives. Help friends and relatives learn to be supportive of abstinence.

3) BELF-ESTEEM BUIIDING: Evaluate positive personal characteristics. Make a list of positive and negative attributes. Examine cognitive distortions about yourself and develop appropriate counter thoughts. Start acknowledging and congratulating yourself for changes and successes.

4) MOURNING IOSSES: Accept the loss of gambling, and start the grieving process. Evaluate the losses resulting from your gambling.

5) COMMITMENT TO TREATMENT: Continue active participation in treatment. Provide constructive feedback to other group members. Continue to work on treatment issues between treatment sessions. Complete and share homework assignments. 


\section{STAGE III}

CRITERIA :

1) GAMBLING AB8TINENCE: Abstinence from gambling for 90 days. Practice plan for relapse prevention.

2) BOCIAL stRUCTURE: Continue assessing and changing social network to support abstinence. Continue working with friends and relatives to support abstinence. Examine how addictive behavior has effected your family, friends and social supports.

3) Consequences: Examine the effects and consequences of your addiction. Mourn the losses without condemning yourself. Continue grieving the loss of gambling. List the people whom you have hurt and start making amends. Develop plan for restitution.

4) SELF-AWARENESS: Continue to assess and address your cognitive distortions. Continue acknowledging and congratulating yourself for changes and successes. Work on becoming aware of emotions. Explore your irrational thoughts and dishonesty. Make and implement plan to address dishonesty and irrational thoughts. Understand how irrational thoughts and dishonesty fits into the larger context of your life and personality.

5) RELATIONSHIPS: Examine past addictive behavior and assess how that behavior influenced, shaped and effected relationships. Learn to anticipate behaviors harmful to relationships prior to engaging in them, and replace with effective behaviors.

6) LEADERSHIP AND COMMITMENT: Initiate and actively participate in treatment. Discuss work on past behaviors with group. Exhibit effective new behaviors in group. Continue to work on treatment issues between treatment sessions, integrate new behaviors into everyday patterns. 


\section{STAGE IV}

CRITERIA:

1) GAMBLING ABSTINENCE: Remain abstinent from gambling. Continue relapse prevention work.

2) RELATIONSHIPS: Practice effective new behaviors which foster healthy relationships. Continue assessing and changing social network and relationships to support abstinence.

3) CONSEQUENCES: Continue mourning losses without condemning yourself. Complete the grief process for the loss of gambling. Complete making amends to the people whom you have injured. Start restitution plan.

4) SELF-AWARENESS: Continue to assess and address your cognitive distortions. Continue acknowledging and congratulating yourself for changes and successes. Maintain awareness of emotions, irrational thoughts and dishonesty. Work on effective handling of emotions, irrational thoughts and dishonesty through insight, reflection, and mature self expression. Examine emotions and distortions surrounding completion of treatment, anticipate and plan for managing the losses.

5) DISCHARGE PLAN: Complete and practice discharge plan, and share with group. 


\section{PRINCIPLES OF DEACTIVATION OF CRAVING/URGES}

$\Delta$ Craving is a natural product of drug and alcohol use, urges are a natural product of gambiing. They usually continue on and off well after drug use and gambling stops and physical withdrawal is complete. The principle is basically the same regardless of whether the addiction is to gambling, heroin, cocaine, marijuana, or alcohol.

$\Delta \quad$ Cravings/urges can be stimulated or triggered automatically if a recovering person experiences certain situations that were strongly associated with patterns of former drug use or gambling. Triggers can include internal states, such as depression, or external cues, such as people, places and things.

$\Delta$ For a recovering addict, any drug use or gambling tends to keep the craving/urge triggers strong. This is why attempts at controlled use, such as "I'Il just do a little bit," do not work; the craving/urge gets too strong.

0 Gradually being exposed to craving/urge situations and not getting high or gambling, with the help of strong support and good planning, can work to weaken or extinguish the craving/urge triggers. This process of extinguishing triggers in a recovering person's life is called deactivation.

$\Delta$ Complete abstinence--which means not getting high or gambling at all--is the surest and quickest way to reduce cravings/urges.

- Certain old triggers that have not been appropriately worked on--such as the neighborhood you return to for the first time in years--can remain strong even after years of abstinence. Especially powerful, but infrequent triggers, such as loss of a loved one, can evoke old habits in an otherwise solid recovery. Be careful! 


\section{PRINCIPLES OF DEACTIVATION OF CRAVING/URGES, cOn't}

- Determination and willpower are poor defenses against cravings/urges. Changing your lifestyle--to gain friends and support, to learn new ways to relax and have fun, and to be a productive and growing person-can reduce cravings/urges and their dangers to your recovery. Real strength grows with time, work, guidance, and support.

0 You may relapse. If that happens, get back on the recovery road immediately. You should have a plan to follow if you relapse. A relapse does not mean that you have failed or have totally wasted your efforts. It means rather that you must learn from it and need to plan better, go more slowly, and get more support.

$\Delta \quad$ Even though craving/urges are a natural aftereffect of the disease of addiction, remember that you have the power of choice. You can take steps now to reduce it and conquer it, or you can remain its slave. 


\section{COPING WITH CRAVINGS AND URGES: MAKING A TRIGGER JOURNAL}

\section{REMEMBER :}

I Urges are common in the recovery process. They are not a sign of failure. Instead, try to learn from them, you can learn what your craving/urge triggers are.

\pm Urges are like ocean waves. They get stronger only to a point, then they start to go away.

\pm You win every time you defeat an urge by not using or gambling. Urges continue to get stronger if you give in and feed them. An urge will eventually weaken and die if you do not feed it.

\section{PRACTICE EXERCISE:}

Make a daily record of urges to use drugs, drink and/or gamble. Rate the intensity of the urge, and coping strategies/ ideas/behaviors. You may be able to recognize patterns to your triggers, and coping strategies which are successful. Bring the completed Trigger Journal to group.

1. Filling out the Daily Record/Trigger Journal:

a) Date: Put day and time.

b) Situation: Be specific as to where you are, what you are doing, and your thoughts and feelings.

c) Intensity: Rate your desire to use or gamble, 1 represents no desire, and 100 represents the strongest desire.

d) Coping strategies: Note how you attempted to cope with the urge. Also add the effectiveness of the coping strategies.

2. Before you start: on the next page is an example of how to use the Daily Record/ Trigger Journal.

3. FILL IT OUT! The following pages have blank Trigger Journals--use them. 
TRIOCER JOUPHAL/ DAILY RECORO

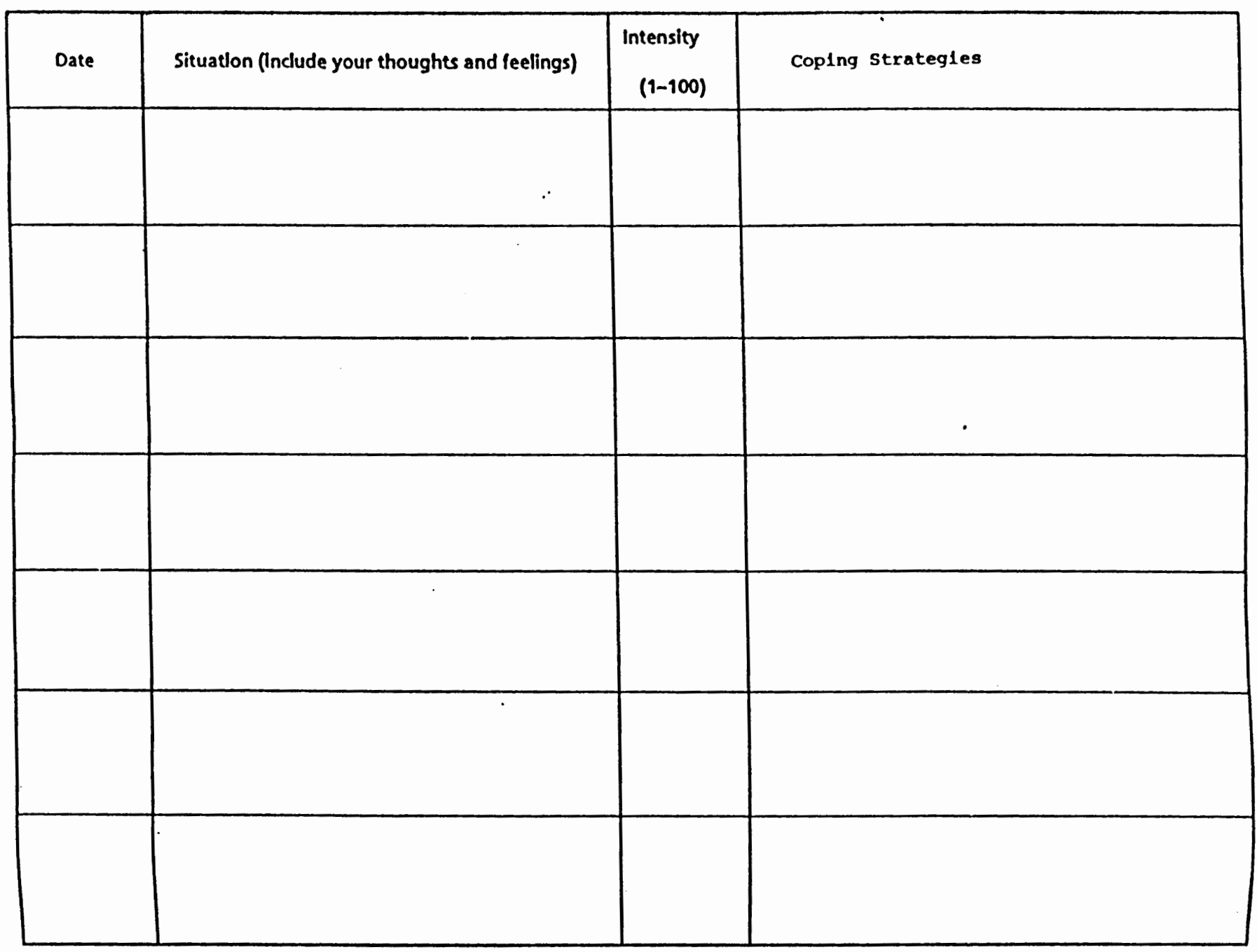




\section{AWARENESS OF NEGATIVE THINKING}

\section{REMINDER SHEET:}

- Negative self-Talk: The distorted, irrational, overgeneralizing, or all-or-nothing thoughts which we say to ourselves which make us feel inadequate, overwhelmed, and incompetent are negative self-talk.

* self-talk effects our feelings and bebavior: Feeling upset, depressed or tense doesn't just happen, it's our self-talk that causes us to get upset.

* Bad events don't equal bad feelings: We can choose to respond to negative events in positive ways. This gives us power and control, instead of giving power to the negative events.

ABC yodel for handing events: Events $=A$, they happen, and we respond with self-talk = B. B influences our feelings and behavior $=C$. The $A B C$ model helps us become aware of our negative self-talk. If we can catch these distortions in our thoughts and correct them, our feelings and behaviors will no longer be self-defeating.

Positive 8elf-ralk: These are the positive messages which we give ourselves, such as when we notice and compliment ourselves upon our accomplishments. No matter how small, we should cheer our own victories. We can learn to make ourselves feel better and take positive actions in our lives.

* Negative self-talk supports our addiction: When we criticize and deride ourselves, it gives us an excuse to drink/use/gamble. When we use positive self-talk, we feel better about ourselves; are less moody, upset, tense, angry, or depressed. In other words, we are less likely to want to drink/use/gamble to get rid of the bad feelings.

self-talk is a habit: Both positive and negative selftalk are habits. We must first become aware of our self-talk, then exercise our positive self-talk "muscles." Just like you won't be able to do 100 push ups until you build up your muscles, at first it will be hard to strengthen your positive self-talk. 


\section{AWARENESS OF NEGATIVE THINKING, p. 2}

REMINDER BHEET, con't:

- Exaggerations and distortions: Learn to recognize exaggerated and unrealistic expectations and types of negative self-talk, including:

* All-or-Nothing Thinking: You see things as either or, things are either all good or all bad.

* Overgeneralization: You allow a single negative event or aspect to support the distortion that everything is bad or you are completely inadequate.

* Magnification/Catastrophizing: You exaggerate the importance of things, turning little problems into catastrophes. No one else's failures are as bad as yours.

* Minimization: Real difficulties are distorted into nothing. Positive traits or actions become tiny.

* Mental Filter: You find one negative problem and think of it exclusively. Everything is negative because of one flaw.

* Disqualifying the Positive: Your positive behaviors, and positive experiences are ignored. They are not considered, they "don't count."

* Mind Reading: You assume that you know that people dislike you, or are out to get you. You interpret all of their actions to fit this picture.

* Fortune Teller Error: You convince yourself that bad things will happen, that nothing will change.

* Emotional Reasoning: Because you feel bad, you are certain that life is bad.

* Bhould statements: Instead of accomplishing what really needs to be accomplished, you try to control yourself with "should" and "must" and "ought." This is an opportunity to make yourself fail, by trying to be perfect.

* Labeling/mislabeling: When you do or feel something that you don't like, you see yourself as the negative label describing the action or the feeling.

* Personalization: You blame yourself for everything negative that occurs. 


\section{AWARENESS OF NEGATIVE THINKING, p. 3}

\section{PRACTICE EXERCIBE:}

REMEMBER: $\quad A=$ EVENT,$B=$ SELF-TALK, $C=$ FEELINGS $/$ BEHAVIOR

Briefly describe an event/A that seemed to make you feel unhappy, inadequate, or want to drink/use/gamble:

Describe all of the self-talk/B which led to

feeling unhappy, inadequate, or wanting to

drink/use/gamble. Write as many as you can.

Now write down the negative feelings or behaviors/C that resulted: 
NOTE: At first, you may only notice your feelings/C. If that is the case, work backwards to the precipitating event. Fill out the $c$ part on this form first, and then go back to the $A$ and $B$ parts. Fill out the $B$ part even if you can't remember your thoughts exactly. You can come up with at least two or three examples of negative self-talk/B that happened automatically after the event/A. 


\section{MANAGING NEGATIVE SELF-TALK}

\section{REMINDER BHEET:}

- URGES/CRAVINGS ARE RELATED TO NEGATIVE SELF TALK: LoOK for negative self-talk when you experience an urge or craving.

- ChALLENGE NEGATIVE SELF-TALK: Shout "STOP!" mentally, then substitute positive self-talk.

- NEgAtive fEelings MEAN NEEDing to COPE: Relabel your negative feelings, or urges/cravings, as signals to use coping skills.

- CHEER YOUR VICTORIES: Notice your successes and positive changes--no matter how small and revel in them.

- ENJOY FEELING POSITIVE: Notice how you feel better (perhaps only slightly at first, more with practice). pat yourself on the back for having stopped your negative self-talk.

- BELIEVE IN YOUR POSITIVE SELF: Congratulate yourself for real, if small, accomplishments, then believe it! You deserve to feel good about yourself, even when things are going badly. 


\section{MANAGING NEGATIVE SELF-TALK, p. 2}

PRACTICE EXERCIBE: POSitive Thinking worksheet

List 3 events/A that occur this next week. Then list your negative self-talk/B response, and what is inaccurate or distorted about it. Finally write positive challenges to the negative selftalk.

EVENTS/A :

1)

2)

3)

NEGATIVE SELF-TALK/B :

1)

2) 
158

4)

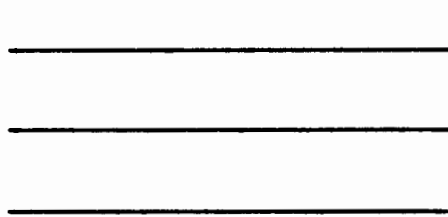




\section{MANAGING NEGATIVE SELF-TALK, p. 3}

PRACTICE EXERCI8E: Positive Thinking Worksheet, con't

POSITIVE SELF-TALK/CHALLENGES:

1)

2)

4) 


\section{DRINK/DRUG/GAMBLING REFUSAL SKILLS}

\section{Reminder Sheet}

When you are urged to drink/use/gamble, keep the following in mind:

a Say "no" first.

D Voice should be clear, firm, and unhesitating.

D Make direct eye contact.

D Suggest an alternative:

a Another activity.

a Some place safe to eat or drink (nonalcoholic beverages).

D Ask the person to stop suggesting that you drink/use/gamble and not to do so again.

D Change the subject.

a Avoid the use of vague answers.

D Don't feel guilty about refusing.

NOTES : 


\section{DRINK/DRUG/GAMBLING REFUSAL SKILLS, p. 2}

\section{Practice Exercise}

Listed below are some people who might suggest that you drink/use/gamble in the future. Give some thought to how you will respond to them, and write your responses under each item.

Someone close to you who knows about your addiction:

Coworker:

Boss : 


\section{DRINK/DRUG/GAMBLING REFUSAL SKILLS, p. 3}

\section{Practice Exercise}

New acquaintance:

Waitress/waiter with others present:

Relative at a family gathering: 


\section{MANAGING THOUGHTS ABOUT YOUR ADDICTION}

one way to cope with your triggers and urges to

drink/use/gamble is to evaluate and develop counters to your thoughts. Generate 10 statements [to strengthen your resolve not to drink /use/gamble] for each of the following issues. Write the statements on a card which you can carry with you:

* Consider the benefits to you if you don't drink/use/gamble. How is/will your life be better without the addiction.

* Remember and describe the negative and unpleasant drinking/using/gambling experiences.

* Think about your losses as a result of drinking/ using/gambling. Recount these negative consequences.

* Think about the people in your life. List ten people who would be saddened or hurt if you drank/used/gambled.

\section{CARRY THESE CARDS WITH YOU, AND READ WHEN YOU EXPERIENCE URGES OR TRIGGERS.}




\section{MANAGING THOUGHTS ABOUT YOUR ADDICTION,}

\section{page 2}

\section{Additional Tools for managing thoughts about alcohol/ drugs/gambling:}

* Challenge your thoughts: Do you really need to drink/use/gamble? Will you really not have fun without?

* Distraction: Think of something unrelated to drinking/using/gambling.

* Positive thinking: Remind yourself of your successes

so far.

* Use images of riding out the craving until it passes.

- Decision delay technique: If nothing else is working, then look at your watch and put off decision to drink/use/gamble for 15 minutes or more. (Use images to tough it out until the urge passes.)

- Leave or change the situation.

+ Call someone and try to talk it out.

Notes: 


\section{SEEMINGLY IRRELEVANT DECISIONS}

\section{REMINDER SHEET:}

8ID (seemingly Irrelevant Decisions): These are the ordinary mundane choices which you make every day that seem to have nothing to do with drinking/using/gambling. Although not a direct choice whether to drink/use/gamble, SIDs may move you, a step at a time, closer to that choice.

Handing SIDs:

- VICTIM: If you find yourself after a relapse thinking or saying "it just happened," you are telling yourself that you are the victim of circumstances. In reality, you are the victim of SID. Once you start re-examining the decisions which led to your relapse, you will be able to connect the SIDs with your relapse.

- THINK AHEAD: Examine every decision/choice that you make, regardless of how mundane, or irrelevant to your addiction. Thinking ahead will help you anticipate potential dangers, and change directions when necessary. You will gain a strong sense of control.

- LOW-RISK OPTIONS: You will find that you can usually choose a low-risk option, one which will not lead to placing you in a dangerous or risky situation. When you choose a high-risk option, you must make plans to stay safe.

- EARLIER = EASIER: As you become aware of SIDS, you will be better able to make choices which will prevent you from getting into high-risk situation. The farther away from the high-risk situation, the easier it will be to resist the urge to drink/use/gamble. 


\section{SEEMINGLY IRRELEVANT DECISIONS, p. 2}

\section{REMEMBER:}

When making any decision, whether large or small, do the following:

- Consider what options you may have.

- Think ahead to the possible outcomes of each option.

- What positive or negative consequences can you anticipate, and what are the risks of relapse?

$\checkmark$ Select one of the options:

() Choose one that will minimize your relapse risk.

(- If you decide to choose a risky option, plan how to protect yourself while in the high-risk situation.

\section{PRACTICE EXERCISE:}

Think about a decision you have made recently or are about to make. The decision could involve any aspect of your life, such as your job, recreational activities, friends, or family. Identify "safe" choices and choices that might increase your odds of relapsing.

Decision to be made: 


\section{SEEMINGLY IRRELEVANT DECISIONS, p. 3}

\section{PRACTICE EXERCISE, con't:}

Safe alternatives:

Risky alternatives: 


\section{PLANNING FOR DANGEROUS SITUATIONS}

\section{THE NINE MOST COMMON DANGERS}

1. Being in the presence of alcohol/drugs/gambling, people who drink/use/gamble, or places where you used to drink/use /gamble

2. Negative feelings particularly anger; also sadness, loneliness, guilt, fear, and anxiety.

3. Positive feelings that make you want to celebrate.

4. Boredom.

5. Physical pain.

6. Listening to war stories and just dwelling on drinking /using/gambling.

7. Suddenly having a lot of cash.

8. Using prescription drugs that can get you high even if you

use them properly.

9. Believing that you are finally cured--that is, that you no longer have alcohol/drug/gambling urges in any of the above situations or others. That you can control your addiction and that therefore it is safe for you to drink /use/gamble occasionally. 


\section{PLANNING FOR DANGEROUS SITUATIONS, page 2}

\section{EMERGENCY PLAN}

Write a detailed emergency plan for coping with high-risk relapse situations.

1.

2 .

3 .

4 . 
5.

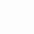




\section{PLANNING FOR DANGEROUS SITUATIONS, page 3}

\section{MY DANGEROUS SITUATIONS}

1) The following situations pose the greatest danger to me at this time. I should avoid them if at all possible. If I can't avoid them, I accept the need for careful planning and as much support as I can get.

2) These situations are the ones I can handle as long as I remain aware and honest with myself about my recovery needs. There are things about these situations that could get out of hand if I forget what I'm all about.

3) These are no longer truly dangerous situations for me. They used to be, but I have experienced enough growth and recovery so that I can now handle them as everyday events. 


\section{ENHANCING SOCIAL SUPPORT NETWORKS}

I WHO might be able to support you? Iist people who have in the past been:

U Usually supportive:

$\Delta$ Usually neutral (don't know about your problems):

$\Delta$ Usually hindering (supportive only with your effort):

1 mHAT types of support will be most helpful? Iist people who could provide support in the following areas:

- Help with problem solving:

- Moral support: 


\section{ENHANCING SOCIAL SUPPORT NETWORKS, page 2}

I Types of support, con't:

- Someone to share the load:

- Information and resources:

- Emergency help:

1 How can you get the support or help you need?

- Ask for what you need. Be specific and direct.

- Add new supporters (people who can help you with current problems).

- Lend your support to others; it helps you to strengthen your own skills.

- Be an active listener when giving or receiving support:

- Give feedback about what was or wasn't helpful;

D Thank the person for his/her support. 


\section{ENHANCING SOCIAL SUPPORT NETWORKS, page 3}

\section{PRACTICE EXERCISE:}

\section{Exercise 1}

Think of a current problem that you would like help with. Describe the problem:

Who might be helpful to you with this problem?

How can you try to get this support from him/her?

How, choose the right time and situation, and try to get this person to support you. Describe what happened: 


\section{ENHANCING SOCIAL SUPPORT NETWORKS, page 4}

\section{Exercise 2}

Name a friend or family member who is currently having a problem, and who could use some more support from you:

Describe what you could do to lend some support:

Now, choose an appropriate time and setting, and give support to this person. Describe what happened: 


\section{STARTING CONVERSATIONS}

\section{POINTERB TO REYEMBER:}

(-) START WITH SIMPLE TOPICS: Small talk is a valid way to start a conversation. Every subject for conversation doesn't need to be about weighty topics. Talk about subjects which the other person can understand and relate to.

(7) CONVERSATION IS TWO-WAY: YOU are not responsible for keeping the conversation going, each person should contribute.

(-) OK TO TALK ABOUT YOURSELF: When you share with others, in a non-bragging manner, you are actually helping the other person to open up to you and develop trust.

- IISTEN AND OBSERVE: Iistening and observing helps you determine what the other person is interested in talking about. Before you start make certain, through observation, that the other person is not deeply involved in another activity/ conversation, or in a rush-no one wants to talk in those situations.

- $\quad$ SPEAK UP: Make eye contact and say something directly to the other person. Don't stand there waiting for the other person to talk.

(-) USE OPEN-ENDED QUESTIONS: An open-ended question is one which the other person can't answer with just a "yes" or "no." It encourages the other person to share ideas with you, and tells the other person that you are interested in what s/he wants to say.

(-) CHECK YOUR RECEPTION: Check how the other person is responding to you. Is the conversation two way? Is the other person answering with short terse replies? If it looks as if the other person is not interested in talking, end the conversation. Conversation should be fun and easy, if it's not--move on.

() END THE CONVERSATION GRACEFULLY: Say something pleasant about how much you enjoyed talking with or meeting the other person. Leave the other person with the feeling that you sincerely enjoyed talking with $\mathrm{him} / \mathrm{her}$. A graceful ending increases the likelihood of a follow-up conversation. 


\section{STARTING CONVERSATIONS page 2}

Where did the conversation take place?

What was the conversation about?

What were the results?

Communication Checklist:

1. Did you listen and observe before and during speaking?

2. Did you start with small talk?

3. Did you ask open-ended questions?

4. Did you share your own ideas, opinions, information?

5. Did you end gracefully? 


\section{FEELING TALK AND LISTENING SKILLS}

\section{REMINDER SHEET:}

sharing your feelings with other people:

1) Feelings are allowed: It's OK to talk about your feelings both positive and negative ones.

2) Appropriate self disclosure: Self disclosure helps you build close relationships. However too much self disclosure too soon can make others uncomfortable. Try to match amounts of self disclosure. Also, share more with people you feel closer to than with new people.

- Iistening to other people:

1) Listening is Your Most Important skill! other people want to be heard. Reflect your listening by restating what the other person has just said.

2) Body Language: Show that you are interested and listening by using body language: leaning forward, eye contact, head nods, etc. Pay attention to the tone of voice, facial expression, and body language of the other person to help you "tune in to" his/her feelings.

3) silences are important: Give the other person sufficient time: to think, to express complex thoughts, and to finish sentences.

4) Time to talk: When the other person has completed his or her thought, it is your turn to talk. Listen for an appropriate time to talk. Show interest and understanding by asking questions about feelings, rephrasing what was said, or adding comments of your own. Share similar experiences or feelings that you have had. 


\section{FEELING TALK AND LISTENING SKILLS, p. 2}

\section{PRACTICE EXERCISE:}

\section{Exercise 1: Practice Expressing Feelings}

Start a conversation with someone and share a feeling during the conversation.

1. Whom did you talk with?

2. What feeling did you share?

3. How did he/she respond? 


\section{FEELING TALK AND LISTENING SKILLS, p. 3}

\section{Exercise 2: Practice Listening to Feelings}

During an interaction you have with someone, notice a feeling that he/she is expressing both verbally and nonverbally.

1. What feeling did he/she express verbally?

2. What nonverbal behaviors did you notice?

3. What feeling was he/she expressing nonverbally?

4. How did you show you were listening? 


\title{
GIVING AND RECEIVING COMPLIMENTS
}

\section{REMINDER SHEET}

\author{
Many people are uncomfortable with \\ receiving compliments. You are not \\ being conceited when you accept a \\ compliment gracefully with a "thank \\ you." People feel pleased when they \\ compliment someone, and that person \\ acknowledges that they appreciated the \\ compliment. \\ offering compliments is a nice way to \\ let people know that you appreciate what \\ they've done and who they are.
}

\section{REMEMBER:}

a Giving compliments:

D State the compliment in terms of your own feelings, use "I" statements. Example: "I like your laugh"

D Be genuine, you will probably find that you can find something which you like about everyone.

D Compliment something specific that the person does, or a particular attribute that you like.

D Receiving Compliments:

D The only acceptable response to a compliment is "thank you," don't turn down a compliment.

D If you are pleased, show that you appreciate it. 


\section{GIVING AND RECEIVING COMPLIMENTS, p. 2}

\section{PRACTICE EXERCISE}

\section{Exercise 1:}

Approach someone whom you admire and find something about that person to compliment. This can be done in the context of a conversation, or you can approach him/her specifically to provide a compliment. Afterwards, write the compliment in the space below:

Communication Checklist:

1. I stated the compliment in terms of my own feelings:

2. I made the compliment specific: 


\section{GIVING AND RECEIVING COMPLIMENTS, p. 3}

\section{Exercise 2}

Be aware of any compliments you receive during this next week. Try to respond according to these guidelines. For one compliment that you receive, record the following:

Describe situation:

What was your response?

Communication Checklist:

1. Did you accept the compliment?

2. Did you turn down or differ with the compliment given to you?

3. Did you show your appreciation? 


\section{PROBLEM LIST}

To stay abstinent from alcohol, drugs, and/or gambling you must develop new strategies for coping with problems. This exercise will help you become aware of what those problems are. For each section describe one or more problems that you may encounter:

Problems with my family or close friends:

Loneliness:

Feeling Angry: 
Anxiety or Tension:

Social Pressure to Drink:

other Problems: 


\section{AM LIST}

Choose a partner. Agree on who will make their "I AM IIST" first. The partner who is going first must state one thing that you like about yourself. Your partner will write the statement on the list, for number 1. You must tell your partner one positive trait about yourself. Examples:

- I care about other people.

+ I am funny.

* I am a nice person.

+ I have a nice smile.

* I have been clean and sober since:

+ I am friendly.

After you state the first positive trait, your partner will pick a positive statement. Make up your own statements that you can say about yourself, and accept only those statements from your partner with which you agree. Alternate statements until you have 10 or more positive statements about yourself. When you are finished, start working on your partner's "I AM LIST." You will write down the positive statements that your partner says and the positive statements that you give your partner. Remember: Each partner must be willing to accept the positive statements about him or herself.

When you get home with your "I AM IISp" tape it to a mirror and say the statements out loud to your self at least once each day. 
Ie

1

2

3

4

5

6

7

8

9 


\section{POSITIVE JOURNAL}

List 3 positive things which you have accomplished, your positive behaviors, activities that you've done and enjoyed, or good things which happen each day for the next week.

\section{MONDAY}

1.

2 .

3 .

TUESDAY

1.

2 .

3 . 


\section{POSITIVE THINGS JOURNAL, con't}

\section{WEDNESDAY}

1.

2.

3 .

THURSDAY

1.

2 .

3.

FRIDAY

1.

2 .

3 . 


\section{POSITIVE THINGS JOURNAL, con't}

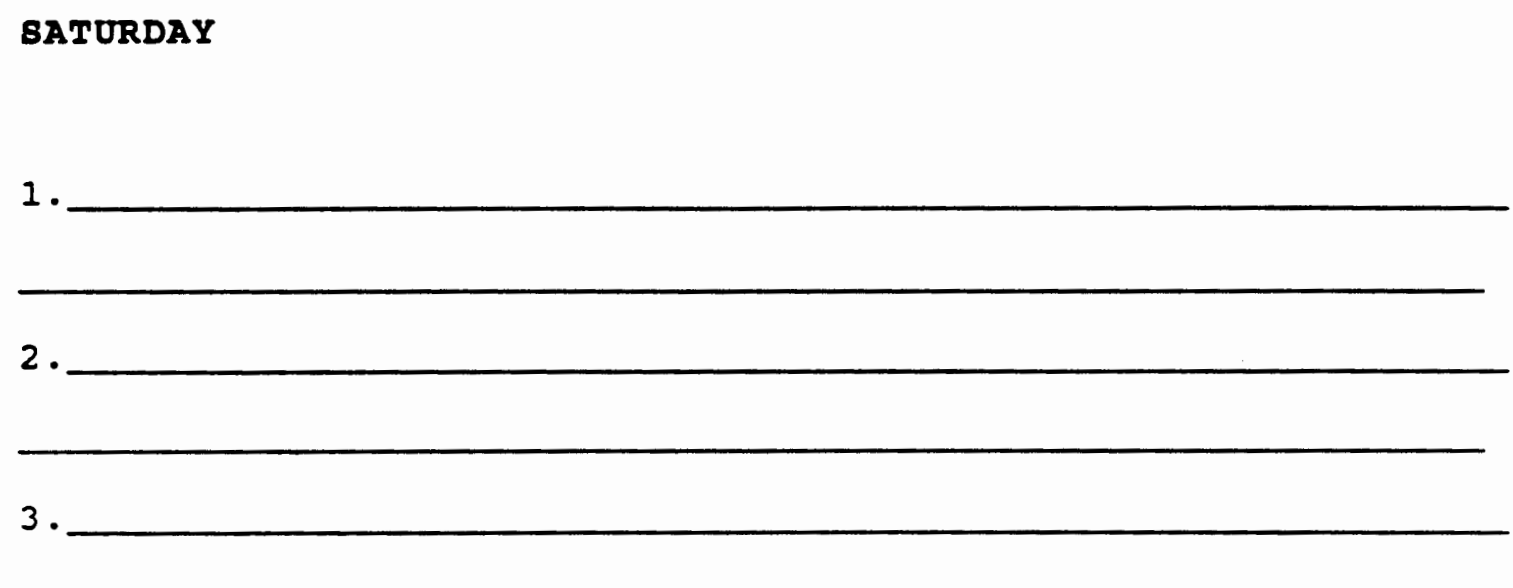

SUNDAY

1.

2 .

3.

REMEMBER! You need to review and congratulate yourself for the positive things you do and your accomplishments. 


\title{
MOURNING THE LOSS OF GAMBLING
}

\begin{abstract}
Abstaining from gambling for the pathological gambler is a major psychological loss. You must not only struggle to accept the loss but at the same time you must also resist the temptation to restor the loss (return to gambling). Generally, there are seven stages which you will go through as you grieve the loss of gambling.
\end{abstract}

\section{STAGE I: DENIAL}

The first reaction to any loss tends to be denial. During this stage, most gamblers want to deny or minimize the connection between gambling and your problems. Denial of the necessity of the loss/giving up gambling, enables you to consider returning to gambling. Denying also allows you to avoid the pain associated with accepting the reality that you must lose gambling as a coping skill.

\section{STAGE II: BARGAINING}

Much as dying patients want to make a bargain so they won't have to die, the pathological gambler wants to make a bargain so you won't really have to give up gambling. You may find yourself trying to limit when you gamble, how you gamble, where you gamble... anything, just so long as you don't have to let go. When you make promises to yourself or others, consider whether you are bargaining. When you are working on this stage, you have moved past denial and are starting to accept that something must be done about the gambling.

\section{STAGE III: HORE}

You are starting to see some of the benefits of living without gambling. Hope for a better, less chaotic, anxious life provides motivation. You may feel "hey, this isn't so bad, stopping gambling will be easy." Enjoy this brief respite in the grief process, because you will need to move on through four more stages. 


\section{MOURNING THE LOSS OF GAMBLING, con't}

\section{STAGE IV: SADNESS}

During this period, you will feel sadness and sorrow as you realize the consequences of your gambling. You will be grieving the financial, social, relationship, and other losses that are results of your uncontrolled gambling. You must also feel the sadness associated with the realization that the loss of your favorite coping strategy, gambling, is permanent. Although this is a difficult time, the sorrow is a good sign, it means that you are progressing through the grief process, and your commitment to abstinence will be strengthened.

\section{STAGE V: GUILT}

Feelings of guilt and shame are unavoidable during the grief process. You will have to recognize the reality of your behaviors which resulted from your addiction to gambling. You will also have to handle the loss reaction, guilt as a result of your acts which forced your to stop gambling. Examining, accepting and working through your guilt is extremely important in successfully grieving the loss of gambling.

\section{STAGE VI: ANGER}

Anger is a universal reaction to loss. You will feel angry as you give up/lose gambling. You may find yourself angry at other people, things, and yourself. Anger is an important emotion to work on during the grief process, but you will want to guard against acting-out your angry feelings. The consequences of allowing the anger to overwhelm you, and you become physically or verbally destructive can send you right back to gambling ( and possibly to jail!). If you can explore and work through your anger, with the help of family, friends, $A A, G A$, and this clinic, the anger will pass.

\section{STAGE VII: ACCEPTANCE}

When you can truly accept that you have no control over gambling, and that you cannot return to gambling as a coping strategy, you will have completed the grieving process. Although you must still work on your recovery, you will have a sense of peace, and you will be able to replace gambling with other activities. 


\section{MY ADDICTION HAS HARMED...}

Think about the actions which have resulted from your addiction to drugs/alcohol/gambling. Recall the times that these actions have damaged other people. List people whom you have hurt in any way, then describe the hurt:

\section{PEOPLE HARMED:}

\section{HARM CADEED:}




\section{MY ADDICTION HAS HARMED, con't...}

PEOPLE HARMED:

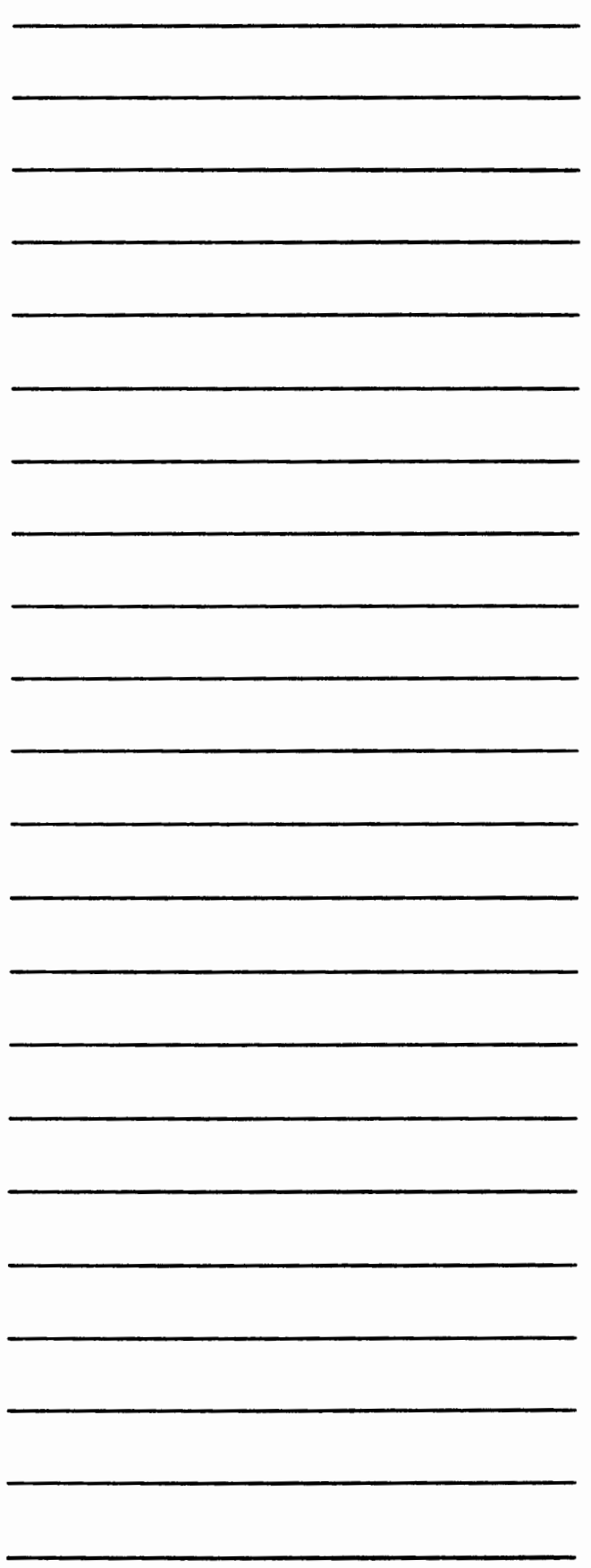

HARY CAUSED:

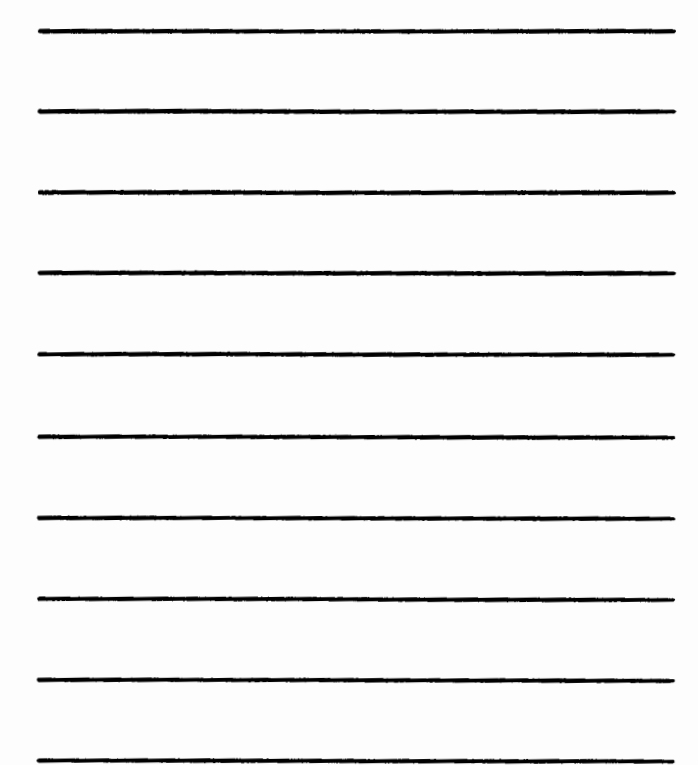




\section{EMOTIONS JOURNAL}

REMINDER :

The following is a list of emotions/feeling words. During the next week, take out this sheet at least 3 times. Take a minute, and think about how you feel. Make a mark by any feelings which apply.

FESTIVE

CONTENTED

RELAXED

CALM

SERENE

COMFORTABLE

JOYOUS

ECSTATIC

ENTHUSIASTIC

GLAD

PLEASED

GRATEFUL

CHEERFUL

EXCITED

CHEERY

BUOYANT

SURPRISED

OPTIMISTIC

VIVACIOUS
MERRY

HILARIOUS

PLAYFUL

ELATED

THRILLED

EAGER

KEEN

EARNEST

AVID

ANXIOUS

ENTHUSIASTIC

EXCITED

SORROWFUL

BLUE

MELANCHOLY

GLOOMY

QUIET

MOURNFUL

DREARY 
BIAH

SULLEN

SULKY

LOW

DISCOURAGED

DISAPPOINTED

CONCERNED

COMPASSIONATE

EMBARRASSED

SHAMEFUL

USELESS

WORTHLESS

INJURED

HURT

ISOLATED

OFFENDED

PAINED

WORRIED

HEARTBROKEN

DESPAIR

LONELY

RESENTFUI

IRRITATED

ENRAGED

FURIOUS

ANNOYED
IRATE

CROSS

BITTER

GRUMPY

FUMING

AWKWARD

BEWILDERED

FEARLESS

ENCOURAGED

COURAGEOUS

CONFIDENT

SECURE

INDEPENDENT

BOLD

DARING

DETERMINED

PROUD

CLOSE

TENDER

PASSIONATE

AGGRESSIVE

WARM

DOUBTFUL

SKEPTICAI

SUSPICIOUS

DISTRUSTFUL 
QUESTIONING

EVASIVE

HESITANT

PERPLEXED

PESSIMISTIC

UPTIGHT

TENSE

HOLLOW

EMPTY

STRONG

WEAK

WEARY

REPUISED

TIRED

ALIVE

FEISTY

CONCERNED

FASCINATED

INTRIGUED

ABSORBED

CURIOUS

CREATIVE

FEARFUL

TIMID
SHAKY

APPREHENSIVE

TERRIFIED

PANICKY

ALARMED

CAUTIOUS

INSECURE

IMPATIENT

NERVOUS

ANXIOUS

HESITANT

AWED

THREATENED

HUMBLE

MIXED-UP

JEALOUS

DISTANT

BORED

PHONEY

COOPERATIVE 


\section{EMOTIONS JOURNAL,PART II}

The following is a list of emotions/feeling words. During the next week, take out this sheet at least 3 times. Take a minute, and think about how you feel. Make a mark by any feelings which apply, then add a statement describing when and where you experienced those emotions.

FESTIVE

CONTENTED

RELAXED

CALM

SERENE

COMFORTABLE

JOYOUS

ECSTATIC

ENTHUSIASTIC

GLAD

PLEASED

GRATEFUI

CHEERFUL

EXCITED

CHEERY

BUOYANT

SURPRISED

OPTIMISTIC

VIVACIOUS

MERRY

HILARIOUS 


\section{EMOTIONS JOURNAL, PART II, con't}

PLAYFUL

ELATED

THRILLED

EAGER

KEEN

EARNEST

AVID

ANXIOUS

ENTHUSIASTIC

EXCITED

SORROWFUL

BLUE

MELANCHOLY

GLOOMY

QUIET

MOURNFUL

DREARY

$\mathrm{BIAH}$

SULIEN

SULKY

LOW

DISCOURAGE

DISAPPOINTED

CONCERNED

COMPASSIONATE 


\section{EMOTIONS JOURNAL, PART II, con't}

EMBARRASSED

SHAMEFUL

USELESS

WORTHLESS

INJURED

HURT

ISOLATED

OFFENDED

PAINED

WORRIED

HEARTBROKEN

DESPAIR

LONELY

RESENTFUL

IRRITATED

ENRAGED

FURIOUS

ANNOYED

IRATE

CROSS

BITTER

GRUMPY

FUMING

AWKWARD 


\section{EMOTIONS JOURNAL, PART II, con't}

BEWILDERED

FEARLESS

ENCOURAGED

COURAGEOUS

CONFIDENT

SECURE

INDEPENDENT

BOLD

DARING

DETERMINED

PROUD

CLOSE

TENDER

PASSIONATE

AGGRESSIVE

WARM

DOUBTFUL

SKEPTICAI

SUSPICIOUS

DISTRUSTFUL

QUESTIONING

EVASIVE

HESITANT

PERPLEXED 


\section{EMOTIONS JOURNAL, PART II, con't}

\section{PESSIMISTIC}

UPTIGHT

TENSE

HOLLOW

EMPTY

STRONG

WEAK

WEARY

REPULSED

TIRED

ALIVE

FEISTY

CONCERNED

FASCINATED

INTRIGUED

ABSORBED

CURIOUS

CREATIVE

FEARFUL

TIMID

SHAKY

APPREHENSIVE

TERRIFIED

PANICKY 


\section{EMOTIONS JOURNAL, PART II, con't}

\section{ALARMED}

CAUTIOUS

INSECURE

IMPATIENT

NERVOUS

ANXIOUS

HESITANT

AWED

THREATENED

HUMBLE

MIXED-UP

JEALOUS

DISTANT

BORED

PHONEY

COOPERATIVE 


\section{DISCHARGE PLAN}

1) List your triggers for drinking, gambling, or using (be thorough yet specific):

2) List counter thoughts for your triggers: 


\section{DISCHARGE PLAN, con't}

3) List your dangerous situations for arinking, gambling, or using (be thorough yet specific):

4) List plans for your dangerous situations: 


\section{DISCHARGE PLAN, con't}

5) Describe your support system for maintaining abstinence from drinking, gambling, or using. List people who will help:

6) List activities which will replace

drinking/using/gambling: 